\title{
CFD Analysis of Core Bypass Phenomena
}

Richard W. Johnson

Hiroyuki Sato

Richard R. Schultz

November 2009
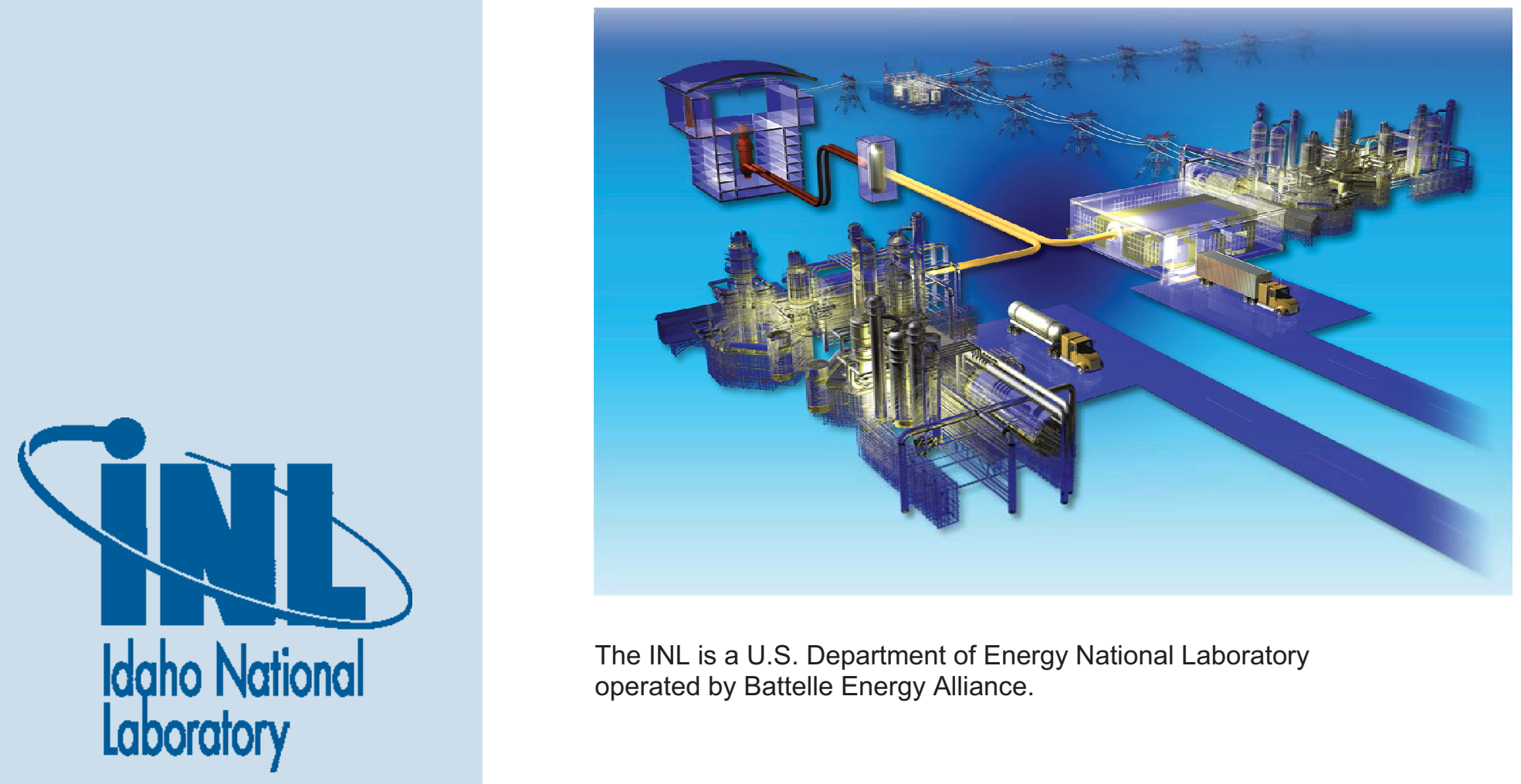

The INL is a U.S. Department of Energy National Laboratory operated by Battelle Energy Alliance. 


\section{DISCLAIMER}

This information was prepared as an account of work sponsored by an agency of the U.S. Government. Neither the U.S. Government nor any agency thereof, nor any of their employees, makes any warranty, expressed or implied, or assumes any legal liability or responsibility for the accuracy, completeness, or usefulness, of any information, apparatus, product, or process disclosed, or represents that its use would not infringe privately owned rights. References herein to any specific commercial product, process, or service by trade name, trade mark, manufacturer, or otherwise, does not necessarily constitute or imply its endorsement, recommendation, or favoring by the U.S. Government or any agency thereof. The views and opinions of authors expressed herein do not necessarily state or reflect those of the U.S. Government or any agency thereof. 


\title{
CFD Analysis of Core Bypass Phenomena
}

\author{
Richard W. Johnson \\ Hiroyuki Sato \\ Richard R. Schultz
}

November 2009

\begin{abstract}
Idaho National Laboratory
Next Generation Nuclear Plant Project

Idaho Falls, Idaho 83415
\end{abstract}

Prepared for the

U.S. Department of Energy

Office of Nuclear Energy

Under DOE Idaho Operations Office

Contract DE-AC07-05ID14517 

Next Generation Nuclear Plant Project

CFD Analysis of Core Bypass Phenomena

INL/EXT-09-16882
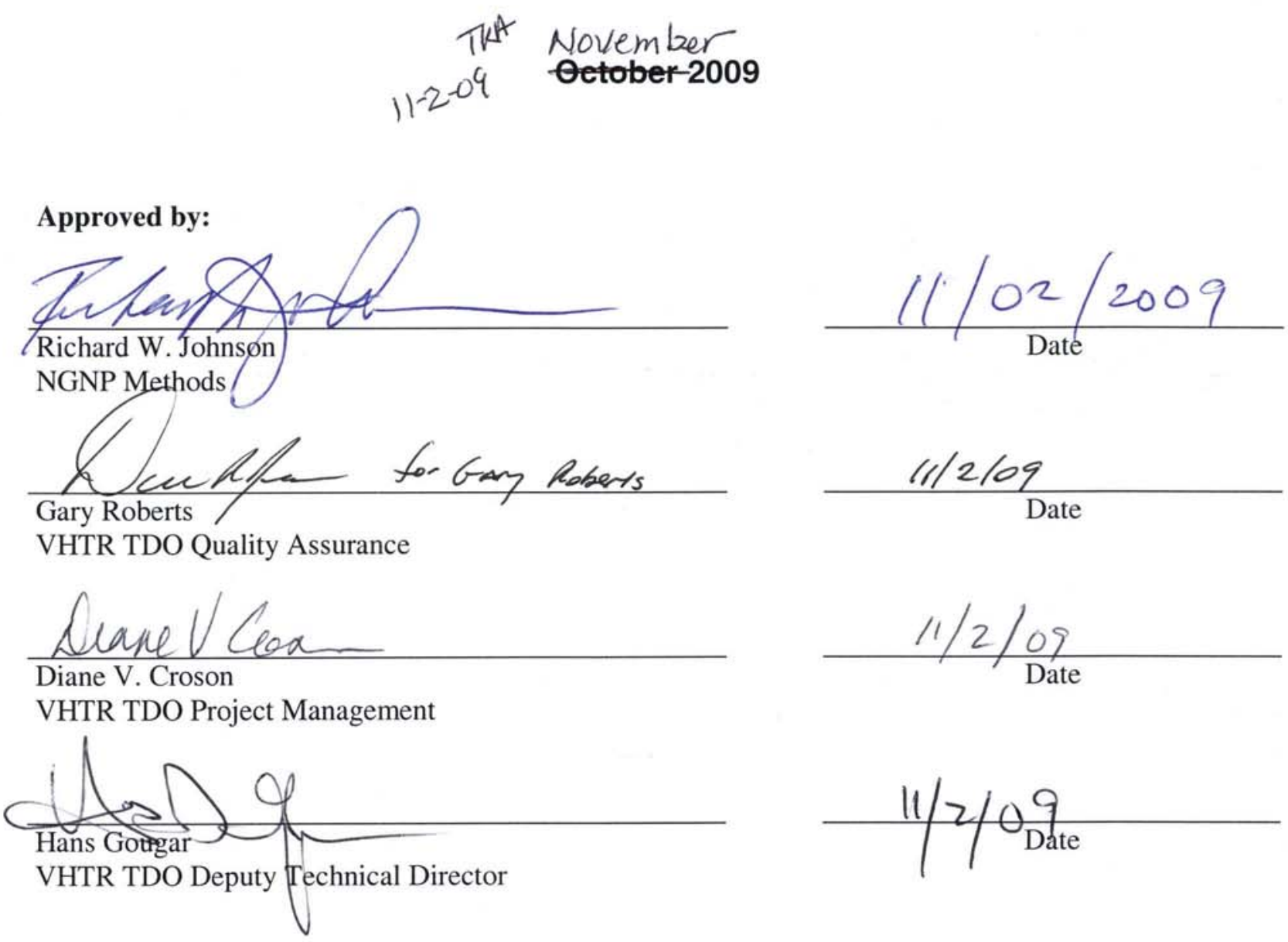



\section{EXECUTIVE SUMMARY}

The U.S. Department of Energy is exploring the potential for the very high temperature gas-cooled reactor (VHTR), which will be either a prismatic or pebble-bed type reactor. One important design consideration for the reactor core of a prismatic VHTR is coolant bypass flow, which occurs in the interstitial regions between fuel blocks. Such gaps are an inherent presence in the reactor core because of tolerances in manufacturing the blocks and the inexact nature of their installation. Furthermore, the geometry of graphite blocks changes over the lifetime of the reactor because of thermal expansion and irradiation damage. The existence of the gaps induces a flow bias in the fuel blocks and results in unexpected increases in maximum fuel temperatures.

Traditionally, simplified methods such as flow network calculations employing experimental correlations have been used to estimate flow and temperature distributions in the core design. However, the distribution of temperature in the fuel pins and graphite blocks as well as coolant outlet temperatures are strongly coupled with the local heat generation rate within fuel blocks which is not uniformly distributed in the core. Hence, it is crucial to establish mechanistic based methods that can be applied to the reactor core thermal hydraulic design and safety analysis.

Computational fluid dynamics (CFD) codes, which have a local physics based simulation capability, are widely used in various industrial fields. This study investigates core bypass flow phenomena with the assistance of commercial CFD codes and establishes a baseline for evaluation methods. A one-twelfth sector of the hexagonal block surface is modeled and extruded down to a whole core length of $10.704 \mathrm{~m}$. The computational domain is divided vertically with an upper reflector, a fuel section, and a lower reflector. Each side of the one-twelfth grid can be set as a symmetry boundary. The geometry used in the present study is shown in Figure E-1.

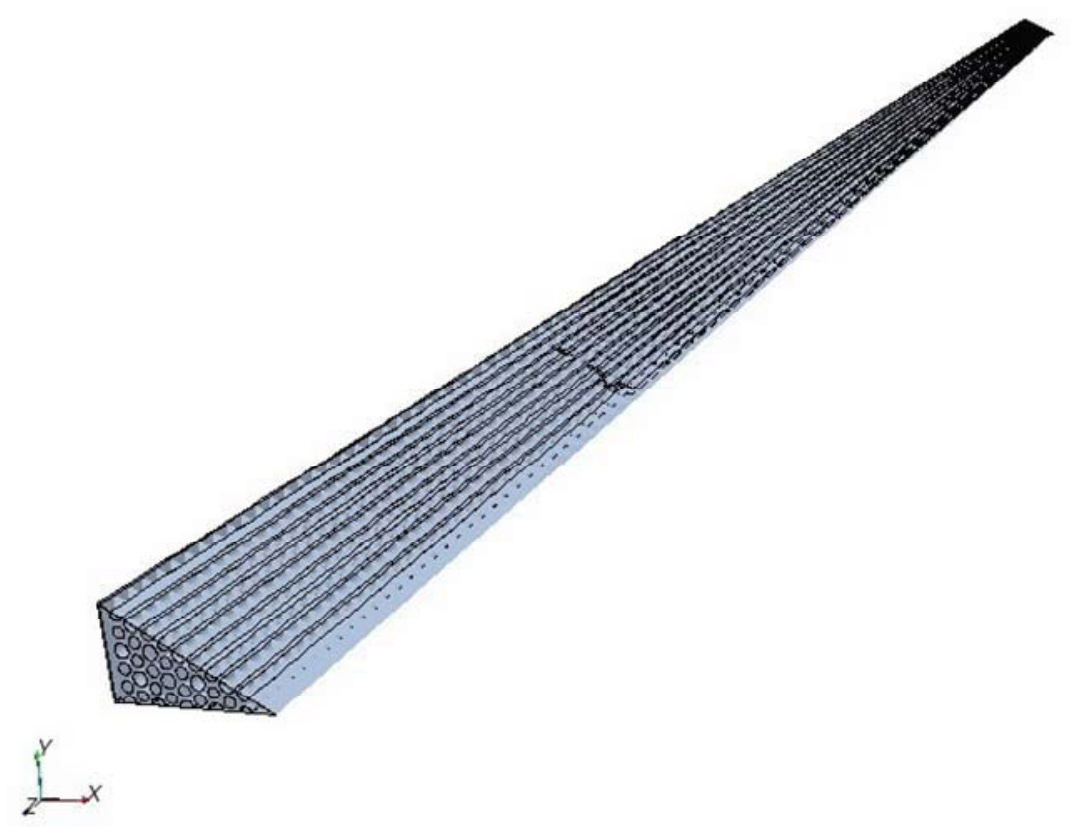

Figure E-1. Illustration of the CFD model used to investigate core bypass flow phenomena.

A steady Reynolds-averaged Navier-Stokes approach is employed using the commercial code FLUENT, which employs the finite volume method. Prior to the calculations, simple validation and grid sensitivity studies are conducted in order to evaluate the turbulence models and reduce numerical errors. Comparative studies are conducted varying several parameters including gap width, heat generation 
profile, turbulence model, and irradiation shrinkage to investigate the sensitivity of the flow and temperatures in the core to each parameter. In addition, a study wherein $20 \%$ bypass flow is achieved, thought to have occurred in earlier gas-cooled reactors, is performed to determine approximate gap widths that would be present and to visualize flow and temperature distributions.

Results of a study that varied the gap width from 0 to $5 \mathrm{~mm}$ show that the bypass flow provides significant cooling to the graphite block, and that the maximum fuel temperature increases with gap width if the bypass flow is "robbed" from the coolant channels. Bypass flow induces a steep overall temperature gradient within the block, which increases with gap width. Bypass flow also causes large variations in coolant outlet temperatures, which can lead to hot streaking in the lower plenum.

Results of a comparative study of turbulence models show that the flow and temperature distribution is significantly affected by the turbulence model chosen. The two turbulence models compared were the standard $\mathrm{k} \sim \varepsilon$ model using an enhanced wall treatment and the standard $\mathrm{k} \sim \omega$ model. A comparison of the two models against established empirical friction correlations for flow in the cylindrical coolant channels showed that the former model achieved acceptable accuracy, whereas the latter did not. This disparity has led to predictions of larger total mass flow rate and lower temperatures for the standard $\mathrm{k} \sim \omega$ model because friction in the coolant channels is too low. Interestingly, the two turbulence models predict about the same friction levels in the rectangular gap passageways.

Results of a comparative study, where the heat generation rate is varied axially for average and peak radial factors, show that the effects of the variable distribution in the axial direction are negligible, except that the maximum fuel temperature is lower for the nonuniform case. When the peak radial factor is used to increase the total heat generation rate, significantly increased temperatures are obtained and coolant flow rates in the coolant channels and interstitial gaps are reduced.

Results of simulating a $20 \%$ core bypass flow ratio indicate that the gap width in the fueled core region would be about $5.5 \mathrm{~mm}$ for gap widths of $3.5 \mathrm{~mm}$ in the reflector regions. Also, a study taking into account the radiation induced dimensional shrinkage indicates a gap width of $5.5 \mathrm{~mm}$ would occur in the fueled blocks for maximum shrinkage. Figure E-2 shows the temperature contours at the plane of the fuel hot spot, taking into account the irradiation induced dimensional change in the graphite block. It is obvious from the figure that significant cooling occurs near the gap because of the bypass flow.

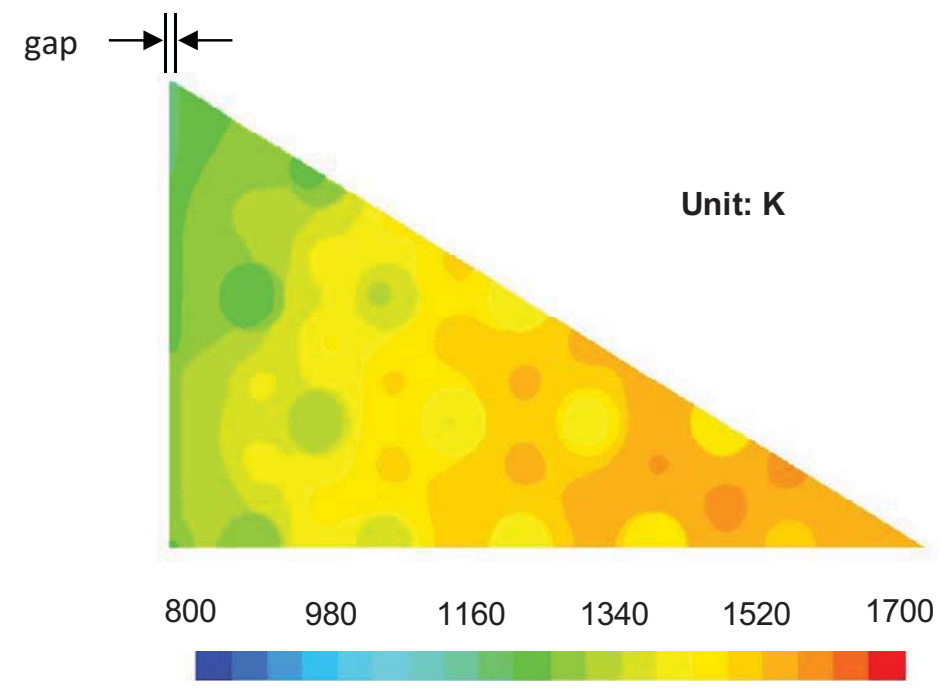

Figure E-2. Temperature contours at the plane of the fuel hot spot, taking into account the irradiation induced dimensional change in the graphite block. 
The study revealed that flow and temperature distributions in the prismatic fuel assembly are strongly coupled and, therefore detailed three-dimensional analyses using CFD is an effective method for evaluating the local physics of coolant and bypass flow phenomena. In particular, it was found that flow rates of coolant in the channels and in the interstitial gaps are a function of the solution and are not known a priori.

The results also show that the geometry of the prismatic blocks, especially gap width, in the reactor core has considerable influence on the bypass flow and, hence, on temperature and flow distributions. Further studies can be made to investigate the effects of wall roughness, thermal property change resulting from irradiation and turbulent to laminar transition in narrow interstitial gaps. Multiphysics simulations with the combination of neutronics, thermal-mechanics, and fluid dynamics are also recommended for future studies. Further validation efforts will also contribute to ensure the credibility of the numerical results. 


\section{ACKNOWLEDGMENTS}

This manuscript has been authored by Battelle Energy Alliance, LLC under Contract No. DE-AC07-05ID14517 with the U.S. Department of Energy. The authors also wish to thank to Prof. Yoichi Fujii-e, former chairman of Atomic

Energy Commission of Japan, for assistance under the Fujii-e Research Initiative by the U.S. Department of Energy. 


\section{CONTENTS}

EXECUTIVE SUMMARY

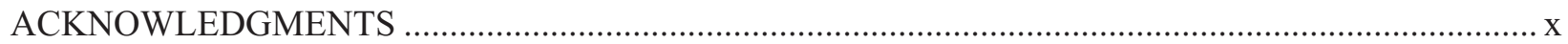

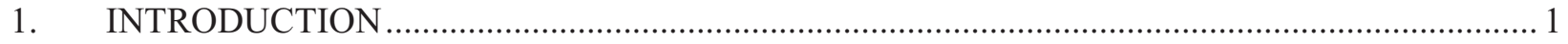

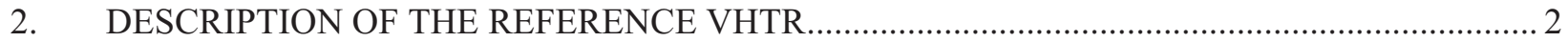

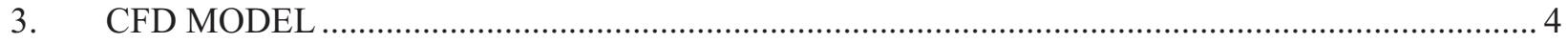

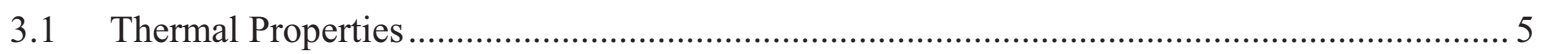

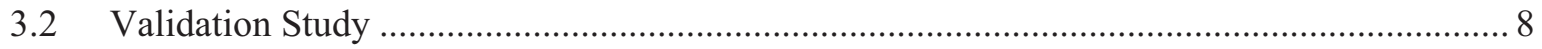

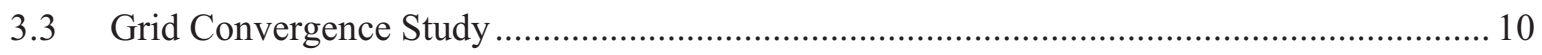

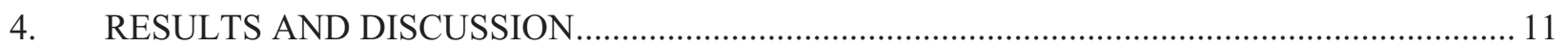

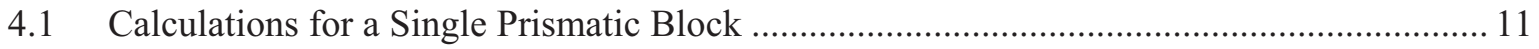

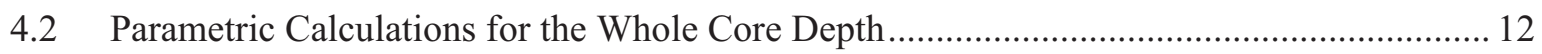

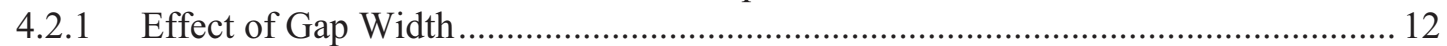

4.2.2 Effect of Heat Generation Rate Profile ............................................................. 17

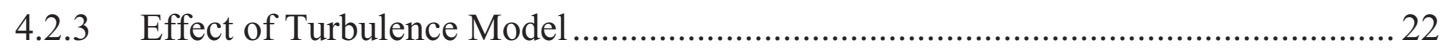

4.2.4 Effect of Gap Width for Fixed Total Mass Flow Rate .............................................. 28

4.3 Calculation Simulating VHTR Bypass Flow Ratio........................................................... 34

4.4 Calculation Simulating Irradiation Induced Dimensional Change....................................... 38

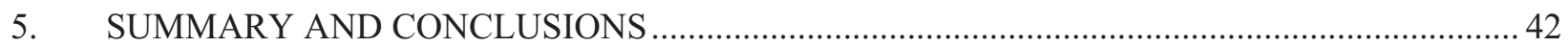

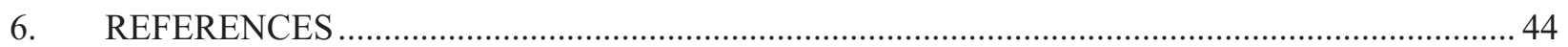

\section{FIGURES}

Figure E-1. Illustration of the CFD model used to investigate core bypass flow phenomena....................vi

Figure E-2. Temperature contours at the plane of the fuel hot spot, taking into account the irradiation induced dimensional change in the graphite block. ................................................ vii

Figure 2-1. Cutaway view of the GTMHR (MacDonald et al. 2003) .......................................................2

Figure 2-2. Cutaway view of fuel and fuel blocks and the cross section of the core (MacDonald et

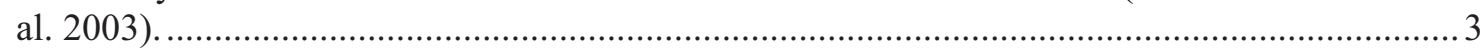

Figure 3-1. Cross-sectional view of a hexagonal block ................................................................... 4

Figure 3-2. Top view of one-twelfth hexagonal block grids............................................................. 5

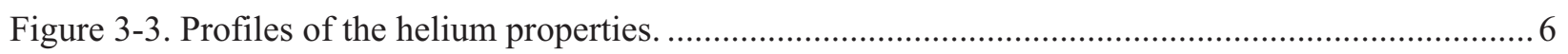

Figure 3-4. Profiles of the graphite $(\mathrm{H}-451)$ properties. ........................................................................... 7

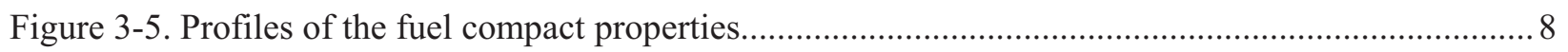


Figure 3-6. Comparison of wall shear stress in a coolant channel between experimental correlations and FLUENT calculations using the standard $\mathrm{k} \sim \varepsilon$ turbulence model with enhanced wall treatment.

Figure 3-7. Comparison of wall shear stress in a coolant channel between experimental correlations and FLUENT calculations using the standard $\mathrm{k} \sim \omega$ turbulence model.................... 9

Figure 3-8. Temperature contours at the fuel hot spot plane for different meshes. .................................. 10

Figure 4-1. Temperature contours at the inlet plane of the block for different gap widths. ...................... 11

Figure 4-2. Temperature contours at the outlet plane of the block for different gap widths. .................... 12

Figure 4-3. Temperature contours at the middle plane of the fuel block for different gap widths............. 13

Figure 4-4. Temperature along line A-B (see Figure 3-2) of the middle plane of the fuel block for

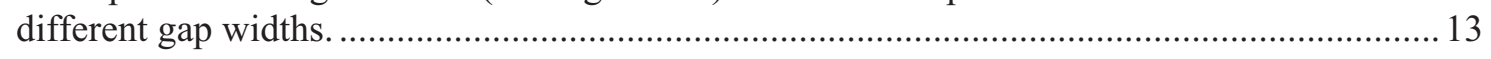

Figure 4-5. Temperature contours at the fuel hot spot plane for different gap widths.............................. 14

Figure 4-6. Temperature along line A-B (see Figure 3-2) of the fuel hot spot plane for different

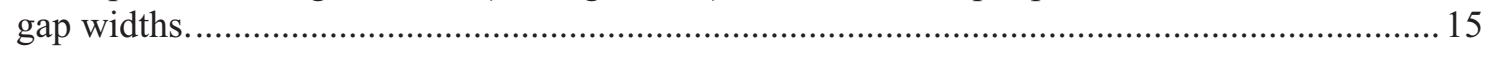

Figure 4-7. Bulk mean helium outlet temperatures for channels and gaps for different gap widths. ......... 15

Figure 4-8. Wall shear stresses at center of the gap for different gap widths. ......................................... 16

Figure 4-9. Profiles of volumetric heat generation rate for average and peak radial factors as a function of core depth.

Figure 4-10. Temperature contours at the middle plane of the fuel block for different heat generation profiles.

Figure 4-11. Temperature along line A-B (see Figure 3-2) of the middle plane of the fuel block

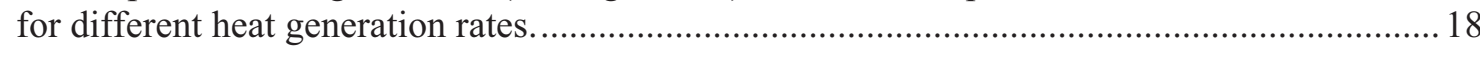

Figure 4-12. Temperature contours at the fuel hot spot plane for different heat generation rates.

Figure 4-13. Temperature along line A-B (see Figure 3-2) of the fuel hot spot plane for different

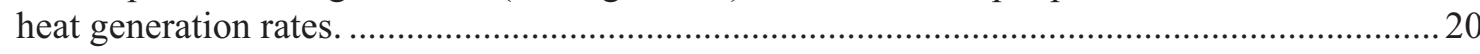

Figure 4-14. Bulk mean helium gas outlet temperatures for channels and gaps for different heat generation rates.

Figure 4-15. Comparison of wall shear stress at center of the gap for different heat generation rates.

Figure 4-16. Comparison of temperature contours at the middle plane of the fuel block for different turbulence models.

Figure 4-17. Temperature along line A-B (see Figure 3-2) of the middle plane of the fuel block for different turbulence models.

Figure 4-18. Temperature contours at the fuel hot spot plane for different turbulence models.

Figure 4-19. Temperature along line A-B (see Figure 3-2) for the fuel hot spot plane for different turbulence models.

Figure 4-20. Bulk mean helium outlet temperatures for channels and gaps for two turbulence models.

Figure 4-21. Comparison of gap wall shear stress for different turbulence model for $3 \mathrm{~mm}$ gap width. 
Figure 4-22. Temperature contours at the middle plane of the fuel block for different gap widths.

Figure 4-23. Temperature along line A-B (see Figure 3-2) of the middle plane of the fuel block

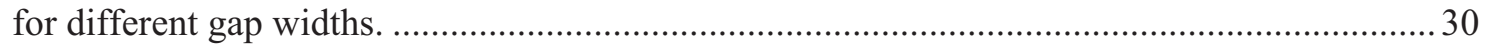

Figure 4-24. Temperature contours at the fuel hot spot plane for different gap widths............................. 31

Figure 4-25. Temperature along line A-B (see Figure 3-2) of fuel hot spot plane for different gap widths. 32

Figure 4-26. Bulk mean helium gas outlet temperatures for channels and gaps for different gap widths. 33

Figure 4-27. Temperature contours at the middle plane of the fuel block for different heat generation rates.

Figure 4-28. Temperature along line A-B (see Figure 3-2) of the middle plane of the fuel block for different heat generation rates. .35

Figure 4-29. Temperature contours at the fuel hot spot plane for different heat generation rates. .36

Figure 4-30. Temperature along line A-B (see Figure 3-2) of the fuel hot spot plane for different heat generation rates. .36

Figure 4-31. Bulk mean helium gas outlet temperatures at coolant channels and gaps for different heat generation rates. .37

Figure 4-32. Temperature contours at the middle plane of the fuel block for different geometries. .38

Figure 4-33. Temperature along line A-B (see Figure 3-2) for the fuel hot spot plane for different geometries 39

Figure 4-34. Temperature contours at the fuel hot spot plane of the fuel block for different geometries

Figure 4-35. Temperature along line A-B of the fuel hot spot plane for different geometries.

Figure 4-36. Bulk mean helium gas outlet temperatures at coolant channels and gaps for different geometries in block region.

\section{TABLES}

Table 2-1. Major specifications of GTMHR. 2

Table 3-1. Coefficients of the piece-wise polynomial equation for the helium properties......................... 6

Table 3-2. Coefficients of the piece-wise polynomial equation for the graphite properties. ....................... 7

Table 3-3. Coefficients of the piece-wise polynomial equation for the fuel compact properties. ............... 7

Table 4-1. Calculation results of flow rates and temperatures for the single block model.

Table 4-2. Calculation inputs and results for total mass flow, gap flow fraction, core differential pressure, max fuel temperature, and gap and max channel outlet temperatures for various gap widths.

Table 4-3. Calculation inputs and results for total mass flow, gap flow fraction, core differential pressure, max fuel temperature, and gap and max channel outlet temperatures for different heat generation profiles. 
Table 4-4. Calculation inputs and results for total mass flow, gap flow fraction, core differential pressure, max fuel temperature and gap, and max channel outlet temperatures for the $\mathrm{k} \sim \omega$ turbulence model for different gap widths.

Table 4-5. Calculation inputs and results for total mass flow, gap flow fraction, core differential pressure, max fuel temperature, and gap and max channel outlet temperatures for constant total mass flow for different gap widths.

Table 4-6. Calculation results for coolant channel, gap, and total flow rates; bypass flow ratio; and the maximum fuel and coolant channel temperature in the reactor for different heat generation rate profiles for $20 \%$ bypass flow

Table 4-7. Calculation inputs and results of total mass flows, gap flow fractions, and maximum fuel temperatures for different geometries

Table 5-1. Summary of the comparative studies for the core bypass flow phenomena. 


\section{CFD Analysis of Core Bypass Phenomena}

\section{INTRODUCTION}

The Energy Policy of Act of 2005 (U.S. Congress 2005) designates that the Next Generation Nuclear Plant (NGNP) will be based on a very high temperature gas-cooled reactor (VHTR) aiming for both electricity generation and process heat utilization in processes such as hydrogen production and coal gasification. The U.S. Department of Energy is exploring the potential for the VHTR, which will be either of a prismatic or a pebble-bed type reactor.

One important design consideration for the reactor core of a prismatic VHTR is coolant bypass flow, which occurs in the interstitial regions between fuel blocks. Such gaps are an inherent presence in the reactor core because of tolerances in manufacturing the blocks and the inexact nature of their installation. Furthermore, the geometry of the graphite blocks changes over the lifetime of the reactor because of thermal expansion and irradiation.

Several studies of bypass flows have been made in the past by applying simplified methods such as flow network calculations and correlations obtained from experiments (Takada et al. 2004; Nakano, Tuji, and Tazawa 2008). However, the distribution of temperature in the fuel pins and graphite blocks, as well as coolant outlet temperatures, are strongly coupled with the local heat generation rate within fuel blocks which is not uniformly distributed in the core. Hence, it is crucial to establish mechanistic based methods that can be applied to the reactor core thermal hydraulic design and safety analysis. A mechanistic study similar to the present one was performed by Tak et al. (2008) wherein a one-twelfth sector of the core was simulated. However, the coolant mass flow was computed using a separate one-dimensional (1-D) code, whereas the mass flow rates are determined naturally as part of the solution in the present study.

The objectives of the present study are to establish a baseline evaluation method for the coolant bypass flow phenomenon and to investigate bypass flow, especially as affected by several parameters that are deemed important to bypass flow. Three-dimensional (3-D) computational fluid dynamic (CFD) calculations for a one-twelfth sector of a prismatic VHTR were conducted to investigate the influence of gap width, turbulence model, axial heat generation profile, peak radial factor, irradiation-induced shrinkage on bypass flow and coolant channel flow, and temperature distributions in the reactor core using a commercial CFD code. The condition of $20 \%$ bypass flow, including the flow in the surrounding reflector regions, was also simulated to see what some potential resulting temperature and flow conditions are. An additional parameter that has an influence on bypass flow is the surface roughness of the flow passages through the graphite. However, the surface conditions can be prescribed for the machining process and it is not known what this prescription will be. Hence, it is assumed that the flow passages are smooth in the present study. 


\section{DESCRIPTION OF THE REFERENCE VHTR}

The gas-turbine modular helium reactor (GT-MHR; General Atomics 1996) was selected as a reference reactor for these calculations. It is a helium-cooled, graphite-moderated, thermal neutron spectrum reactor with $850{ }^{\circ} \mathrm{C}$ core outlet temperature and design power generation of $600 \mathrm{MWth}$. Major specifications are shown in Table 2-1. Figure 2-1 shows the cutaway view of the reactor and cross section of the reactor core, respectively.

Table 2-1. Major specifications of GT-MHR.

\begin{tabular}{lc}
\multicolumn{1}{c}{ Specifications } & Values \\
\hline Reactor power (MWth) & 600 \\
Reactor inlet/outlet temperature $\left({ }^{\circ} \mathrm{C}\right)$ & $490 / 850$ \\
Reactor pressure (bars) & 70 \\
Power density (W/cc) & 5 \\
Reactor mass flow rate $(\mathrm{kg} / \mathrm{s})$ & 320 \\
Effective core height $(\mathrm{m})$ & 7.93 \\
Number of fuel blocks & 1,020 \\
\hline
\end{tabular}

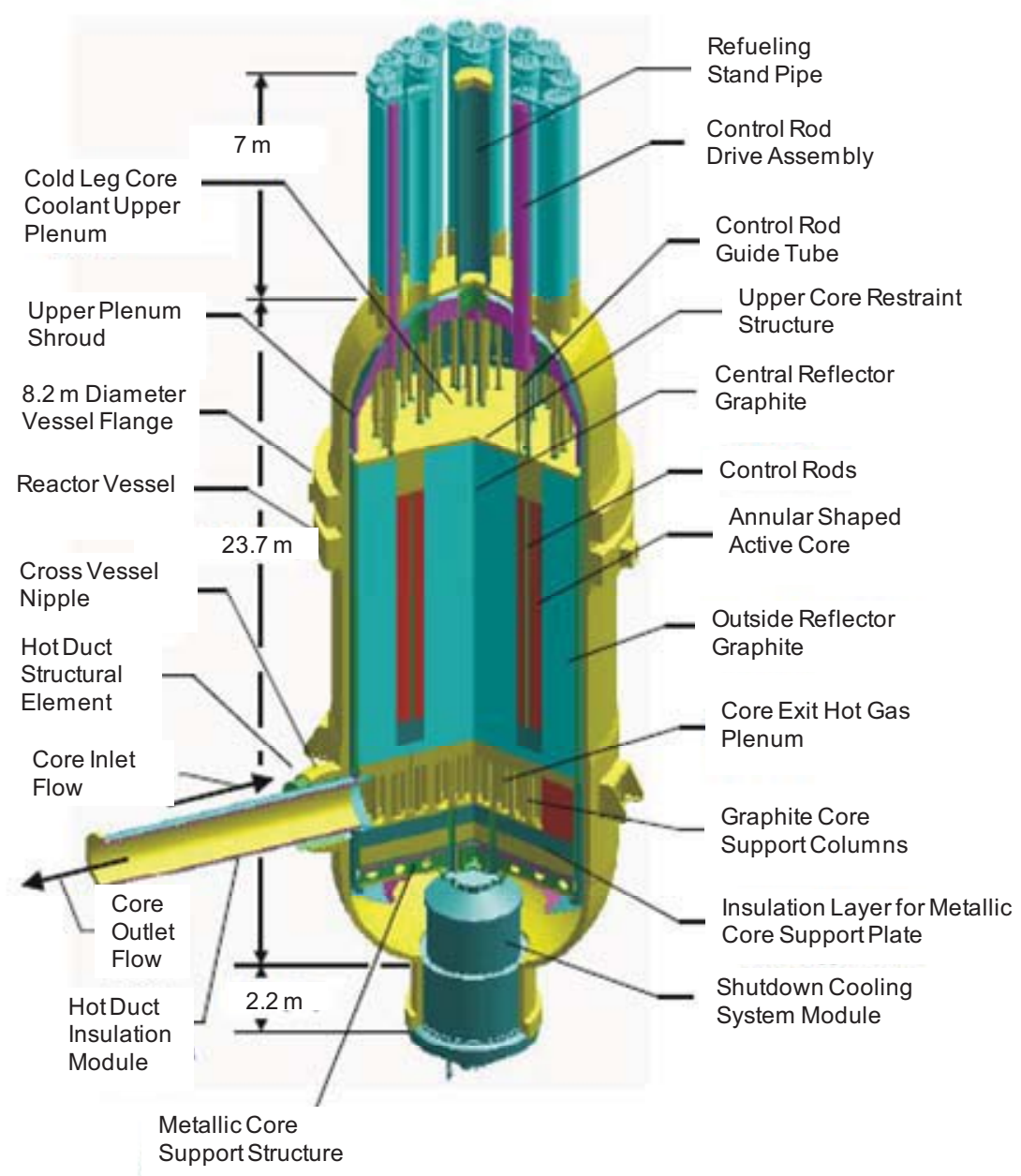

Figure 2-1. Cutaway view of the GT-MHR (MacDonald et al. 2003). 
The GT-MHR core consists of graphite hexagonal blocks. One-third of the blocks are fuel blocks arranged annularly and the other two-thirds are neutron reflector blocks arranged inside and outside of the fuel blocks. The annular fueled section consists of 10 layers of fuel blocks installed between removable upper and lower reflector blocks. Control rods and reserve shut down system channels are located in the annular fuel block region of the core. Figure 2-2 shows a cutaway of fuel and fuel blocks and a cross section of the prismatic core. The average width and height of a block are 360 and $793 \mathrm{~mm}$, respectively. Each fuel block has 210 fuel channels and 102 and 6 flow channels with diameters of 15.88 and $12.70 \mathrm{~mm}$, respectively. The blocks are vertically connected with dowel pins.
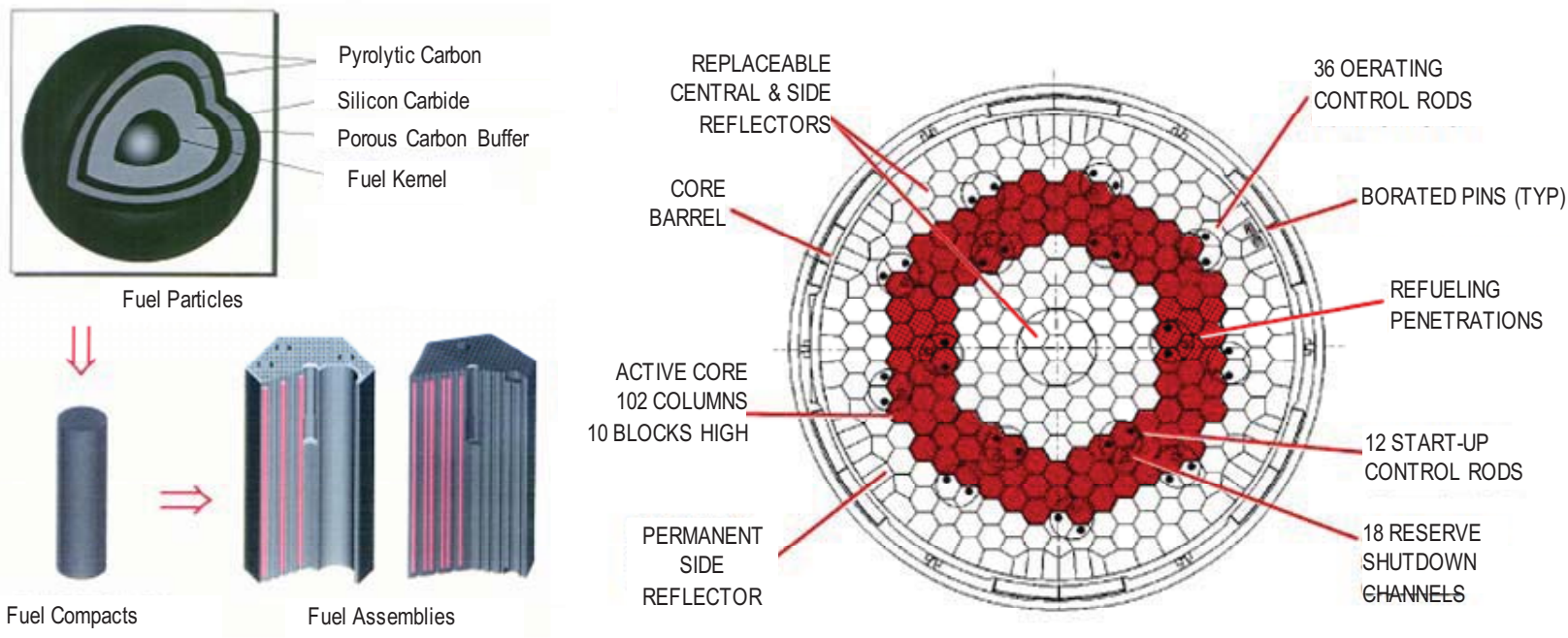

Figure 2-2. Cutaway view of fuel and fuel blocks and the cross section of the core (MacDonald et al. 2003).

Helium coolant enters the reactor pressure vessel through the outer side of an annular pipe, flows upwards between the reactor pressure vessel and core barrel, enters the upper plenum, and then flows downwards. The coolant temperature increases as it flows downward through the flow channels in the graphite blocks, joins at the lower plenum, and exits the vessel through the inner side of the annular pipe.

There are also potential bypass flow passages through the interstitial gaps between graphite blocks. The flow through these interstitial gaps varies because of variation in gap width, which occurs because of tolerances in manufacturing and inexact installation. In addition, the nonuniform neutron fluences and temperature distributions in the actual core cause nonuniform deformation in the graphite block over its lifetime, complicating the flow characteristics. 


\section{CFD MODEL}

The approach to evaluate core bypass phenomena is to model a one-twelfth sector of the hexagonal block - a one-twelfth sector is the smallest region that has symmetry boundaries on all three edges. Figure 3-1 is a schematic of the cross-section of a typical prismatic graphite block that illustrates a onetwelfth sector of the block. By limiting the CFD model to a one-twelfth sector, a much finer mesh can be used. The sector involves 8.5 coolant channels $15.88 \mathrm{~mm}$ in diameter, 0.5 coolant channels $12.70 \mathrm{~mm}$ in diameter, 17.5 fuel pin channels, and 0.5 burnable poison rod channels. Figure 3-2 shows the top view of the hexagonal grid for the one-twelfth sector. Finer meshing is applied in the boundary layers of the coolant channels and the gap, and $y+$ values along the walls are less than 6 . The flow passages in the graphite block are assumed to be smooth. Grids are created for the one-twelfth sector that extend for only one prismatic block in one case and for the whole core length in another case. The single-block deep mesh contains approximately 570,000 cells. The computational domain for the full core length model is divided vertically with an upper reflector section $(1.189 \mathrm{~m})$, a fueled section $(7.93 \mathrm{~m})$, and a lower reflector section $(1.585 \mathrm{~m})$, with a total length of $10.704 \mathrm{~m}$. There are approximately 7.6 million mesh cells. Each side of the one-twelfth sector is appropriately set as a symmetry boundary. The following assumptions are made in this study:

- The coolant channels have no cracks and there is no flow into the graphite.

- There are no horizontal cross flows between the tops and bottoms of adjacent blocks.

- The geometry of the block, the coolant channels, and the gap are uniform from top to bottom.

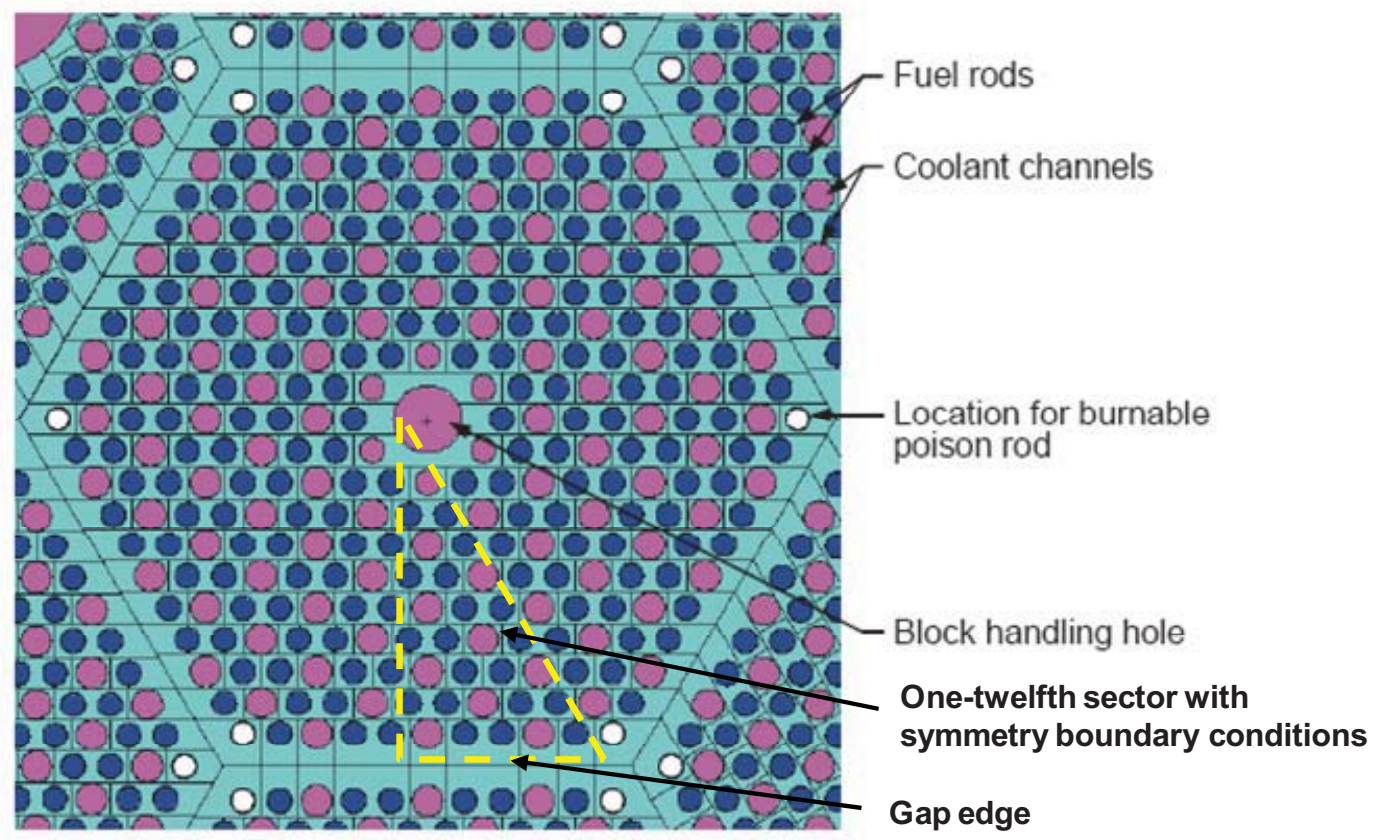

Figure 3-1. Cross-sectional view of a hexagonal block. 


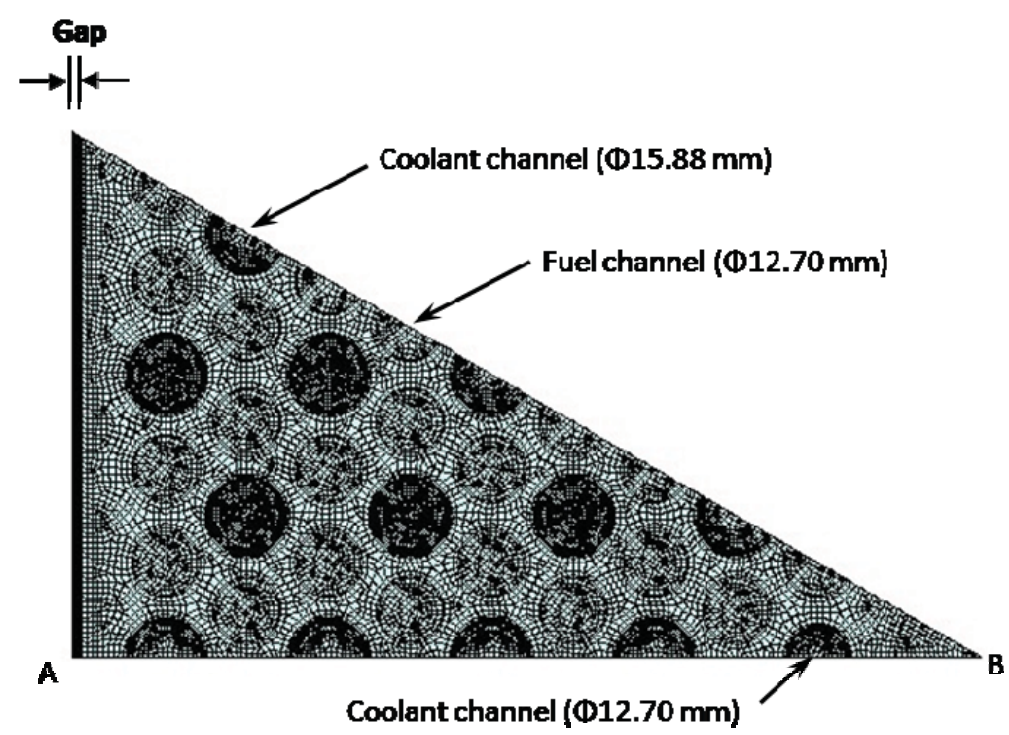

Figure 3-2. Top view of one-twelfth hexagonal block grids.

Flow in this study was determined by setting a differential pressure across the computational domain, which represents actual operating conditions. Note that the inlet pressure specified is a stagnation pressure condition while the specified outlet pressure is simply the static pressure. This boundary specification is realistic because it allows the physics of the flow and heat transfer to determine actual flow rates. In contrast, Tak et al. (2008) set mass flow rates for each coolant channel and gap as determined from separate 1-D code calculations. However, the flow rates in the channels and gaps are a function of the friction, which is dependent on viscosity, which is highly temperature dependent. The mass flow rates are therefore a function of the thermal characteristics of the problem, which are not known a priori.

The commercial CFD codes FLUENT Version 6.3.26 (FLUENT 2006) and STAR-CCM+ version 4.02.007 (STAR-CCM+2008) are used in the present study. An iterative convergence tolerance of $1 \times 10$ 5 is used for FLUENT calculations. Momentum, energy and viscous terms were discretized by the second-order upwind scheme. Pressure-velocity coupling is obtained by the SIMPLE algorithm (Patankar and Spalding 1972). Default under-relaxation factors are used. The STAR-CCM+ calculations also employ second-order upwinding, the coupled implicit solver, and the default Courant number. Iterations are continued until a tolerance of $1 \times 10-4$ is achieved. The residuals computed in STAR-CCM + and FLUENT are defined differently. The tolerances used were determined from a simple exercise of computing Poiseuille flow, which has an analytical solution, and comparing results with the correct solution for increasingly smaller tolerances until acceptable results were obtained.

\subsection{Thermal Properties}

Helium is used as the coolant fluid for the CFD model. Helium properties, assumed to be isobaric at 70 bars, are obtained from the National Institute of Standards and Technology (NIST) data (2009) in the U.S. Department of Commerce. Properties of density, specific capacity, thermal conductivity, and viscosity are incorporated into commercial codes as piece-wise polynomial expressions with five coefficients:

$$
\Phi(T)=A_{1}+A_{2} T+A_{3} T^{2}+A_{4} T^{3}+A_{5} T^{4}
$$


Table 3-1 shows the coefficients used in the present study for the several properties. Figure 3-3 illustrates graphical profiles for each of the helium properties.

Table 3-1. Coefficients of the piece-wise polynomial equation for the helium properties.

\begin{tabular}{ccccccc}
\hline & \multicolumn{2}{c}{$\begin{array}{c}\text { Density } \\
\left(\mathrm{kg} / \mathrm{m}^{3}\right)\end{array}$} & \multicolumn{2}{c}{$\begin{array}{c}\mathrm{Cp} \\
(\mathrm{J} / \mathrm{kg} \mathrm{K})\end{array}$} & $\begin{array}{c}\text { Viscosity } \\
(\mathrm{Pa} \mathrm{s})\end{array}$ & $\begin{array}{c}\text { Thermal } \\
\text { conductivity } \\
(\mathrm{W} / \mathrm{m} \mathrm{K})\end{array}$ \\
\cline { 2 - 7 } $\begin{array}{c}\text { Temperature } \\
\text { range }(\mathrm{K})\end{array}$ & $250-650$ & $650-1500$ & $250-450$ & $450-1500$ & $250-1500$ & $250-1500$ \\
\hline $\mathrm{A}_{1}$ & $3.95 \mathrm{E}+1$ & $1.69 \mathrm{E}+1$ & $5.29 \mathrm{E}+3$ & $5.18 \mathrm{E}+3$ & $5.52 \mathrm{E}-6$ & $4.17 \mathrm{E}-2$ \\
$\mathrm{~A}_{2}$ & $-1.88 \mathrm{E}-1$ & $-3.33 \mathrm{E}-2$ & $-9.18 \mathrm{E}-1$ & $3.18 \mathrm{E}-3$ & $5.44 \mathrm{E}-8$ & $4.48 \mathrm{E}-4$ \\
$\mathrm{~A}_{3}$ & $4.38 \mathrm{E}-4$ & $3.23 \mathrm{E}-5$ & $3.09 \mathrm{E}-3$ & $6.68 \mathrm{E}-6$ & $-2.10 \mathrm{E}-11$ & $-2.00 \mathrm{E}-7$ \\
$\mathrm{~A}_{4}$ & $-5.00 \mathrm{E}-7$ & $-1.54 \mathrm{E}-8$ & $-4.66 \mathrm{E}-6$ & $-6.63 \mathrm{E}-9$ & $9.06 \mathrm{E}-15$ & $9.26 \mathrm{E}-11$ \\
$\mathrm{~A}_{5}$ & $2.23 \mathrm{E}-10$ & $2.89 \mathrm{E}-12$ & $2.66 \mathrm{E}-9$ & $1.72 \mathrm{E}-12$ & $-1.74 \mathrm{E}-18$ & $-1.88 \mathrm{E}-14$ \\
\hline
\end{tabular}

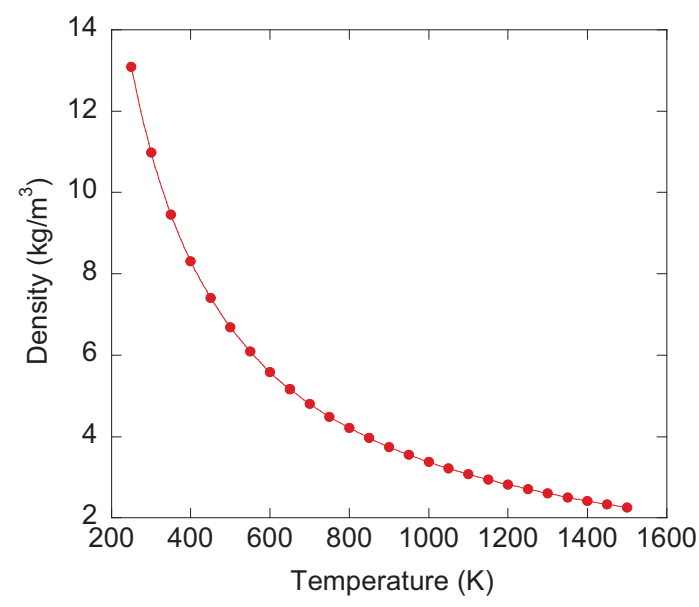

(a) Density

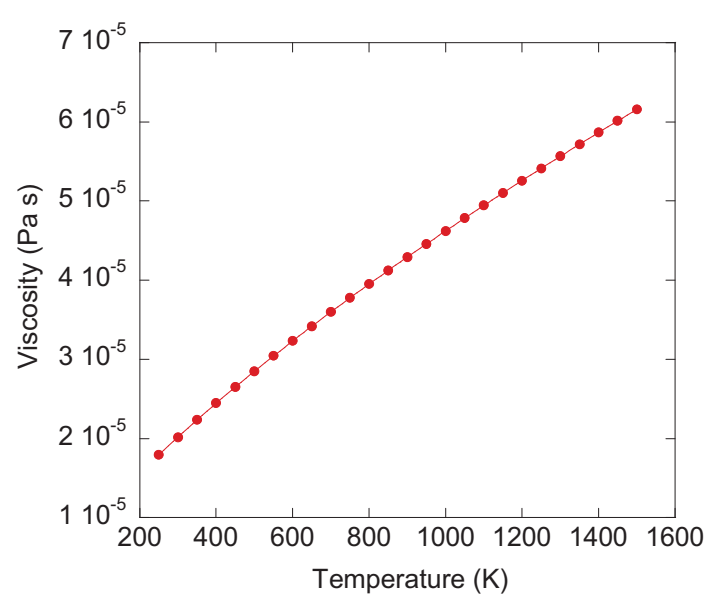

(c) Viscosity

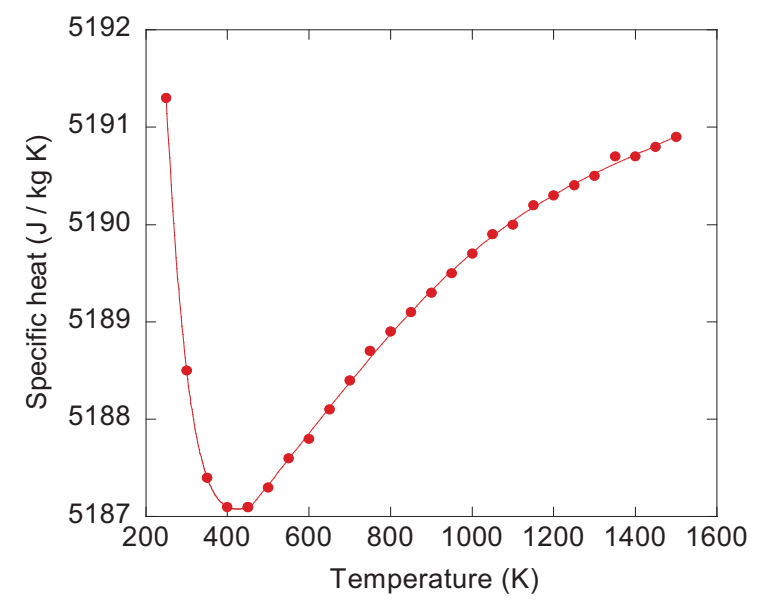

(b) Specific heat

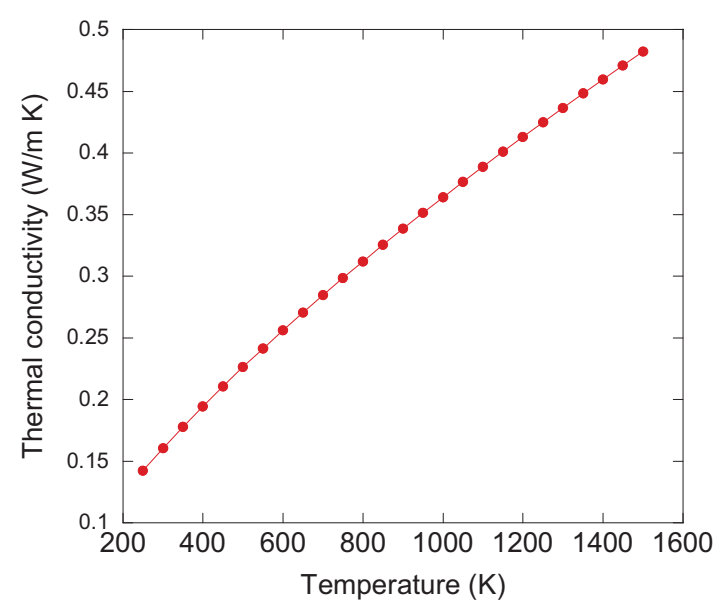

(d) Thermal conductivity

Figure 3-3. Profiles of the helium properties. 
Graphite H-451 is used for the solid region. Properties of density, specific heat capacity, and thermal conductivity, based on the data used in the Fort St. Vrain safety analysis report (General Atomics 1977), are also incorporated as piece-wise polynomial equations using Equation 3-1. Table 3-2 provides the coefficients used for the graphite in this study. Figure 3-4 provides graphs for each H-451 property.

Table 3-2. Coefficients of the piecewise polynomial equation for the graphite properties.

\begin{tabular}{ccccc} 
Temperature & Density $\left(\mathrm{kg} / \mathrm{m}^{3}\right)$ & $\mathrm{Cp}(\mathrm{J} / \mathrm{kg} \mathrm{K})$ & \multicolumn{2}{c}{ Thermal conductivity $(\mathrm{W} / \mathrm{m} \mathrm{K})$} \\
\cline { 2 - 5 } range $(\mathrm{K})$ & $255.6-2200$ & $255.6-2200$ & $255.6-1644.4$ & $1644.4-1922.2$ \\
\hline $\mathrm{A}_{1}$ & $1.74 \mathrm{E}+3$ & $-3.93 \mathrm{E}+2$ & $1.24 \mathrm{E}+2$ & 41.5 \\
$\mathrm{~A}_{2}$ & - & 4.91 & $-3.32 \mathrm{E}-1$ & - \\
$\mathrm{A}_{3}$ & - & $-4.16 \mathrm{E}-3$ & $4.09 \mathrm{E}-4$ & - \\
$\mathrm{A}_{4}$ & - & $1.66 \mathrm{E}-6$ & $-2.11 \mathrm{E}-7$ & - \\
$\mathrm{A}_{5}$ & - & $-2.54 \mathrm{E}-10$ & $4.02 \mathrm{E}-11$ & - \\
\hline
\end{tabular}

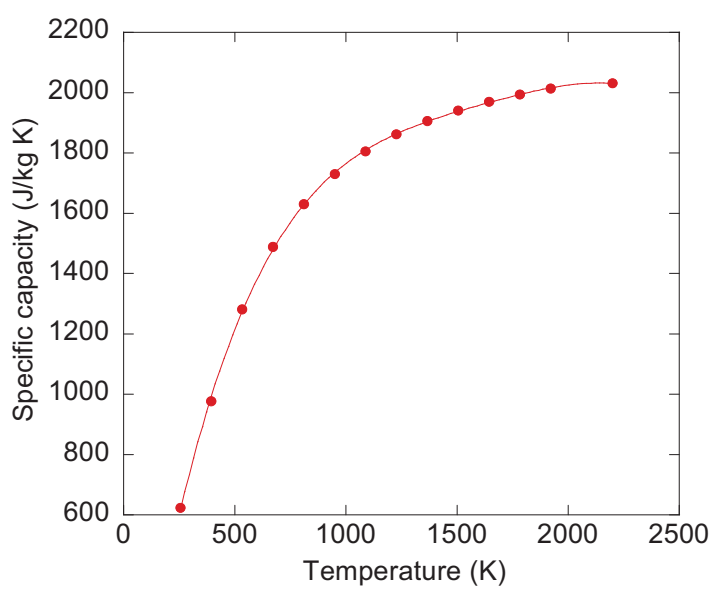

(a) Specific heat capacity

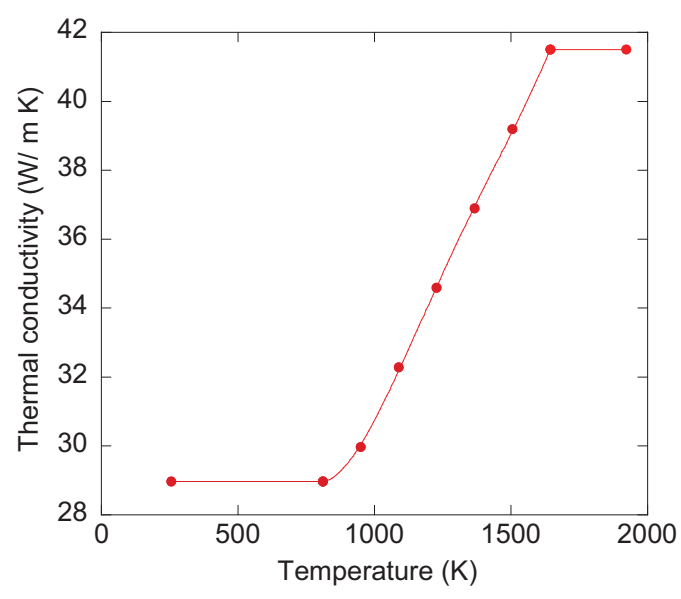

(b) Thermal conductivity

Figure 3-4. Profiles of the graphite (H-451) properties.

Graphite H-451 properties are used for the block and burnable poison regions. Properties of density, specific capacity, and thermal conductivity, based on the data from previous thermal hydraulic studies conducted by Idaho National Laboratory (INL; MacDonald et al. 2003), are used for the fuel compact regions. Table 3-3 shows the coefficients used in this study for Equation 3-1. Figure 3-5 shows the profiles for each property.

Table 3-3. Coefficients of the piecewise polynomial equation for the fuel compact properties.

\begin{tabular}{|c|c|c|c|c|c|}
\hline \multirow{2}{*}{$\begin{array}{c}\text { Temperature } \\
\text { range } \\
(\mathrm{K})\end{array}$} & $\begin{array}{l}\text { Density } \\
\left(\mathrm{kg} / \mathrm{m}^{3}\right)\end{array}$ & \multicolumn{3}{|c|}{$\begin{array}{c}\mathrm{Cp} \\
(\mathrm{J} / \mathrm{kg} \mathrm{K})\end{array}$} & $\begin{array}{c}\text { Thermal } \\
\text { conductivity } \\
(\mathrm{W} / \mathrm{m} \mathrm{K})\end{array}$ \\
\hline & $255.6-2200$ & $255.6-533.3$ & 533.3-1088.9 & 1088.9-2200 & $255.6-2200$ \\
\hline $\mathrm{A}_{1}$ & $2.39 \mathrm{E}+3$ & $5.81 \mathrm{E}+2$ & $-2.96 \mathrm{E}+3$ & $4.14 \mathrm{E}+2$ & 3.94 \\
\hline $\mathrm{A}_{2}$ & - & - & $1.50 \mathrm{E}+1$ & $8.63 \mathrm{E}-1$ & $3.59 \mathrm{E}-3$ \\
\hline $\mathrm{A}_{3}$ & - & - & $-2.33 \mathrm{E}-2$ & $-6.14 \mathrm{E}-4$ & $-1.98 \mathrm{E}-9$ \\
\hline $\mathrm{A}_{4}$ & - & - & $1.64 \mathrm{E}-5$ & $2.09 \mathrm{E}-7$ & $3.19 \mathrm{E}-12$ \\
\hline $\mathrm{A}_{5}$ & - & - & $-4.40 E-9$ & $-2.70 \mathrm{E}-11$ & $-9.77 \mathrm{E}-16$ \\
\hline
\end{tabular}




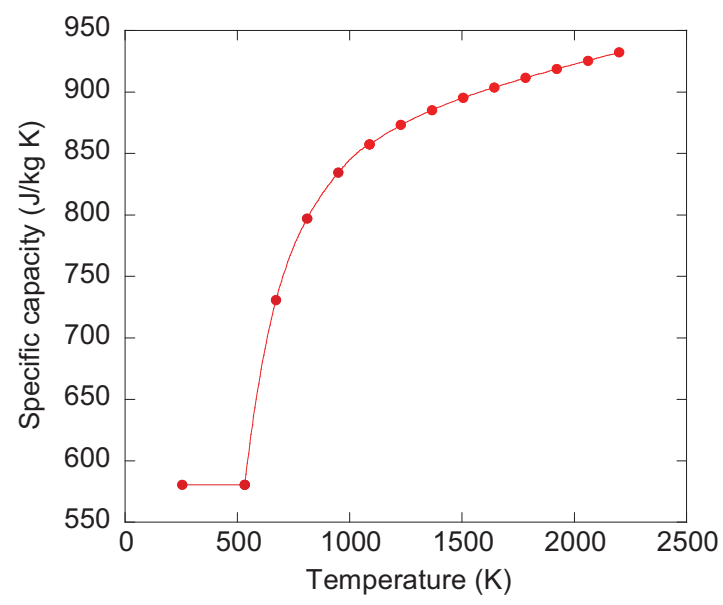

(a) Specific capacity

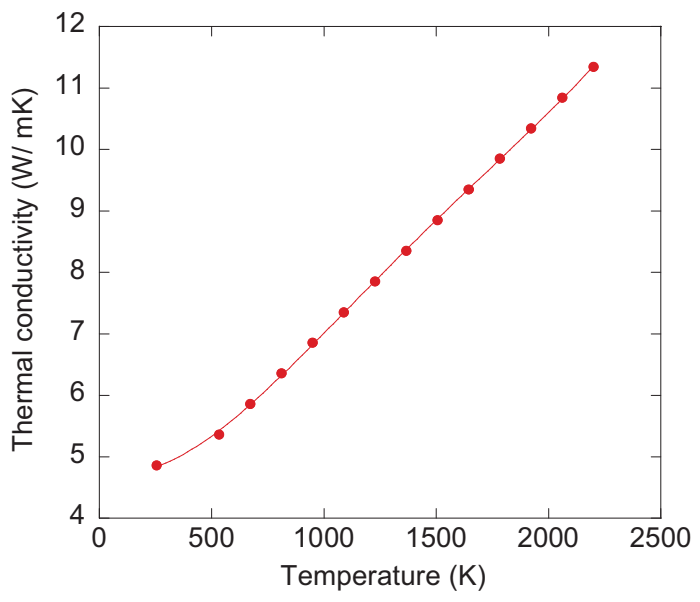

(b) Thermal conductivity

Figure 3-5. Profiles of the fuel compact properties.

\subsection{Validation Study}

While the flow and heat transfer cannot yet be fully validated, the computed friction in the coolant channels can be compared with established empirical correlations in order to evaluate the adequacy of the employed turbulence models in computing the friction, which is a key factor in determining the flow rate of the coolant in the flow passages. In the present study, wall shear stress in the cylindrical coolant channel calculated by FLUENT is compared with the results using published correlations. A differential pressure of $5.0 \mathrm{psi}$ is set for the one-twelfth sector for the full core depth mesh. A uniform heat generation rate of $27.88 \mathrm{~W} / \mathrm{m}^{3}$, which is obtained from a study conducted by the INL (MacDonald et al. 2003), is prescribed for the fuel region. The standard $\mathrm{k} \sim \varepsilon$ model with enhanced wall treatment and standard $\mathrm{k} \sim \omega$ model with shear correction option are applied. The following correlations are used for comparison:

$f=\frac{0.3164}{\operatorname{Re}^{0.25}}$ Blasius (Fox and McDonald 1985)

$\frac{1}{\sqrt{f}}=-2 \log _{10}\left\{\frac{\varepsilon}{3.7 D}+\frac{2.51}{\operatorname{Re}}\left[1.14-2 \log _{10}\left(\frac{\varepsilon}{D}+\frac{21.25}{\operatorname{Re}^{0.9}}\right)\right]\right\}$ Zigrang-Sylvester (Zigrang and Sylvester 1985)

where $f$ is the friction factor, $\varepsilon$ is wall surface roughness and Re is the Reynolds number. The friction factors are corrected for variable fluid properties by the expression given by Schlichting and Gersten (2000):

$$
\frac{c_{f}}{c_{f_{c . p .}}}=\left(\frac{\rho_{w}}{\rho_{m}}\right)^{m_{\rho}}\left(\frac{\mu_{w}}{\mu_{m}}\right)^{m_{\mu}}
$$

where

$$
m_{\rho}=\frac{1}{2}-4.9 \sqrt{\frac{c_{f_{c . p .}}}{2}}, m_{\mu}=4.9 \sqrt{\frac{c_{f_{c . p .}}}{2}}
$$


Here, $c f_{c . p}$ is the friction coefficient at constant properties, and the $w$ and $m$ subscripts refer to the wall and the bulk values, respectively. The friction coefficient $c_{f}$ is equal to one-fourth of the friction factor $f$. Figure 3-6 shows the comparison of wall shear stress in a coolant channel for the standard $\mathrm{k} \sim \varepsilon$ turbulence model with enhanced wall treatment and the above experimental correlations. Note that the Reynolds number varies axially because of heating.

The maximum variations between the FLUENT simulations and Zigrang-Sylvester and Blasius correlations are 2.2 and $0.74 \%$, respectively.

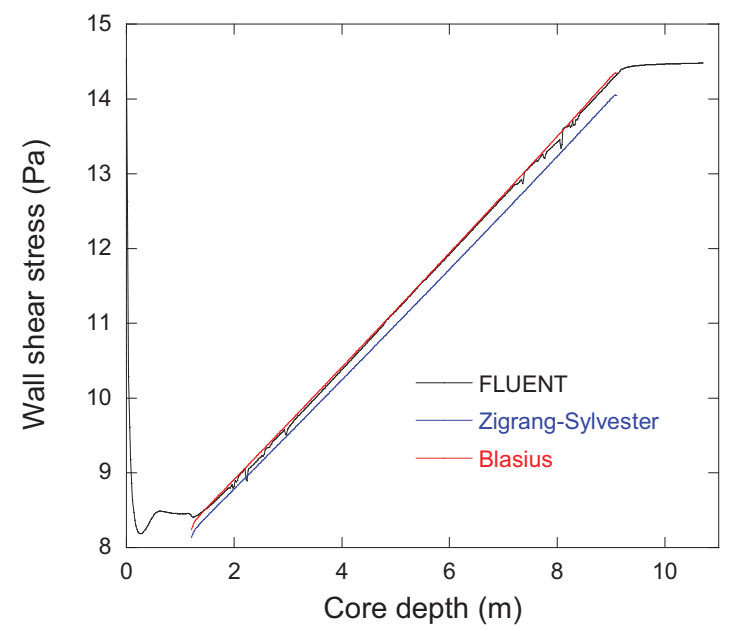

Figure 3-6. Comparison of wall shear stress in a coolant channel between experimental correlations and FLUENT calculations using the standard $\mathrm{k} \sim \varepsilon$ turbulence model with enhanced wall treatment.

Figure 3-7 shows the results of wall shear stress for the standard $\mathrm{k} \sim \omega$ model compared to the empirical correlations. Relative to the $\mathrm{k} \sim \varepsilon$ results, the $\mathrm{k} \sim \omega$ model results exhibit larger differences. Also, the slope of the predicted curve in Figure 3-7 is different than for the correlations. The maximum differences between FLUENT simulation using the standard $\mathrm{k} \sim \omega$ model and Zigrang-Sylvester and Blasius expressions are 4.3 and $2.3 \%$, respectively. The standard $\mathrm{k} \sim \varepsilon$ model with enhanced wall treatment shows better agreement with the empirical correlations in the coolant channel region and, therefore the model is employed for the several studies below, except where noted.

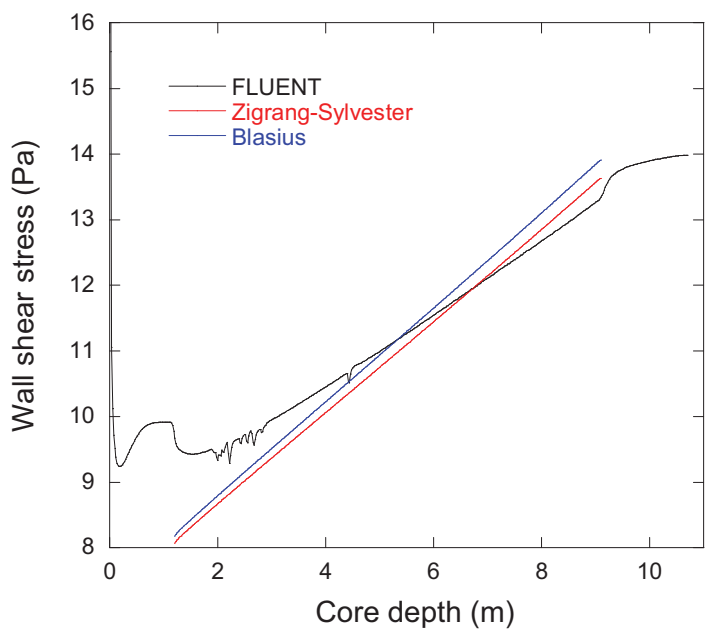

Figure 3-7. Comparison of wall shear stress in a coolant channel between experimental correlations and FLUENT calculations using the standard $\mathrm{k} \sim \omega$ turbulence model. 


\subsection{Grid Convergence Study}

A grid convergence study is conducted using FLUENT for the full-core grid (7.6 million cells) with $0 \mathrm{~mm}$ gap width and a finer mesh. The number of cells in the solid region for the finer mesh is increased and the total mesh number reaches about 10.9 million. A differential pressure of 5.0 psi and uniform heat generation rate of $27.88 \mathrm{MW} / \mathrm{m}^{3}$ are applied in both cases. The standard $\mathrm{k} \sim \varepsilon$ model with enhanced wall treatment is employed.

Flow and temperature distributions are compared between base and fine-mesh cases. Differences in the total mass flow rate, bulk coolant channel outlet temperature, and maximum fuel temperature are 0.31 , 0.30 , and $0.40 \%$, respectively. Figure 3-8 shows the temperature contours of the plane involving the fuel hot spot between the two grids. The results show that the reference grid generated is sufficiently fine for simulating the flow distribution in the fuel block.

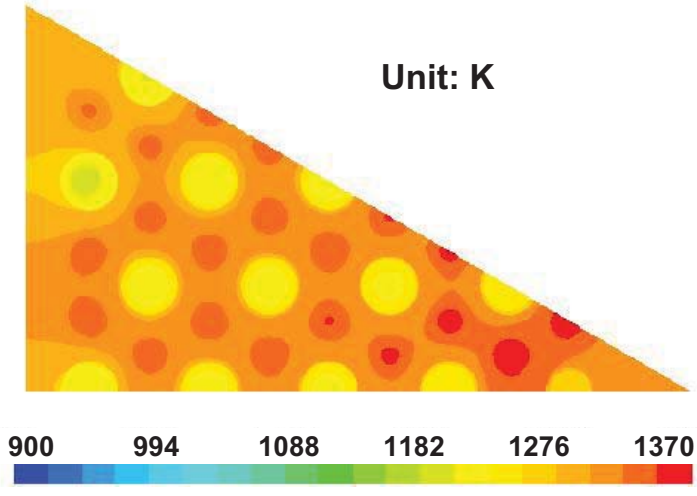

(a) Base case (7.6 million)

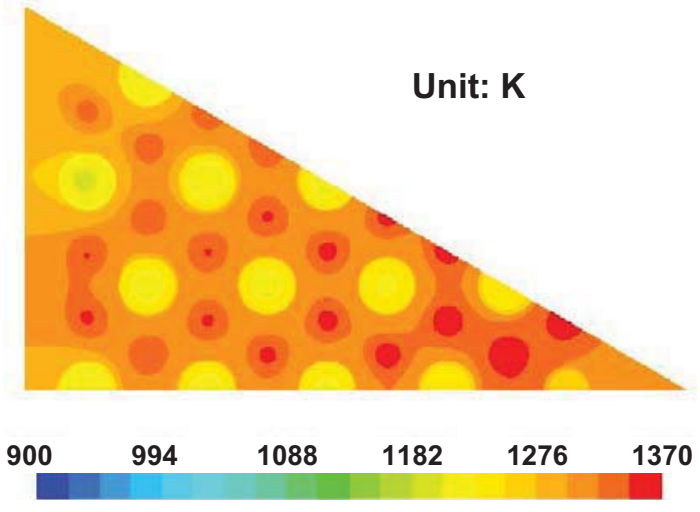

(b) Fine mesh (10.9 million)

Figure 3-8. Temperature contours at the fuel hot spot plane for different meshes. 


\section{RESULTS AND DISCUSSION}

\subsection{Calculations for a Single Prismatic Block}

Calculations are made using the one-block deep grid employing FLUENT and STAR-CCM + . Bypass flow cases where the gap width is $0 \mathrm{~mm}$ (the reference case) and $2 \mathrm{~mm}$ are computed to observe differences resulting from different gap widths and between the two CFD codes.

A differential pressure from inlet to outlet of $0.5 \mathrm{psi}$ is used; the prescribed inlet pressure is the stagnation pressure, whereas the outlet pressure is simply the static pressure. The inlet temperature is set to $490{ }^{\circ} \mathrm{C}$. A volumetric heat generation rate of $27.88 \mathrm{MW} / \mathrm{m}^{3}$ is assumed for the fuel pins based on a previous study (MacDonald et al. 2003). The standard $\mathrm{k} \sim \varepsilon$ turbulence model with two layer all $\mathrm{y}+$ treatment is applied for the STAR-CCM+ case while the standard $\mathrm{k} \sim \varepsilon$ model with enhanced wall treatment is used for the FLUENT case. The inlet turbulent conditions used for both CFD codes are $0.01 \mathrm{~J} / \mathrm{kg}$ for the turbulent kinetic energy and $0.1 \mathrm{~J} / \mathrm{kg} \mathrm{s}$ for the dissipation rate. Calculations are performed on an SGI Altix ICE 8200.

Figure 4-1 shows the temperature contours at the inlet plane for 0 and $2 \mathrm{~mm}$ gap widths using STAR-CCM+. Clearly, the presence of the bypass flow in the gap reduces the graphite temperature near the outer edge of the block, significantly contributing to the overall cooling of the block. Figure 4-2 shows temperature contours at the outlet plane of the block, also for STAR-CCM+ results. Again, the $2 \mathrm{~mm}$ gap-width case indicates that significant cooling occurs for the block near the gap. In fact, the cross-sectional hot spot, which occurs at two fuel pins near the outer edge of the block for the no-gap case, is displaced for the $2 \mathrm{~mm}$ gap-width case to the fuel pins nearest the block center. An overall temperature gradient in the graphite block also occurs for the case of the $2 \mathrm{~mm}$ gap width, unlike the nogap case. Hence, the presence of the bypass flow provides significant cooling to the periphery of the graphite block and affects the location of the block hot spot, indicating that it is important to understand the effects of bypass flow on the flow and temperature distributions in the core.

Table 4-1 shows the calculation results for total mass-flow, gap-flow fraction, overall average channel outlet temperature, and gap outlet temperature for the two CFD codes. The calculation results for flow rate and temperature agree well; the mass flow difference is within $1.5 \%$. Toutlet-Tinlet for the gap flow is different by $3.5 \%$. The study shows that calculations are closely matched by the two commercial codes.

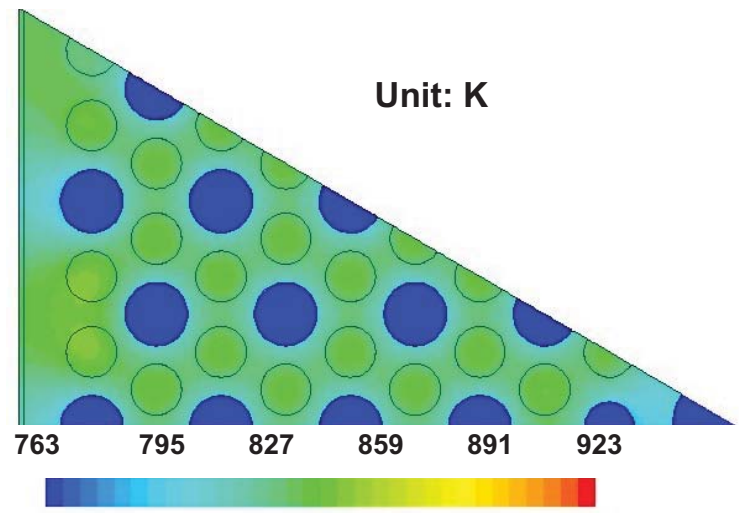

(a) $0 \mathrm{~mm}$

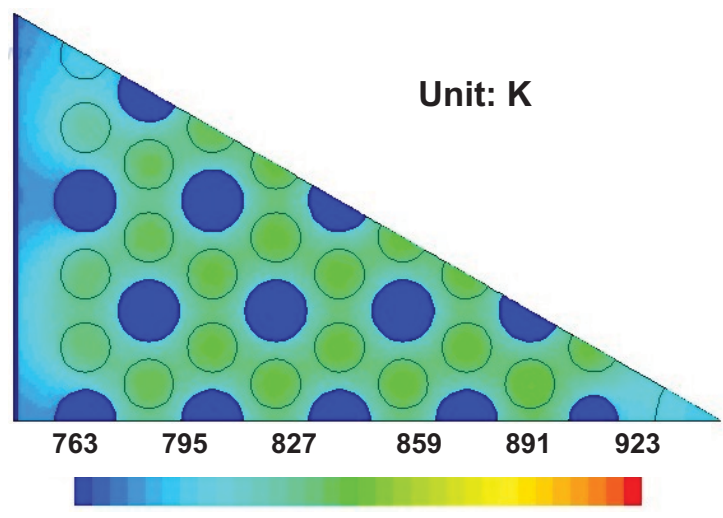

(b) $2 \mathrm{~mm}$

Figure 4-1. Temperature contours at the inlet plane of the block for different gap widths. 


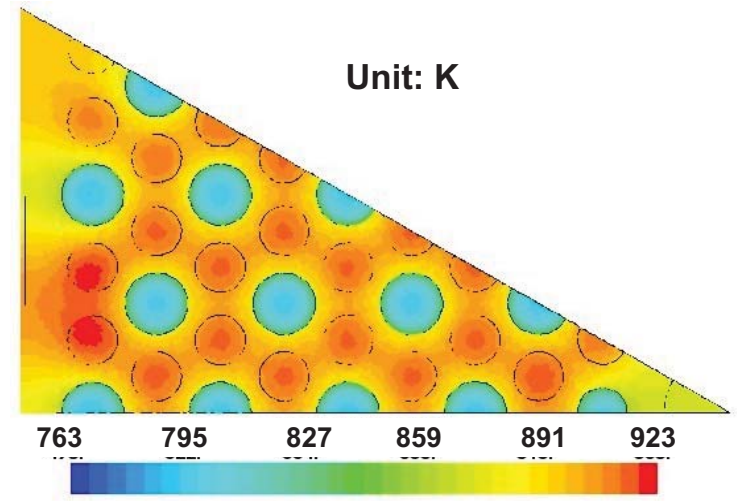

(a) $0 \mathrm{~mm}$

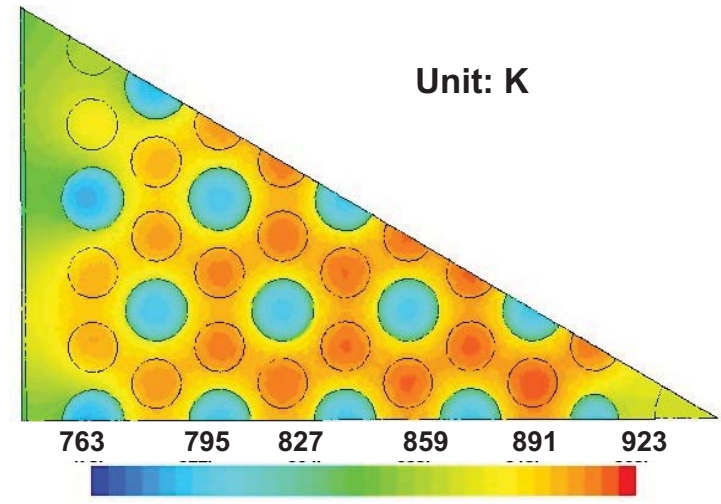

(b) $2 \mathrm{~mm}$

Figure 4-2. Temperature contours at the outlet plane of the block for different gap widths.

Table 4-1. Calculation results of flow rates and temperatures for the single block model.

\begin{tabular}{lcc}
\hline \multicolumn{1}{c}{ Calculated code } & FLUENT & STAR-CCM+ \\
\hline Gap width $(\mathrm{mm})$ & 2.0 & 2.0 \\
Total mass flow rate $(\mathrm{kg} / \mathrm{s})$ & 0.203 & 0.206 \\
Gap flow fraction $(\%)$ & 2.70 & 2.70 \\
Avg. bulk channel outlet temp $\left({ }^{\circ} \mathrm{C}\right)$ & 537 & 537 \\
Gap outlet temperature $\left({ }^{\circ} \mathrm{C}\right)$ & 577 & 574 \\
\hline
\end{tabular}

\subsection{Parametric Calculations for the Whole Core Depth}

Comparative studies are conducted for the grid that represents the whole core depth using FLUENT while varying several parameters that affect the bypass flow. These parameters are the gap width, axial heat generation rate profile with average and peak radial factors, turbulence model, and mass flow rate.

\subsubsection{Effect of Gap Width}

The effect of gap width is investigated for gap widths of $0,1,2$, and $3 \mathrm{~mm}$. A differential pressure of $5.0 \mathrm{psi}$ is set for all of the gap-width cases. This boundary condition simply allows for additional mass flow in the interstitial (gap) region without reducing the flow in the coolant channels. The core inlet temperature is set to $490{ }^{\circ} \mathrm{C}$. A uniform volumetric heat generation rate of $27.88 \mathrm{MW} / \mathrm{m}^{3}$ is used for the fuel pins.

Figure 4-3 shows temperature contours of the middle plane of the fuel block (5.154 $\mathrm{m}$ core depth) for gap widths of $0,1,2$, and $3 \mathrm{~mm}$. The temperature scale is the same for all temperature contours plotted, including the fuel hot spot planes shown later in order to compare the temperatures between the two planes. As can be seen, the effect of varying the gap width is that the region near the gap becomes progressively cooler as the gap width increases. Figure 4-4 shows the temperature distribution along line A-B (see Figure 3-2) for all four gap-width cases. It shows that the temperature within the block decreases from the center to the gap. The fuel temperature close to the block center (point A) shows almost the same temperature in all gap-width cases. The largest gap-width case shows the largest temperature difference from the center outward, while 0 and $1 \mathrm{~mm}$ gap-width cases show little temperature difference. In the case of the $3 \mathrm{~mm}$ gap width, the maximum temperature difference within the middle plane of the block is approximately $100^{\circ} \mathrm{C}$. 


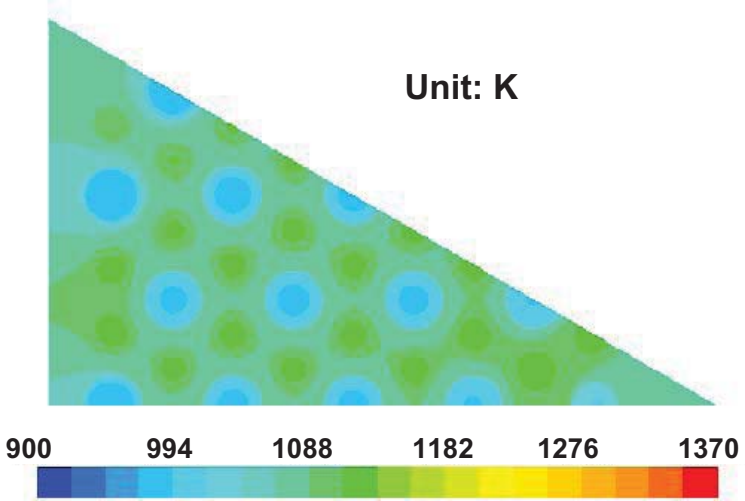

(a) $0 \mathrm{~mm}$

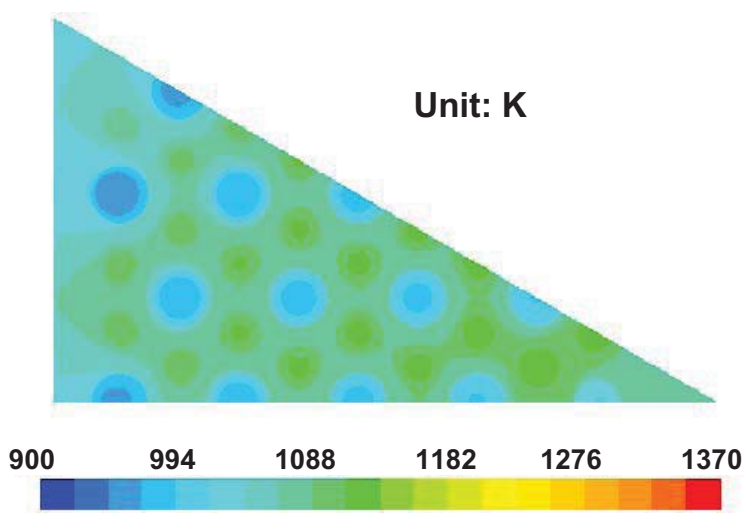

(c) $2 \mathrm{~mm}$

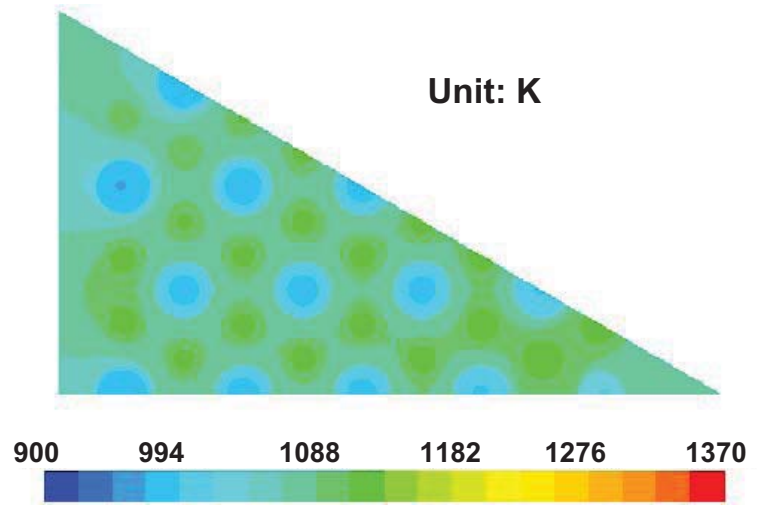

(b) $1 \mathrm{~mm}$

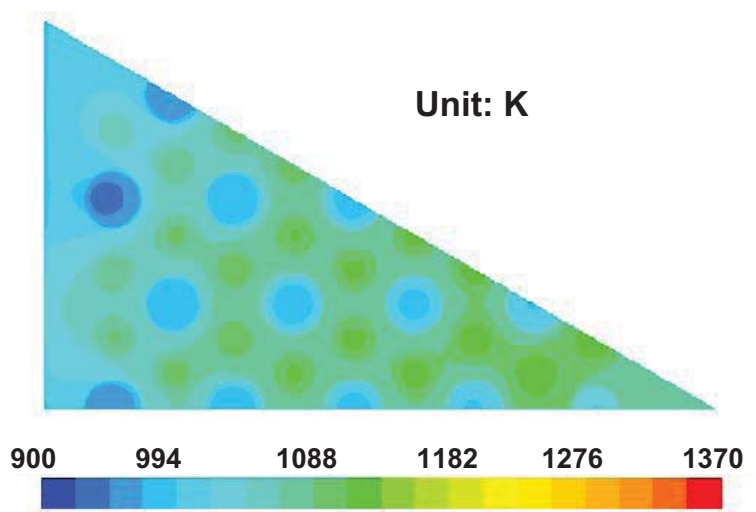

(d) $3 \mathrm{~mm}$

Figure 4-3. Temperature contours at the middle plane of the fuel block for different gap widths.

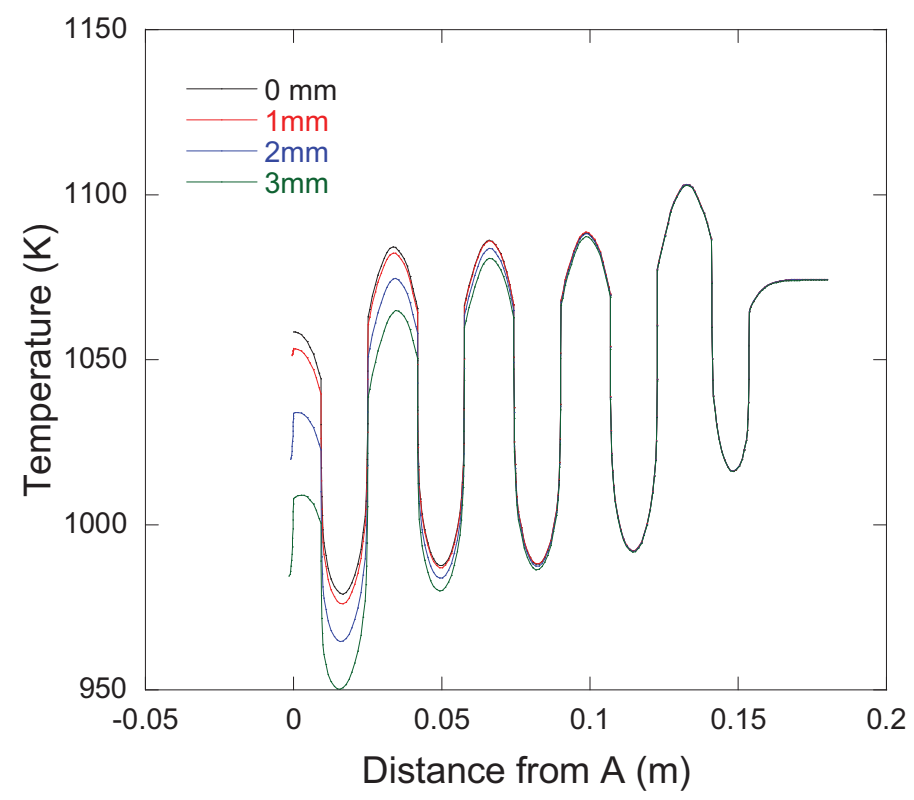

Figure 4-4. Temperature along line A-B (see Figure 3-2) of the middle plane of the fuel block for different gap widths. 
Figure 4-5 shows the temperature contours of the plane where the overall fuel hot spot is located, which is about $0.06 \mathrm{~m}$ above the bottom of the fueled section for all gap-width cases. Again, the region near the gap is increasingly cooler as the gap width increases, which creates an increasingly larger overall temperature gradient from the block center to the gap region. Figure 4-6 shows the temperature distribution along line A-B (see Figure 3-2). As can be seen, the hottest region is at the fuel channel closest to the center of the hexagonal block. Similar to the middle plane temperature gradients, the temperature within the block decreases from the center to the gap region, which means that gap flow has a significant effect on graphite block cooling. The overall temperature gradient is much steeper than for the middle plane; the maximum temperature difference within the hot spot plane of the graphite block is approximately $120^{\circ} \mathrm{C}$ (for the $3 \mathrm{~mm}$ gap-width case). Comparing the 3 and $0 \mathrm{~mm}$ gap-width cases, the temperature decrease in the graphite block adjacent to the gap within the hot spot plane is about $65^{\circ} \mathrm{C}$. However, the fuel temperature close to the center shows almost the same temperature in all the gap-width cases.

Figure 4-7 shows the bulk mean helium gas temperatures at the coolant channel and gap outlets. The hottest temperature appears at the small $12.70 \mathrm{~mm}$ diameter coolant channel outlet located in the center region of the block. The outlet temperature differences of corresponding coolant channels between the 0 and $1 \mathrm{~mm}$ gap-width cases are within $3{ }^{\circ} \mathrm{C}$, but this difference increases as the gap width increases, reaching a value of $43{ }^{\circ} \mathrm{C}$. In contrast, differences of outlet temperatures at coolant channels located in the center region among different gap-width cases are within $2{ }^{\circ} \mathrm{C}$. This causes an increase of temperature gradient within the graphite block as the gap width increases. The highest temperature difference among coolant outlets is $82{ }^{\circ} \mathrm{C}$ for the case of the $3 \mathrm{~mm}$ gap width.

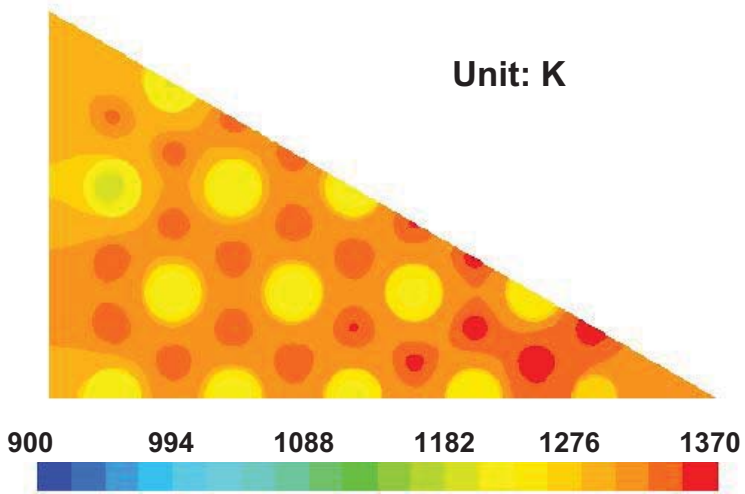

(a) $0 \mathrm{~mm}$

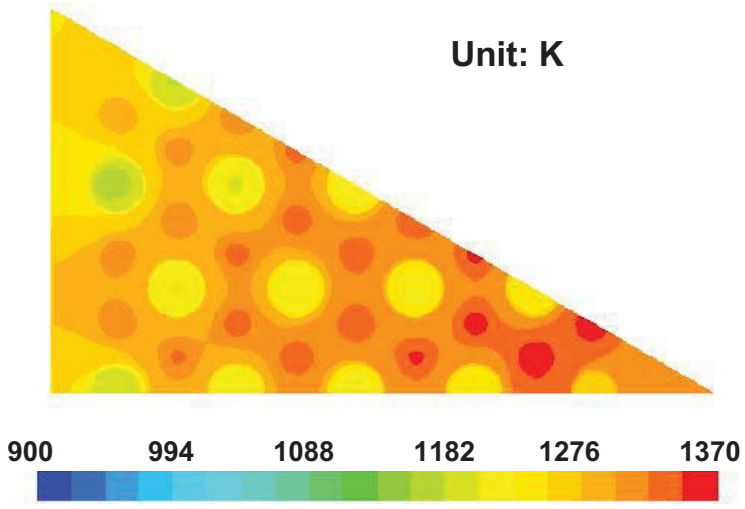

(c) $2 \mathrm{~mm}$

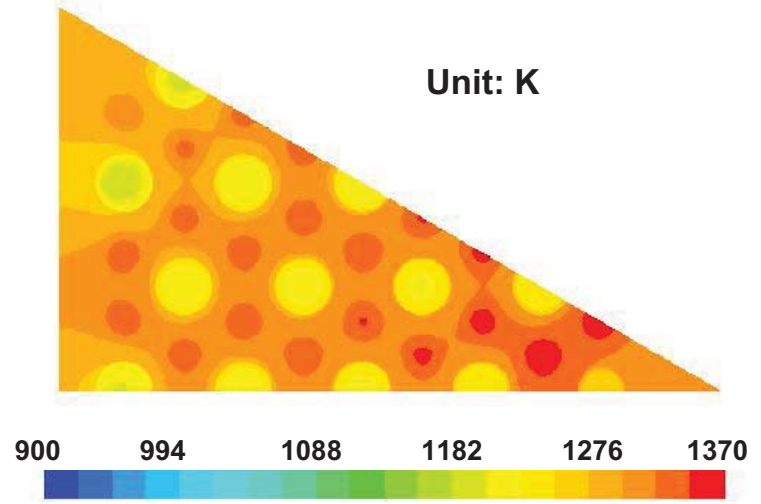

(b) $1 \mathrm{~mm}$

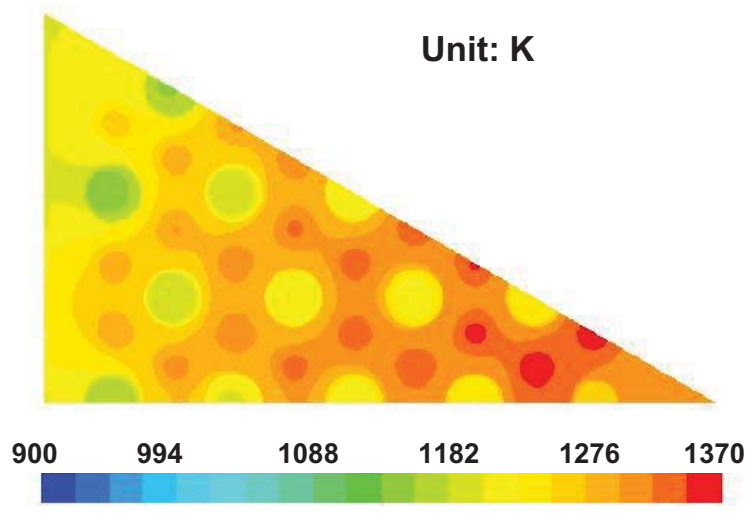

(d) $3 \mathrm{~mm}$

Figure 4-5. Temperature contours at the fuel hot spot plane for different gap widths. 


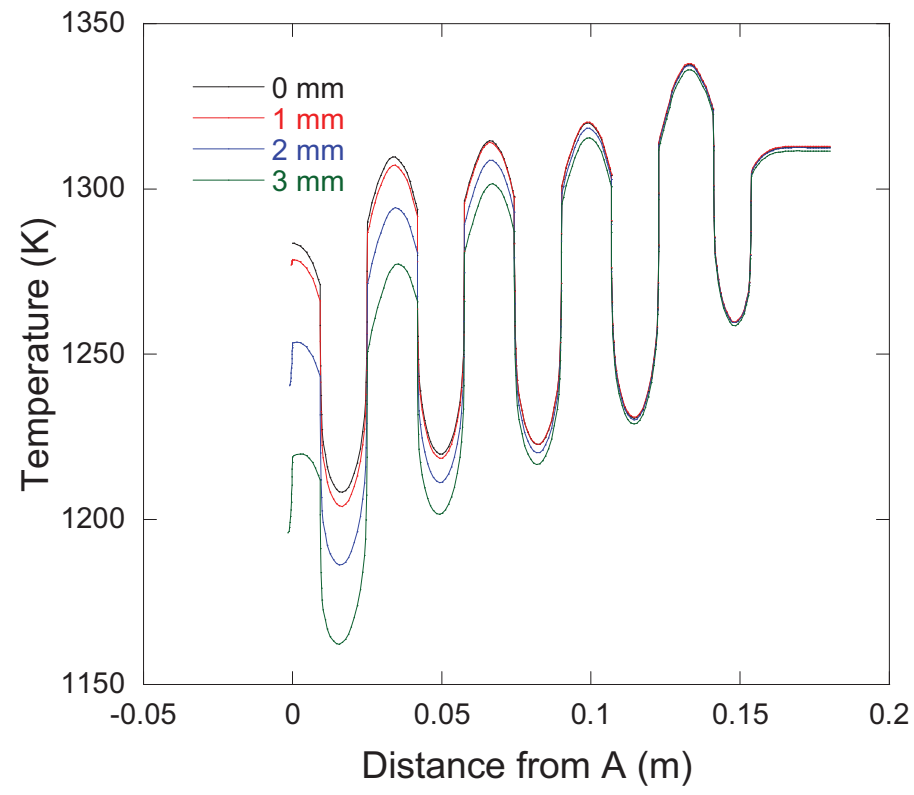

Figure 4-6. Temperature along line A-B (see Figure 3-2) of the fuel hot spot plane for different gap widths.

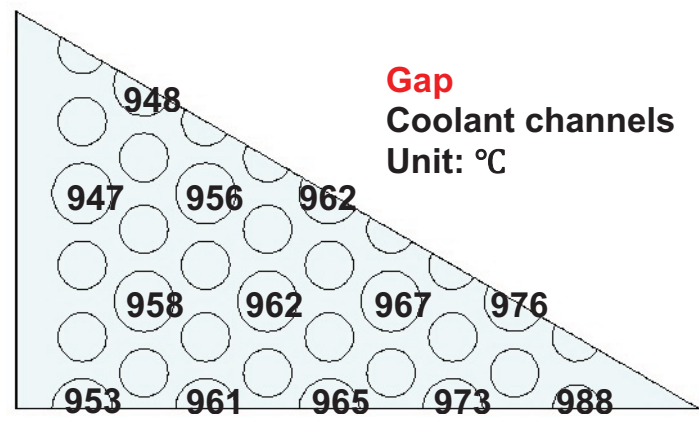

(a) $0 \mathrm{~mm}$

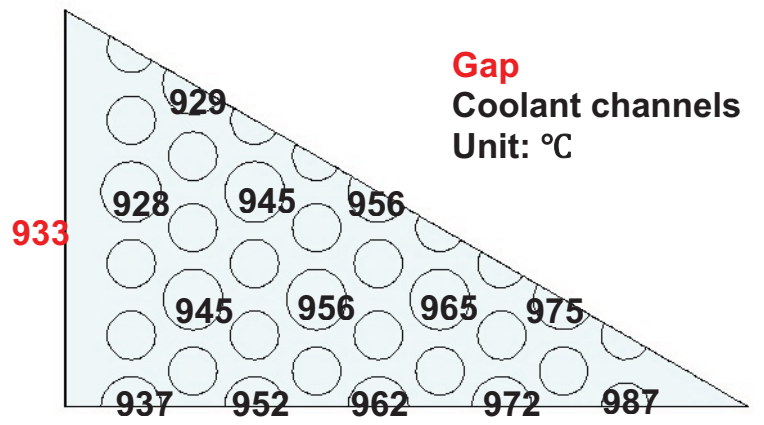

(c) $2 \mathrm{~mm}$

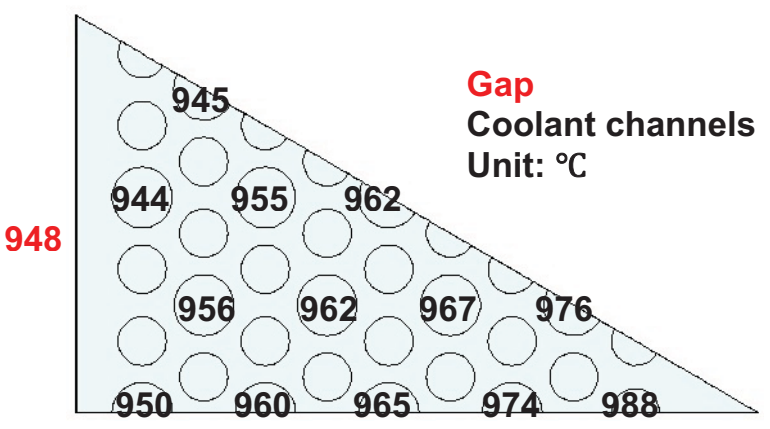

(b) $1 \mathrm{~mm}$

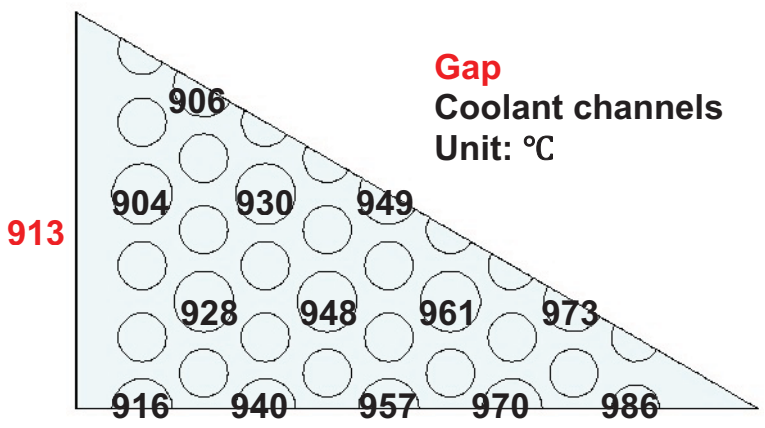

(d) $3 \mathrm{~mm}$

Figure 4-7. Bulk mean helium outlet temperatures $\left({ }^{\circ} \mathrm{C}\right)$ for channels and gaps for different gap widths.

The fact that the exit temperatures of some gas flow channels are relatively high could lead to hot spots occurring in the lower plenum, which is called hot streaking. The results indicate that consideration of the bypass flow is important not only for the hot spots in the core, but also for the hot streaking and hot 
spot issues in the lower plenum. The strong variation of temperature in the graphite when there are significant gaps present could also affect the structural integrity of the graphite and the fuel neutronics.

Table 4-2 shows the calculation inputs and results of total mass flow, gap flow fraction, maximum fuel temperatures, and gap and max coolant channel outlet temperature. As expected, the flow fraction increases as gap width increases and the total mass flow rate increases. In contrast, calculation results of maximum fuel temperatures among all gap-width cases show small differences. This is because the mass flow rate of helium in the coolant channels remains about the same for all cases because of the unchanged pressure differential boundary condition used.

Table 4-2. Calculation inputs and results for total mass flow, gap flow fraction, core differential pressure, max fuel temperature, and gap and max channel outlet temperatures for various gap widths.

\begin{tabular}{lcccc}
\hline \multicolumn{1}{c}{ Gap width $(\mathrm{mm})$} & 0.0 & 1.0 & 2.0 & 3.0 \\
\hline Total mass flow rate $(\mathrm{kg} / \mathrm{s})$ & 0.200 & 0.200 & 0.204 & 0.210 \\
Gap flow fraction $(\%)$ & 0 & 0.425 & 1.98 & 4.18 \\
Maximum fuel temperature $\left({ }^{\circ} \mathrm{C}\right)$ & 1093 & 1093 & 1092 & 1091 \\
Gap outlet temperature $\left({ }^{\circ} \mathrm{C}\right)$ & - & 948 & 933 & 913 \\
Max channel outlet temperature $\left({ }^{\circ} \mathrm{C}\right)$ & 988 & 988 & 987 & 986 \\
\hline
\end{tabular}

Figure 4-8 shows the wall shear stress at the center of the gap wall in the axial direction for the non-0 gap cases. As can been seen, the shear stress increases in the flow direction, since the viscosity increases because of the temperature increase. The gradient of wall shear stress is also different among the gapwidth cases. One of the reasons is a difference of temperature distribution between each gap-width case as shown in the previous results. The gap mass flow rate and gap flow fraction is a function of the wall shear stress. Wall shear stresses are functions of flow velocity parallel to the wall and the velocity is affected by the temperature dependent thermal properties of the helium coolant. The differences in the axial distribution of the wall shear stress for the different gap-width cases show that the temperature and flow distributions are strongly coupled. Hence, it is important to consider local heat generation rates within fuel blocks that are not uniformly distributed in the core.

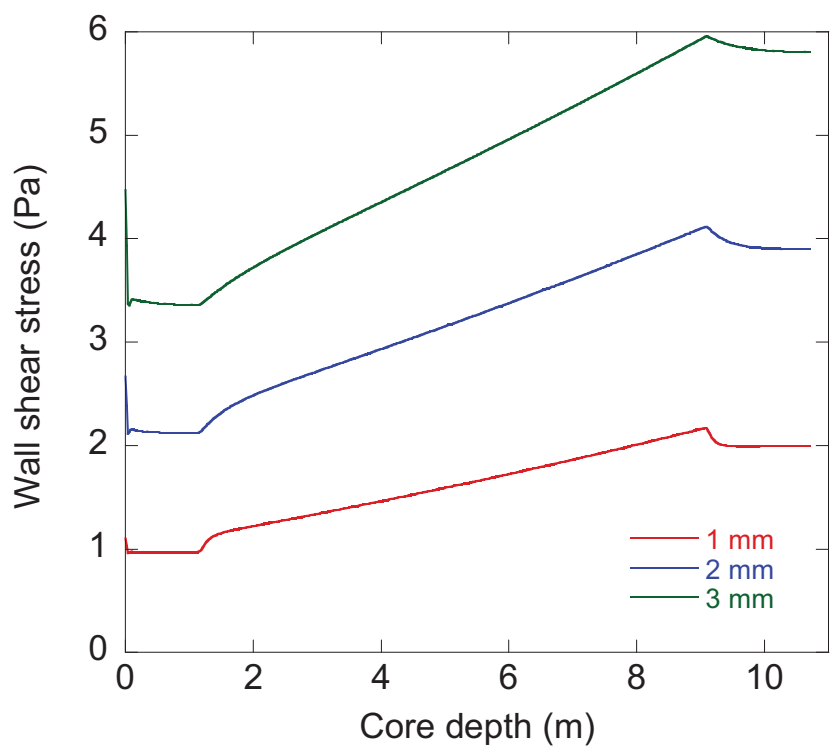

Figure 4-8. Wall shear stresses at center of the gap for different gap widths. 


\subsubsection{Effect of Heat Generation Rate Profile}

In the actual prismatic VHTR, the heat generation rate is not uniform because of the arrangement of the core and the design of the fuels. In this section, nonuniform heat generation cases for the axial and radial peaking factors are calculated with a $3 \mathrm{~mm}$ gap width in order to investigate the effect of heat generation profile. The expression used in the present study is

$$
q^{\prime \prime}=A_{r} q_{c o n}\left\{1+\left(A_{P}-1\right) \frac{\sin \pi(z-1.189)}{L}\right\}
$$

where $q^{\prime \prime}$ is volumetric heat generation in the fuel channel, $q_{c o n}$ is a constant set to obtain the same total heat generation in the core, $A_{r}$ is the radial generation factor, $A_{p}$ is the axial peaking factor, $z$ is the zcoordinate and $L$ is the active core length of $7.93 \mathrm{~m}$.

In this study, two cases, $A_{r}=1.0, A_{p}=1.3$ and $A_{r}=1.25, A_{p}=1.3$ are used in order to investigate the effects of average and peak radial factors. The values for the factors are based on previous neutronics calculations (MacDonald et al. 2003). The expression is incorporated into FLUENT by using a user-defined function. Figure 4-9 shows the profiles of volumetric heat generation rate as a function of core depth for the average and peak radial factor. A differential pressure of $5.0 \mathrm{psi}$ is used as is the standard $\mathrm{k} \sim \varepsilon$ turbulence model with enhanced wall treatment.

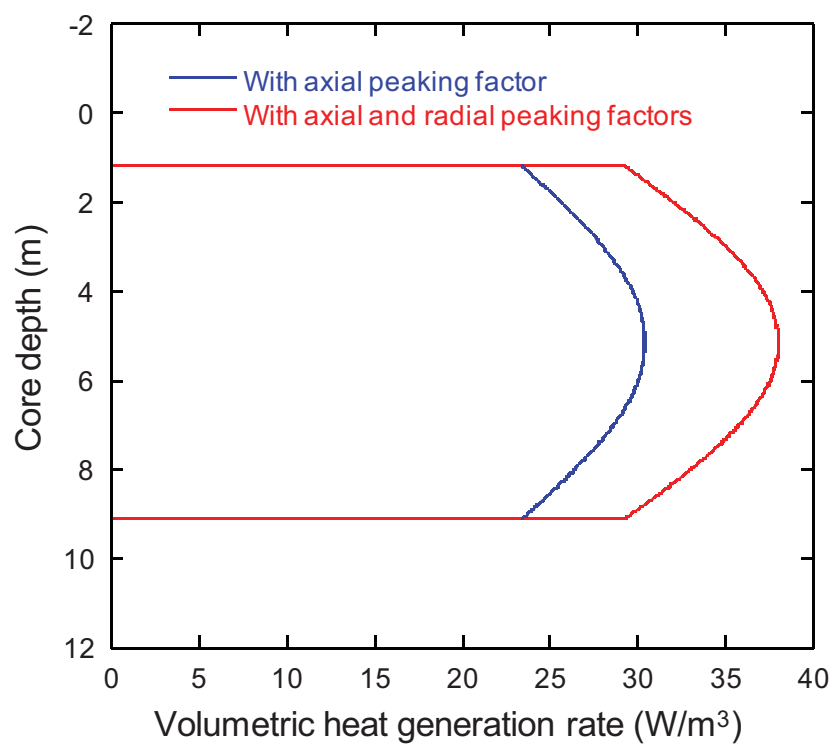

Figure 4-9. Profiles of volumetric heat generation rate for average and peak radial factors as a function of core depth.

Figure 4-10 shows comparison of temperature contours of the middle plane of the fuel block (5.154 $\mathrm{m}$ core depth) for a reference case of uniform heat generation profile for a $3 \mathrm{~mm}$ gap width at 5 psi differential pressure and for the cases of axial variation at the average and peak radial factor. As expected, the cases for uniform and axial variation at the average radial factor have similar contours as the amount of heat generated is the same. For the case of the axial variation at the peak radial factor, the block crosssection is much hotter; this is because the amount of heat generation is 1.25 times greater. Figure 4-11 shows the comparison of temperature distribution along line A-B (see Figure 3-2) for uniform and axial variation at the average and peak radial factor heat generation profiles. 


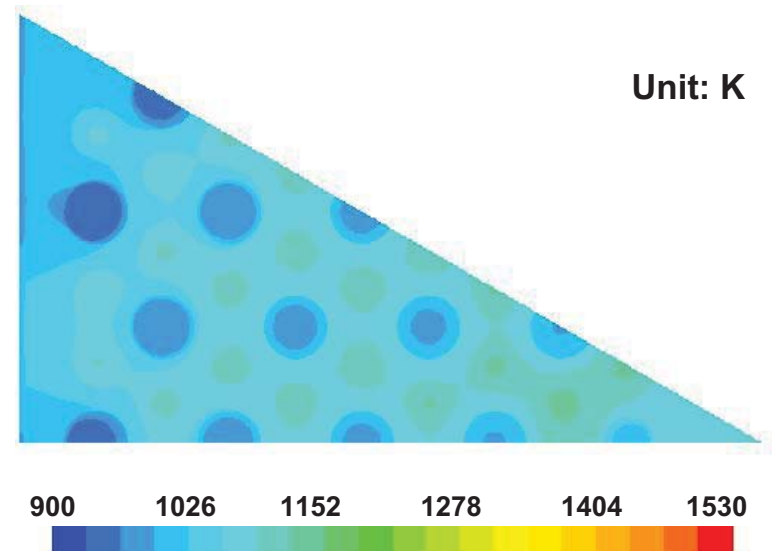

(a) Uniform heat generation

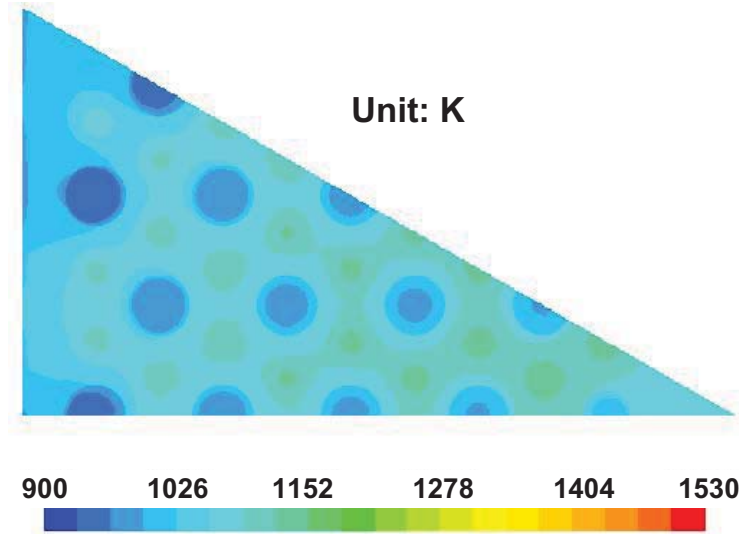

(b) Axial variation at average radial factor

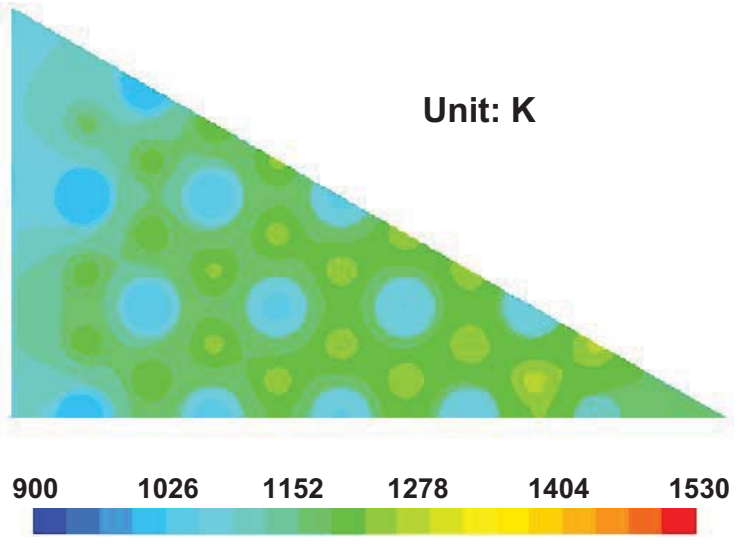

(c) Axial variation at the peak radial factor

Figure 4-10. Temperature contours at the middle plane of the fuel block for different heat generation profiles.

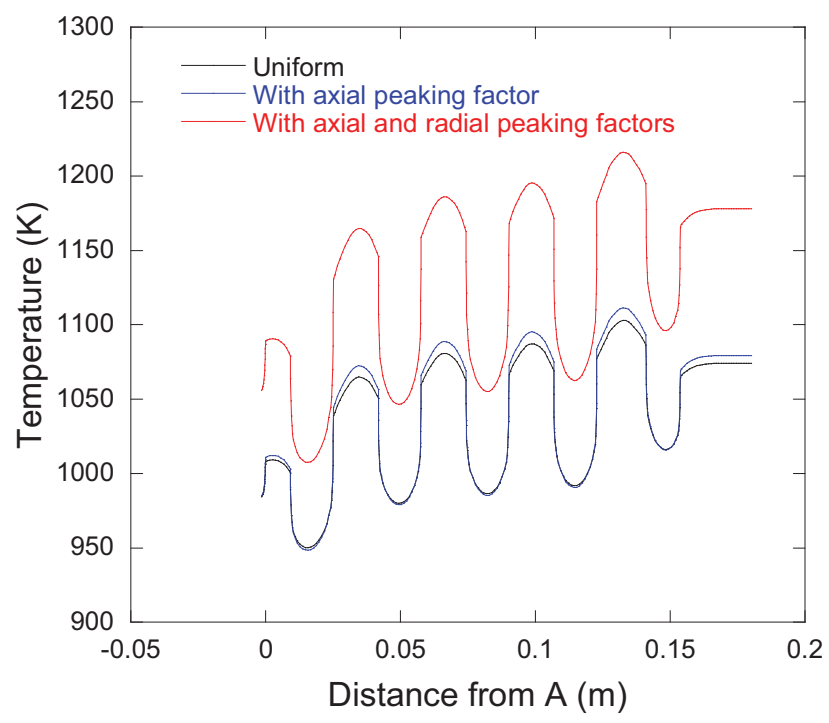

Figure 4-11. Temperature along line A-B (see Figure 3-2) of the middle plane of the fuel block for different heat generation rates. 
As can be seen, temperature within the block decreases from the center to the gap and the tendency is the same for all cases. However, the results for axial variation at the peak radial factor show much higher temperatures. The maximum temperature difference between the uniform heat generation case and axial variation at the peak radial factors in A-B line is about $113^{\circ} \mathrm{C}$. As for the axial variation at the average radial factor case, the maximum temperature difference from the uniform case is about $8{ }^{\circ} \mathrm{C}$ high and $2{ }^{\circ} \mathrm{C}$ low in the block and coolant channel regions, respectively.

Figure 4-12 shows the temperature contours for the plane involving the fuel hot spot. The location is the same for all cases and it is about $0.06 \mathrm{~m}$ above the bottom of the fueled section. The contours for the uniform and axial variation only cases are about the same; the axial variation at the peak radial factor is, again, hotter because of the peak factor. Figure 4-13 shows the temperature distribution along line A-B (see Figure 3-2). As can be seen, hot spots are located at the fuel channel closest to the center of the hexagonal block in all cases. Similar to the middle plane, temperature within the block decreases from the center to the gap region because of the cooling effect of bypass flow on the graphite block. The maximum temperature difference between the cases of uniform heat generation and axial variation at the peak radial factor for line A-B is about $162{ }^{\circ} \mathrm{C}$. As for the temperature of axial variation only compared to the uniform heat generation case, it shows a counter trend compared to the results of the middle plane. The temperature for axial variation only case is slightly higher in the coolant channel regions and lower in block regions. The maximum temperature difference is about $3{ }^{\circ} \mathrm{C}$ higher and $12{ }^{\circ} \mathrm{C}$ lower in coolant channel and block regions, respectively.

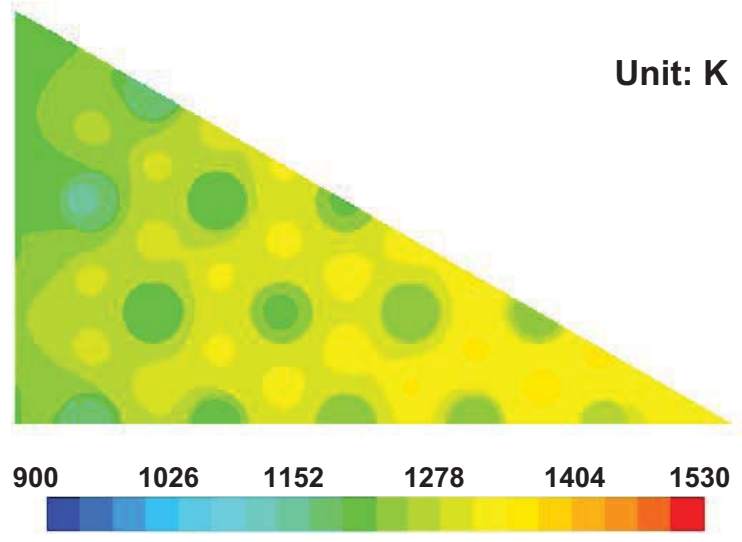

(a) Uniform heat generation

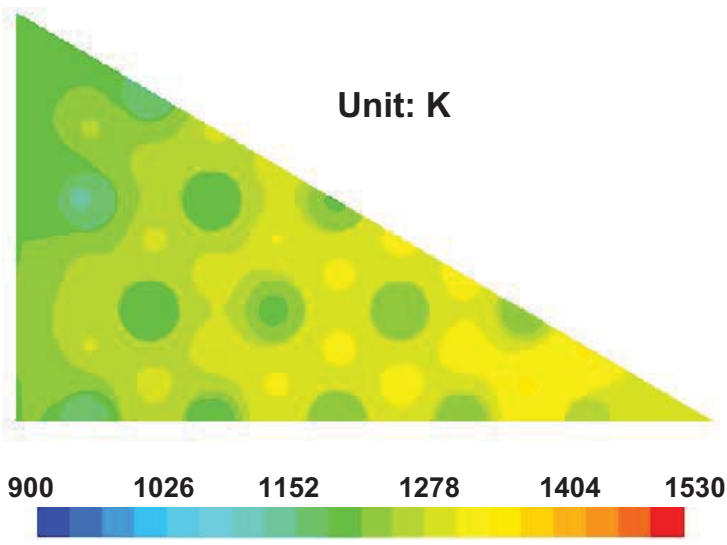

(b) Axial variation at average radial factor

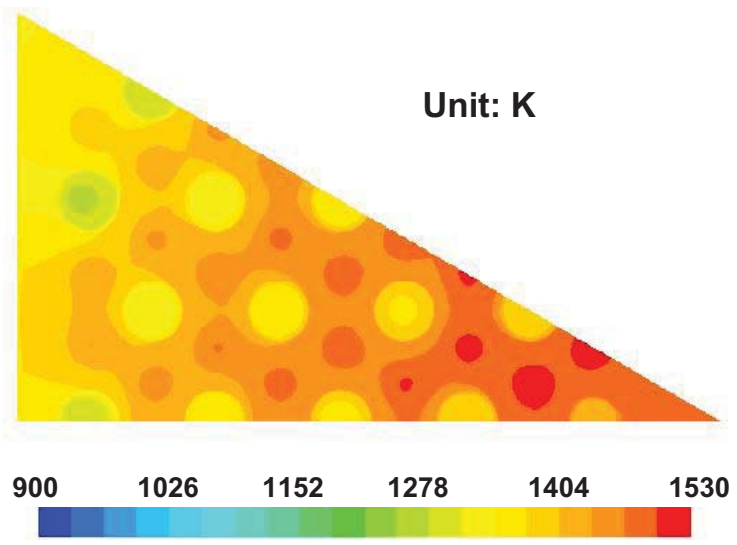

(c) Axial variation at the peak radial factor

Figure 4-12. Temperature contours at the fuel hot spot plane for different heat generation rates. 


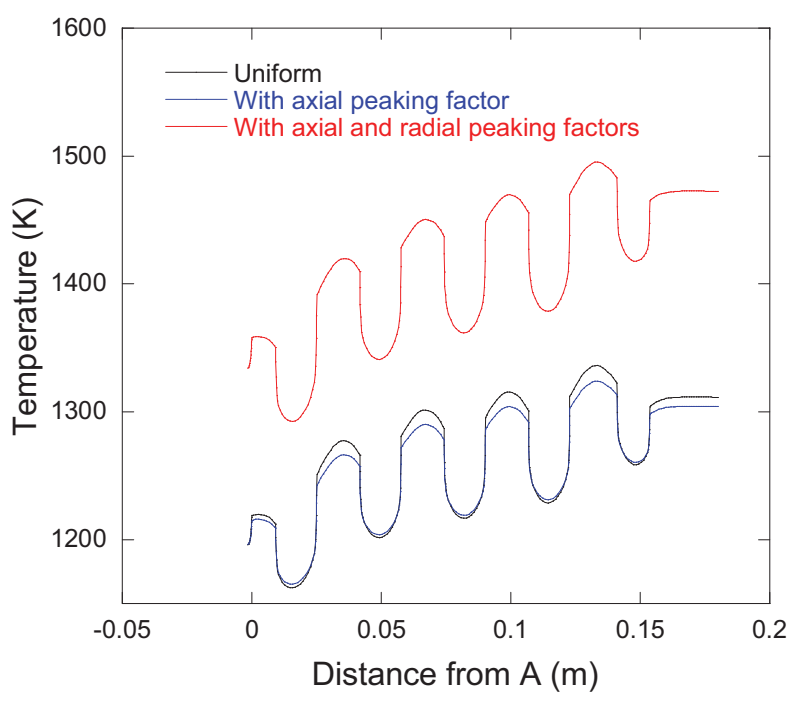

Figure 4-13. Temperature along line A-B (see Figure 3-2) of the fuel hot spot plane for different heat generation rates.

Figure 4-14 shows the bulk mean helium gas temperatures at the coolant channel and gap outlets. As can be seen, the hottest temperature appears for the small $12.70 \mathrm{~mm}$ diameter coolant channel outlet located at the center region of block, in all cases. Outlet temperatures between the cases of uniform and axial variation only are almost the same. In contrast, the outlet temperatures for the axial variation case at the peak radial factor are considerably higher.

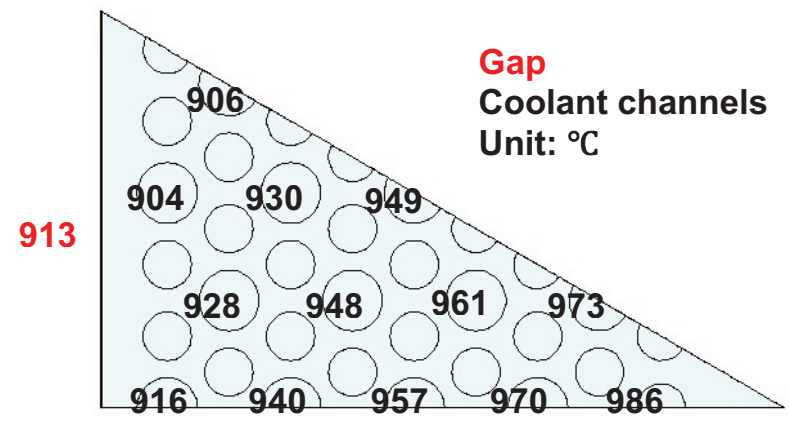

(a) Uniform heat generation (Same as Figure 4-7 (d))

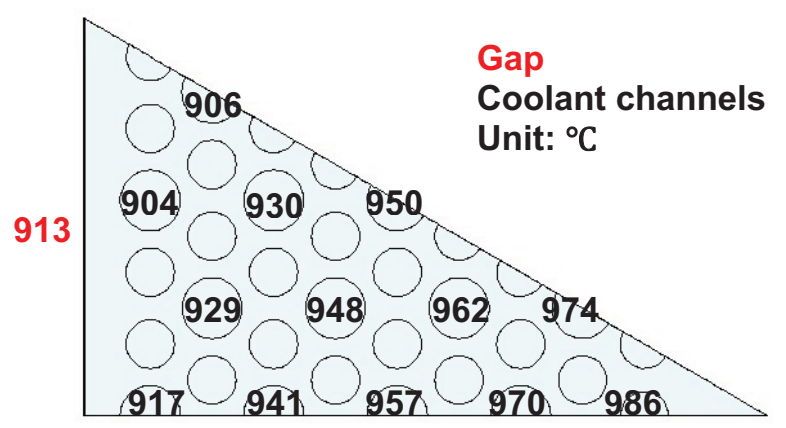

(b) With axial variation at average radial factor

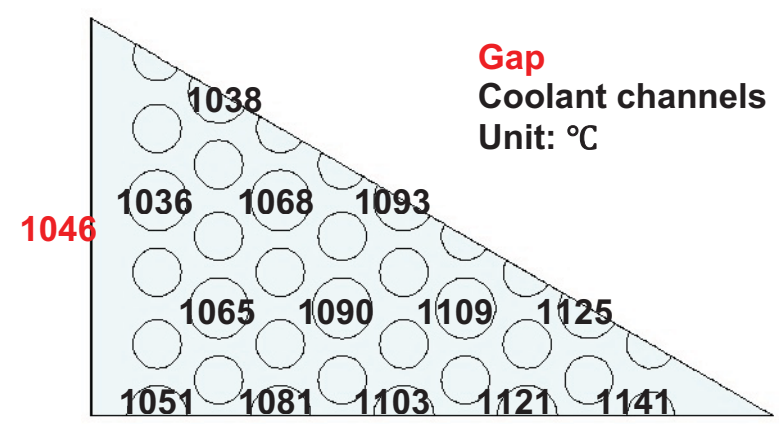

(c) With axial variation at peak radial factor

Figure 4-14. Bulk mean helium gas outlet temperatures $\left({ }^{\circ} \mathrm{C}\right)$ for channels and gaps for different heat generation rates. 
Table 4-3 shows the calculation inputs and results for total mass flow, gap flow fraction, core differential pressure, max fuel temperature, and gap and max channel outlet temperatures for the different heat generation profiles. As can be seen, the results for uniform and axial variation at the average radial factor cases are almost the same, except that the max fuel temperature is $18{ }^{\circ} \mathrm{C}$ lower for the nonuniform case. This is because the heat generation rate is lower at the hot fuel point than for the uniform case. In contrast, increasing the amount of heat generation by using the peak radial factor decreases both the total flow rate and the bypass flow fraction while dramatically increasing the maximum fuel and channel and outlet gap temperatures. A previous study showed a similar coupling effect on flow and temperature distributions in coolant channels (Johnson and Schultz 2004). The same is also true when gap flows are included.

Table 4-3. Calculation inputs and results for total mass flow, gap flow fraction, core differential pressure, max fuel temperature, and gap and max channel outlet temperatures for different heat generation profiles.

\begin{tabular}{lccc}
\hline & Uniform & $\begin{array}{c}\text { Axial + Average } \\
\text { Radial Factor }\end{array}$ & $\begin{array}{c}\text { Axial + Peak } \\
\text { Radial Factors }\end{array}$ \\
\hline Total mass flow rate $(\mathrm{kg} / \mathrm{s})$ & 0.210 & 0.210 & 0.200 \\
Gap flow fraction $(\%)$ & 4.18 & 4.18 & 4.14 \\
Maximum fuel temperature $\left({ }^{\circ} \mathrm{C}\right)$ & 1091 & 1075 & 1250 \\
Gap outlet temperature $\left({ }^{\circ} \mathrm{C}\right)$ & 913 & 913 & 1046 \\
Max channel outlet temperature $\left({ }^{\circ} \mathrm{C}\right)$ & 986 & 986 & 1141 \\
\hline
\end{tabular}

Figure 4-15 compares wall shear stress at the center of the gap wall in the z-direction. As can be seen, the gradients for the wall shear stress are almost the same for the uniform and axial variation only cases. However, the gradient for the case of axial variation at the peak radial factor is considerably steeper. This is because of the property difference induced by the difference of temperature in the flow direction. The results indicate that the level of heat generation rate is very important when considering bypass flow.

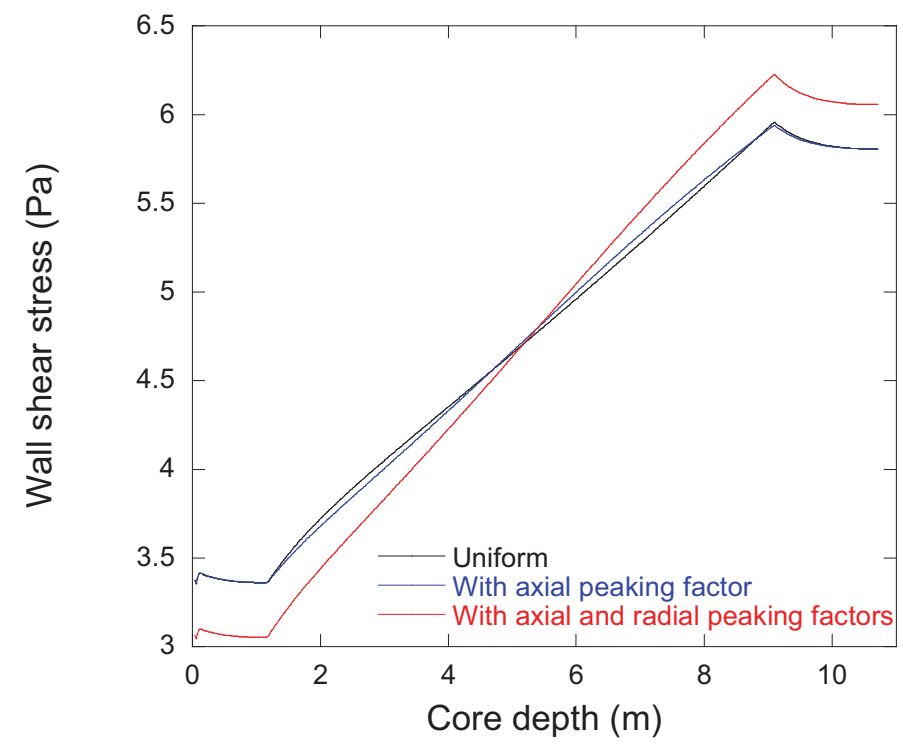

Figure 4-15. Comparison of wall shear stress at center of the gap for different heat generation rates. 


\subsubsection{Effect of Turbulence Model}

This study examines the effect of using different turbulence models. FLUENT is used to perform the calculations. The standard $\mathrm{k} \sim \varepsilon$ model using the enhanced wall treatment and standard $\mathrm{k} \sim \omega$ model are employed. Gap widths of from 0 to $3 \mathrm{~mm}$ are employed in the study. The differential pressure boundary condition is kept constant at 5.0 psi. Uniform heat generation rate of $27.88 \mathrm{~W} / \mathrm{m}^{3}$ is used for all fuel pins. Figure 4-16 shows temperature contours at the middle plane of the fuel block (5.154 m core depth) for results using $\mathrm{k} \sim \varepsilon$ and $\mathrm{k} \sim \omega$ turbulence models. It is apparent that the temperatures are lower for the $\mathrm{k} \sim \omega$ model case. Figure 4-17 shows the temperature distribution along line A-B (see Figure 3-2) for the $\mathrm{k} \sim \varepsilon$ and $\mathrm{k} \sim \omega$ models. As can be seen, the temperature within the block decreases from the center to gap in both cases, but temperatures within the block and coolant for the $\mathrm{k} \sim \omega$ model results are lower than those for the $\mathrm{k} \sim \varepsilon$ model in all cases. The maximum temperature difference between the two models along line A-B is about $30^{\circ} \mathrm{C}$ in all cases, and it occurs at the coolant channel region. Maximum temperature difference within the block is about $19{ }^{\circ} \mathrm{C}$. In addition, larger temperature difference between coolant channels and blocks are observed for $\mathrm{k} \sim \omega$ model.

Figure 4-18 shows the temperature contours of the plane involving the fuel hot spot. The location of the hot sport in the axial direction is the same for both turbulence models. Again, the temperatures for the $\mathrm{k} \sim \omega$ model results are distinctly cooler than for the $\mathrm{k} \sim \varepsilon$ model. Figure 4-19 shows the temperature distribution along line A-B (see Figure 3-2). As can be seen, the hottest region is at the fuel channel closest to the center of the hexagonal block in all cases, while temperatures within the block decrease from the center to the gap region, similar to the middle plane. In comparing the temperatures between $\mathrm{k} \sim \varepsilon$ and $\mathrm{k} \sim \omega$ models, lower temperatures are observed in all regions for the $\mathrm{k} \sim \omega$ model. The maximum temperature difference between the two models along line A-B is about $52{ }^{\circ} \mathrm{C}$, and it is located in the coolant channel region. The maximum temperature difference within the block is about $37^{\circ} \mathrm{C}$. In addition, larger temperature difference between coolant channels and blocks are observed for the $\mathrm{k} \sim \omega$ model.

Figure 4-20 shows the bulk mean helium gas temperatures at the coolant channels and gap outlets. As can be seen, the hottest temperature appears at the small $12.70 \mathrm{~mm}$ diameter coolant channel outlet located at the center region of the block for all cases. Outlet temperatures for the $\mathrm{k} \sim \omega$ model case are considerably lower than those of $\mathrm{k} \sim \varepsilon$ model and the difference is $40-50{ }^{\circ} \mathrm{C}$ at all outlets.

Table 4-4 shows the calculation inputs and results for total mass flow, gap flow fraction, core differential pressure, max fuel temperature, and gap and max channel outlet temperatures for the $\mathrm{k} \sim \omega$ turbulence model for different gap widths. Similar to the results obtained with $\mathrm{k} \sim \varepsilon$ model described in Table 4-2, the total mass flow and gap flow fraction increase as the gap width increases. Also, calculation results for maximum fuel temperature among all the gap-width cases show small differences. In contrast, larger mass flow rates of $9-10 \%$ are obtained for the $\mathrm{k} \sim \omega$ model compared to the $\mathrm{k} \sim \varepsilon$ model. The increase results in the decrease of temperatures within the block so the maximum temperature also decreases. The decreased maximum fuel temperatures are about $30{ }^{\circ} \mathrm{C}$ in all cases. The results show that the selection of turbulence model has a strong impact on the flow and temperature distributions in the block. That is, the turbulence model determines the wall shear stress, which, in turn determines the coolant flow rates for a given differential pressure. 


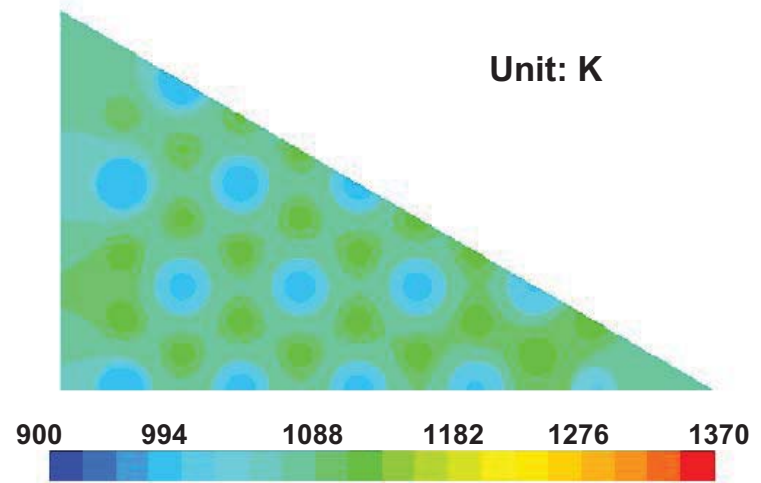

(a) $0 \mathrm{~mm}$ with $\mathrm{k} \sim \varepsilon$ model

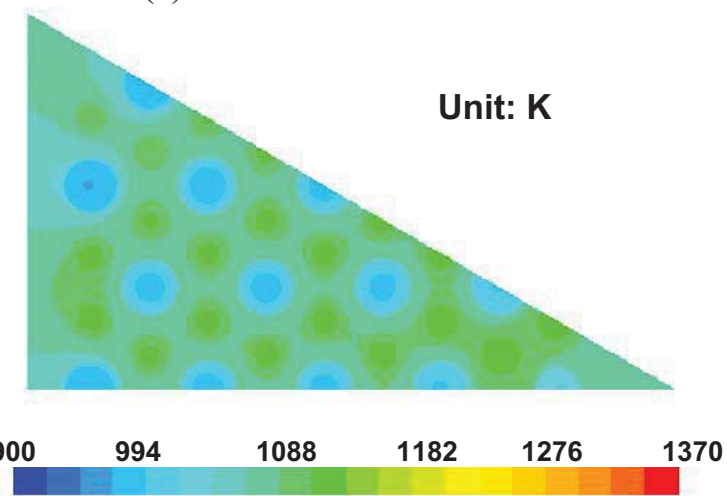

(c) $1 \mathrm{~mm}$ with $\mathrm{k} \sim \varepsilon$ model

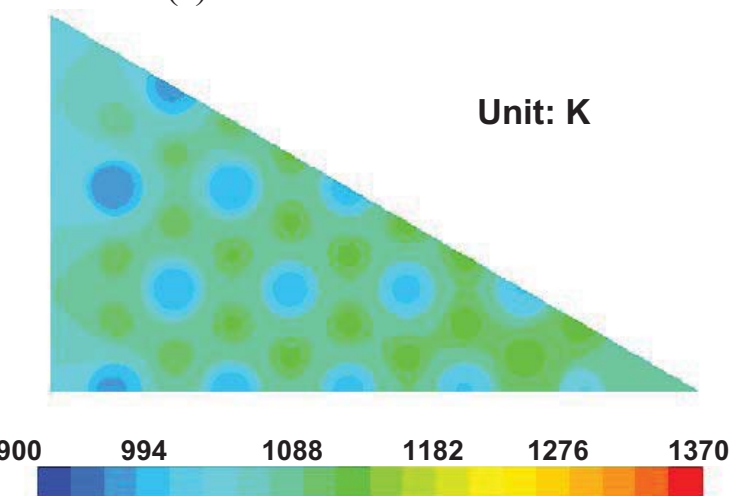

(e) $2 \mathrm{~mm}$ with $\mathrm{k} \sim \varepsilon$ model

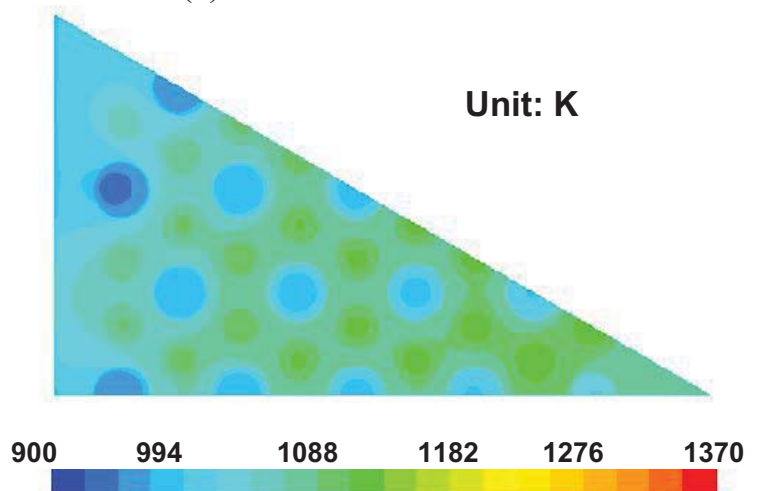

(g) $3 \mathrm{~mm}$ with $\mathrm{k} \sim \varepsilon$ model

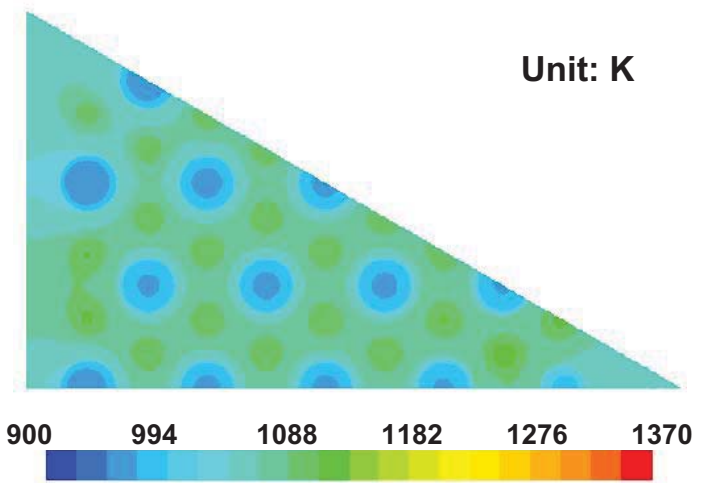

(b) $0 \mathrm{~mm}$ with $\mathrm{k} \sim \omega$ model
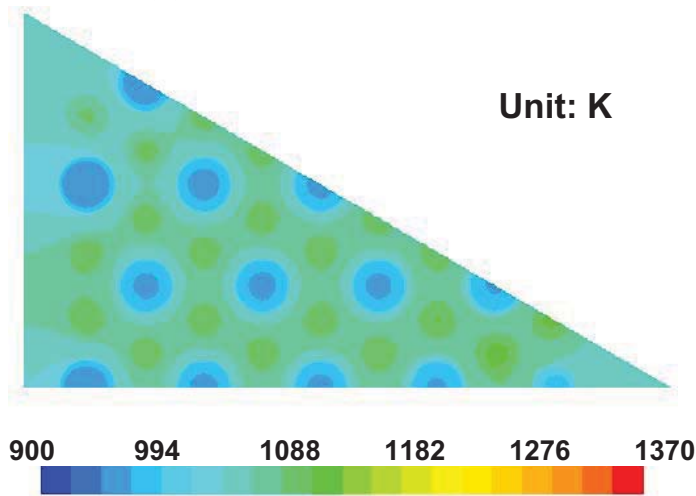

(d) $1 \mathrm{~mm}$ with $\mathrm{k} \sim \omega$ model

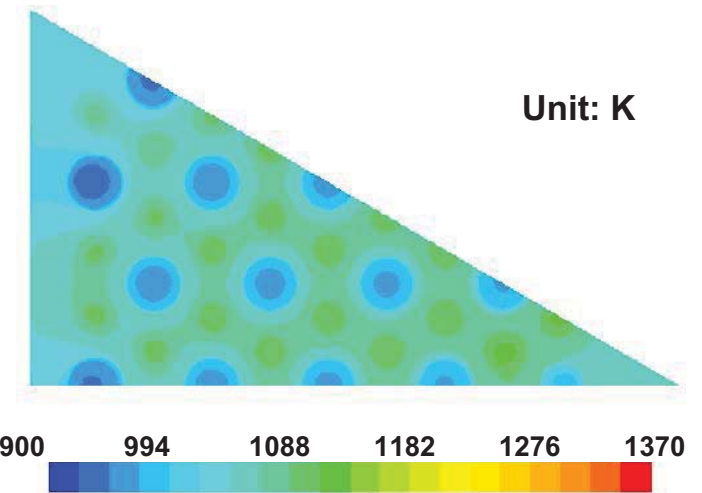

(f) $2 \mathrm{~mm}$ with $\mathrm{k} \sim \omega$ model

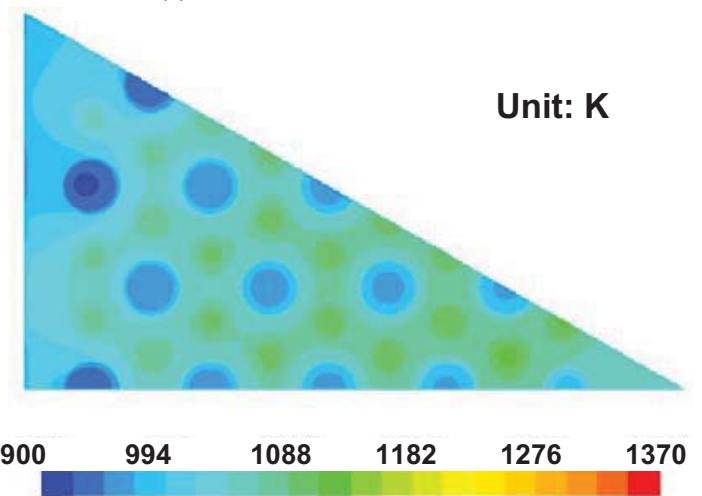

(h) $3 \mathrm{~mm}$ with $\mathrm{k} \sim \omega$ model

Figure 4-16. Comparison of temperature contours at the middle plane of the fuel block for different turbulence models. 


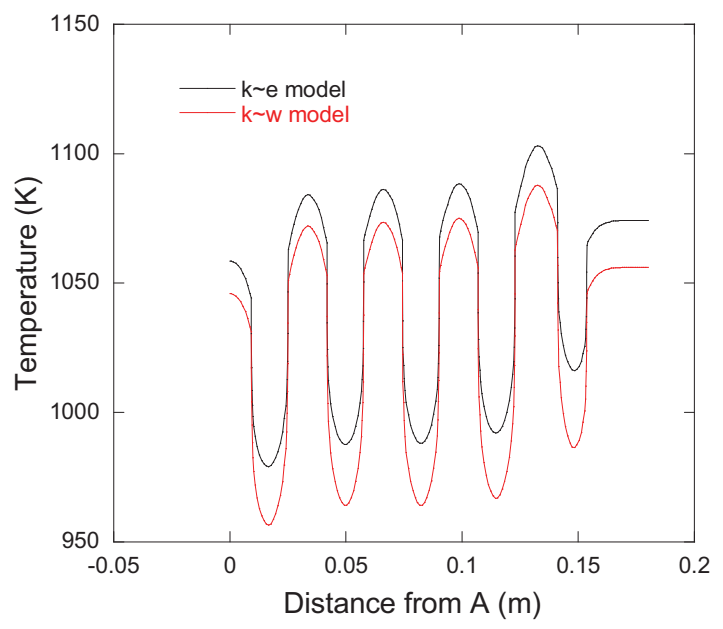

(a) $0 \mathrm{~mm}$

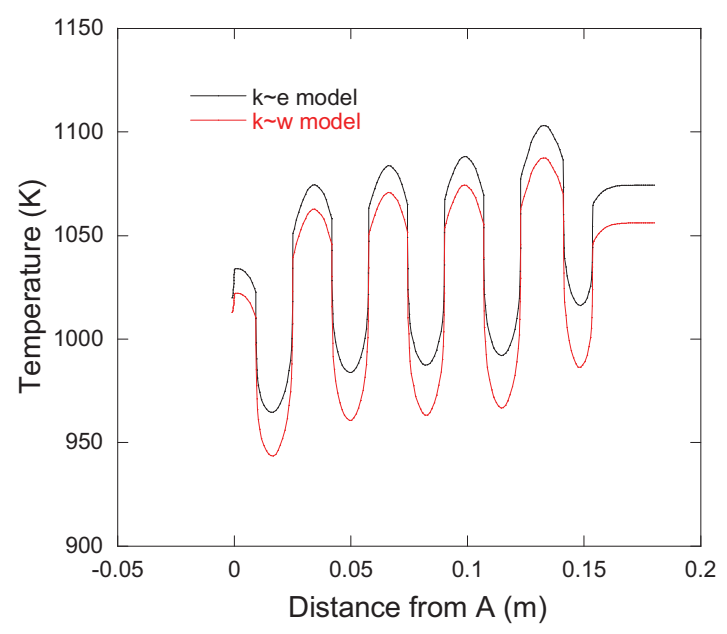

(c) $2 \mathrm{~mm}$

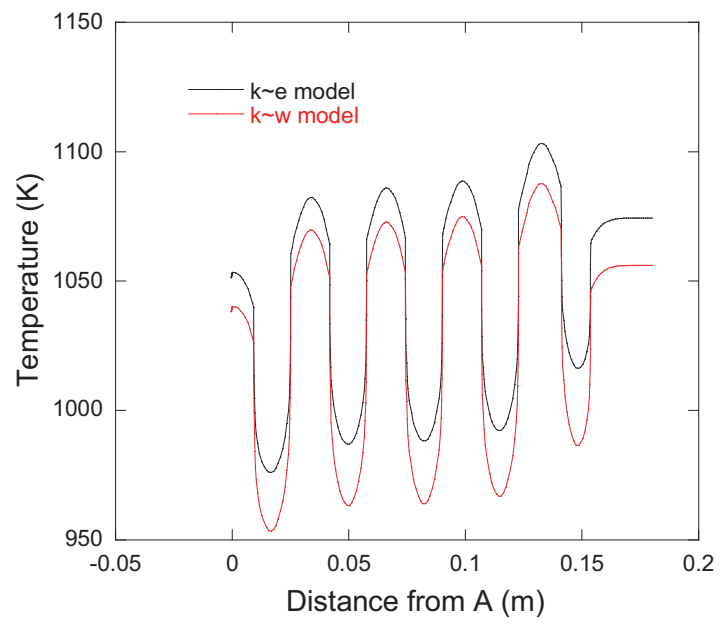

(b) $1 \mathrm{~mm}$

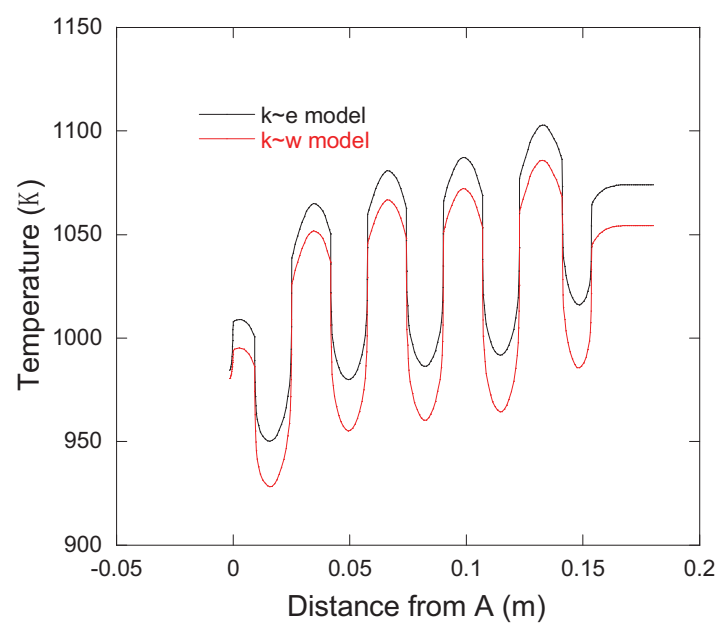

(d) $3 \mathrm{~mm}$

Figure 4-17. Temperature along line A-B (see Figure 3-2) of the middle plane of the fuel block for different turbulence models. 

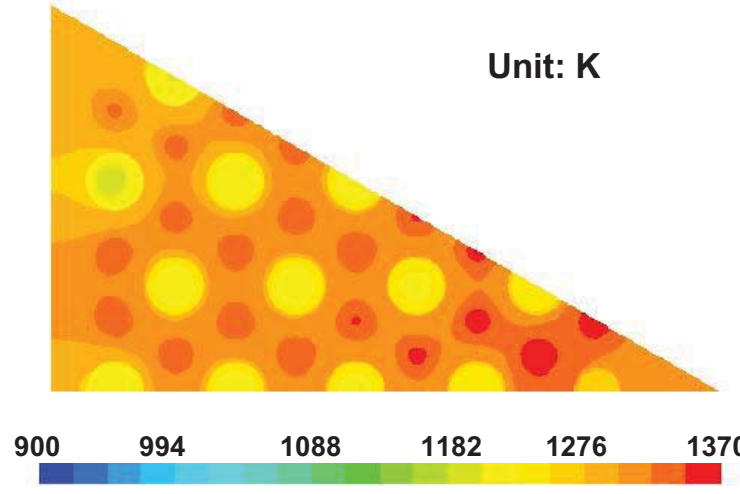

(a) $0 \mathrm{~mm}$ with $\mathrm{k} \sim \varepsilon$ model
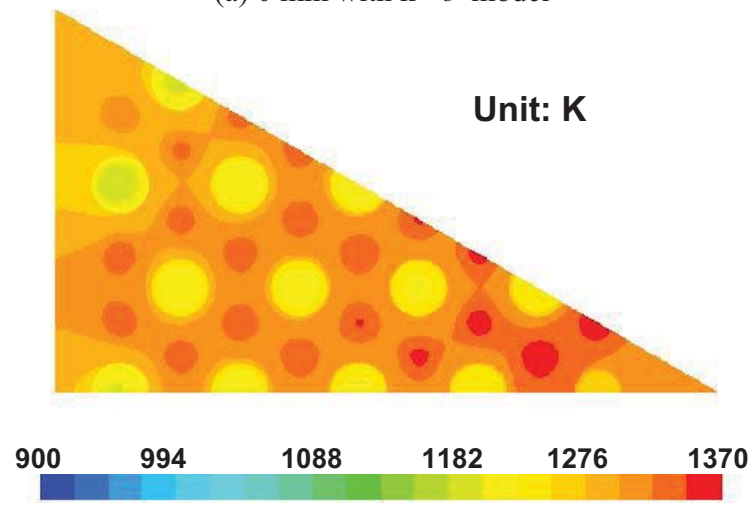

(c) $1 \mathrm{~mm}$ with $\mathrm{k} \sim \varepsilon$ model

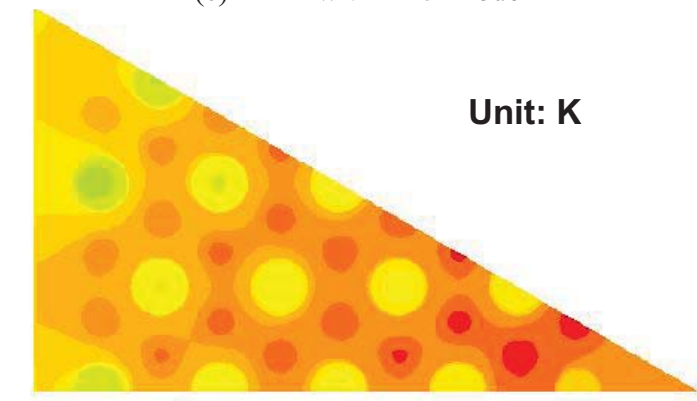

900 994 1088

1182

1370

(e) $2 \mathrm{~mm}$ with $\mathrm{k} \sim \varepsilon$ model

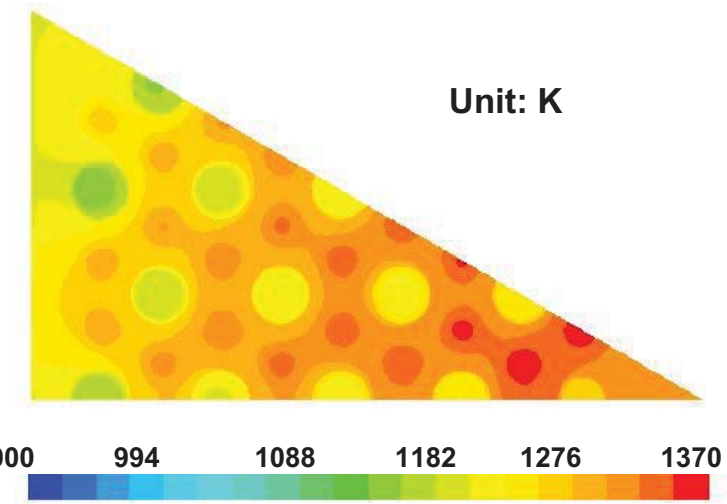

(g) $3 \mathrm{~mm}$ with $\mathrm{k} \sim \varepsilon$ model

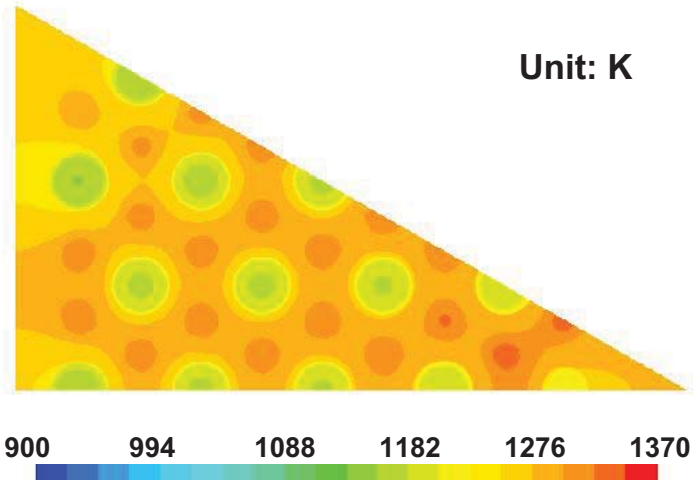

(b) $0 \mathrm{~mm}$ with $\mathrm{k} \sim \omega$ model
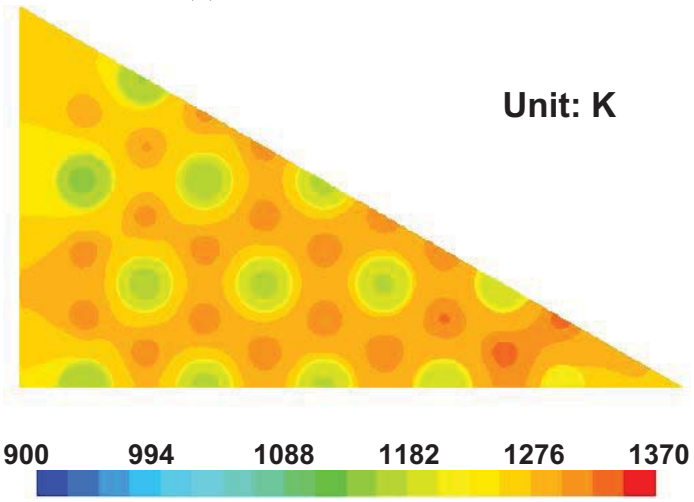

(d) $1 \mathrm{~mm}$ with $\mathrm{k} \sim \omega$ model

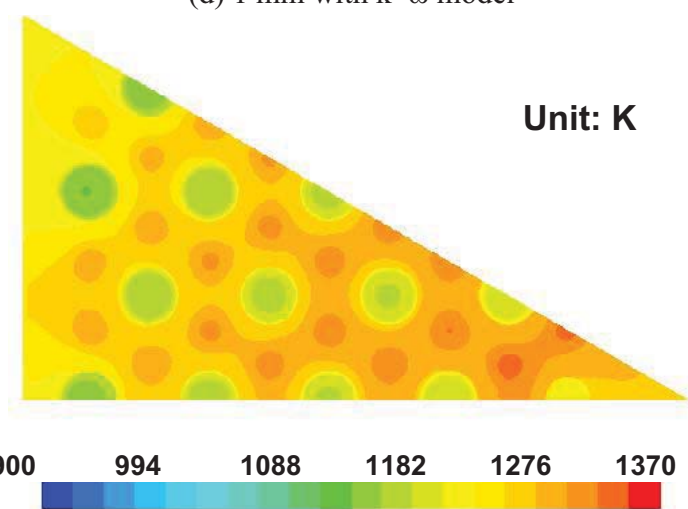

(f) $2 \mathrm{~mm}$ with $\mathrm{k} \sim \omega$ model

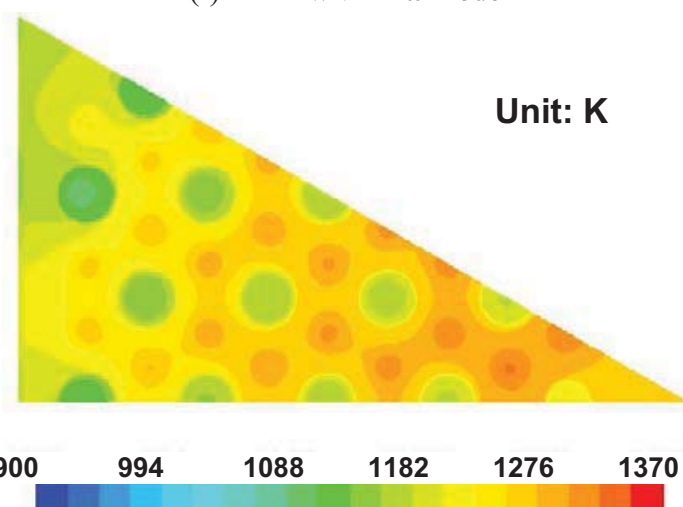

(h) $3 \mathrm{~mm}$ with $\mathrm{k} \sim \omega$ model

Figure 4-18. Temperature contours at the fuel hot spot plane for different turbulence models. 


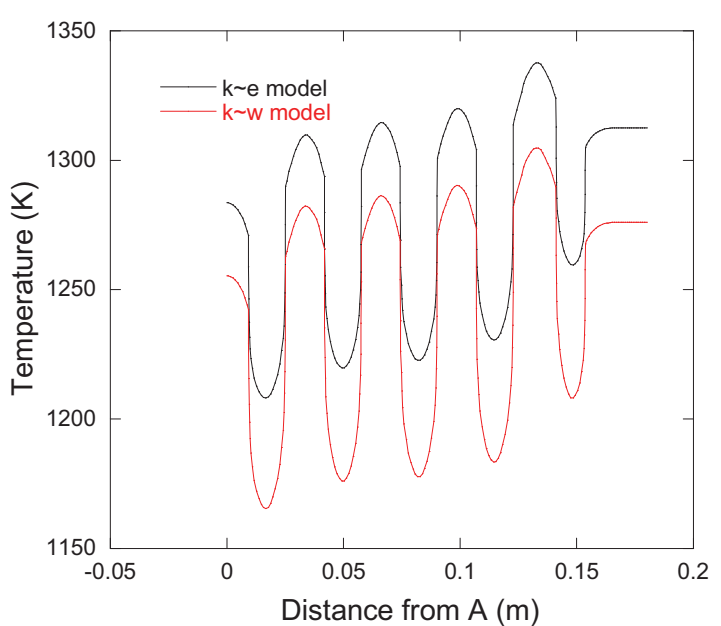

(a) $0 \mathrm{~mm}$

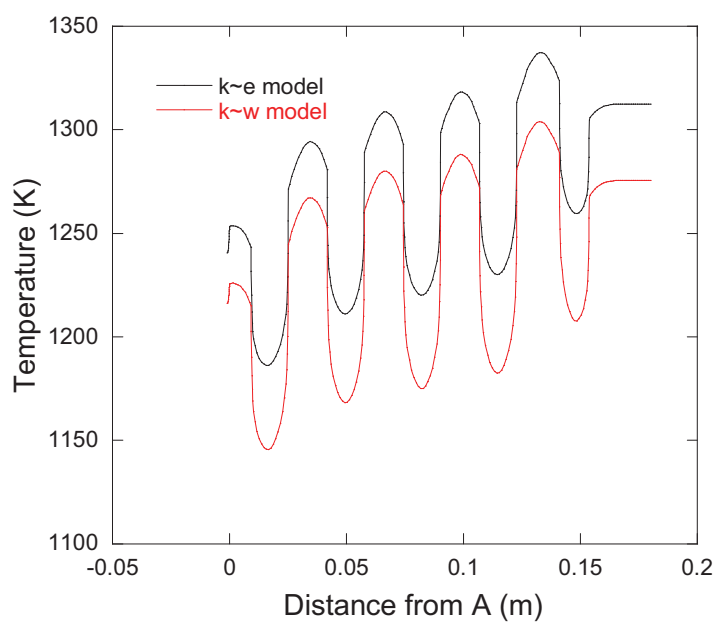

(c) $2 \mathrm{~mm}$

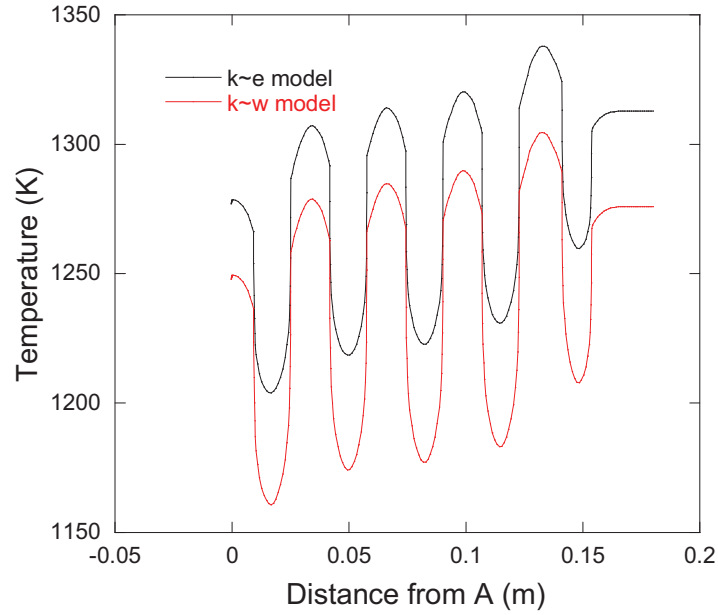

(b) $1 \mathrm{~mm}$

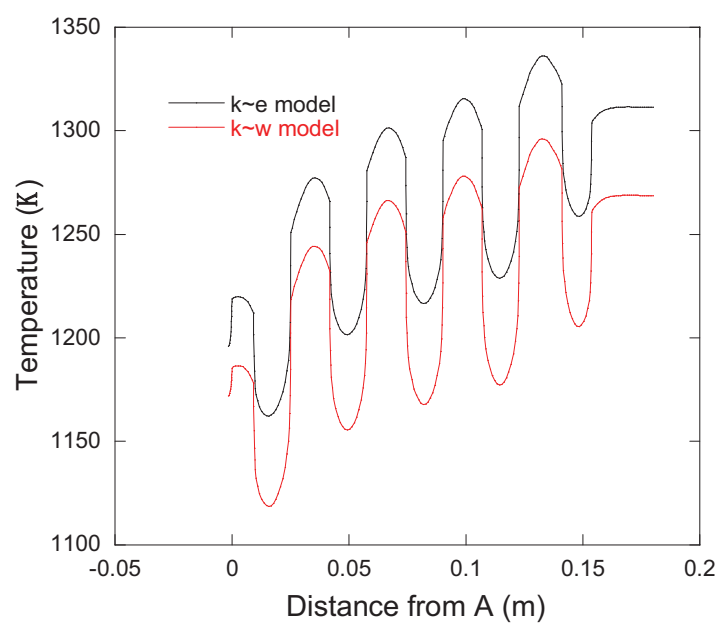

(d) $3 \mathrm{~mm}$

Figure 4-19. Temperature along line A-B (see Figure 3-2) for the fuel hot spot plane for different turbulence models.

Table 4-4. Calculation inputs and results for total mass flow, gap flow fraction, core differential pressure, max fuel temperature and gap, and max channel outlet temperatures for the $\mathrm{k} \sim \omega$ turbulence model for different gap widths.

\begin{tabular}{lcccc}
\hline \multicolumn{1}{c}{ Gap width $(\mathrm{mm})$} & 0.0 & 1.0 & 2.0 & 3.0 \\
\hline Total mass flow rate $(\mathrm{kg} / \mathrm{s})$ & 0.218 & 0.219 & 0.219 & 0.232 \\
Gap flow fraction $(\%)$ & - & 0.433 & 1.88 & 4.16 \\
Maximum fuel temperature $\left({ }^{\circ} \mathrm{C}\right)$ & 1061 & 1060 & 1059 & 1052 \\
Gap outlet temperature $\left({ }^{\circ} \mathrm{C}\right)$ & - & 908 & 896 & 874 \\
Max channel outlet temp. $\left({ }^{\circ} \mathrm{C}\right)$ & 943 & 943 & 942 & 937 \\
\hline
\end{tabular}




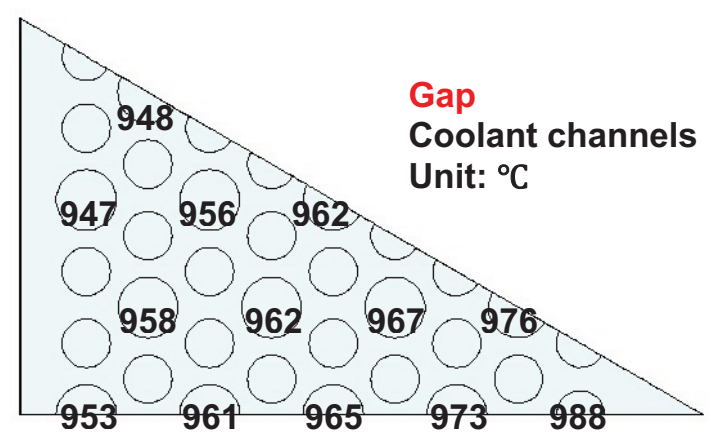

(a) $0 \mathrm{~mm}$ with $\mathrm{k} \sim \varepsilon$ model

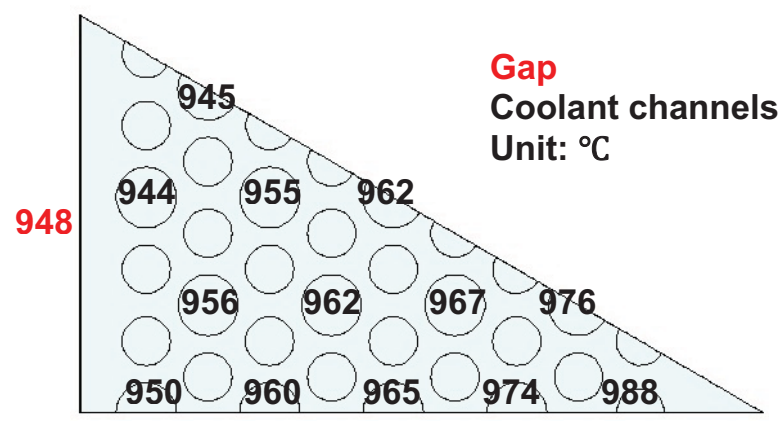

(c) $1 \mathrm{~mm}$ with $\mathrm{k} \sim \varepsilon$ model

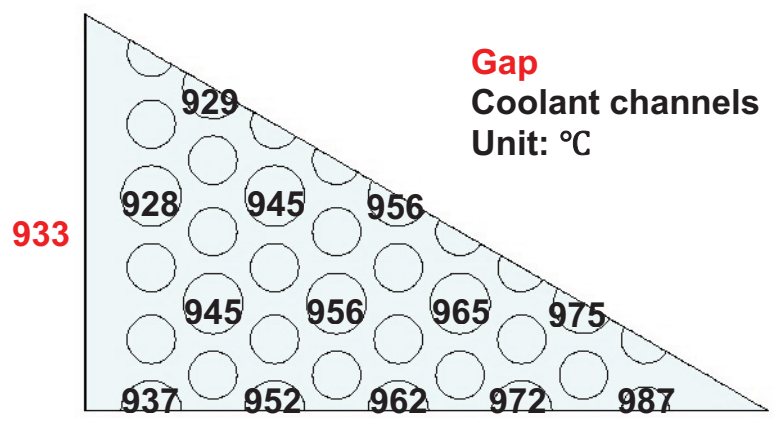

(e) $2 \mathrm{~mm}$ with $\mathrm{k} \sim \varepsilon$ model

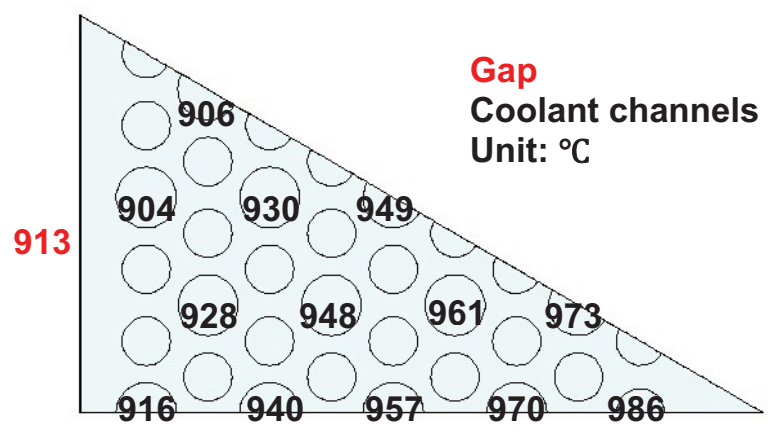

(g) $3 \mathrm{~mm}$ with $\mathrm{k} \sim \varepsilon$ model

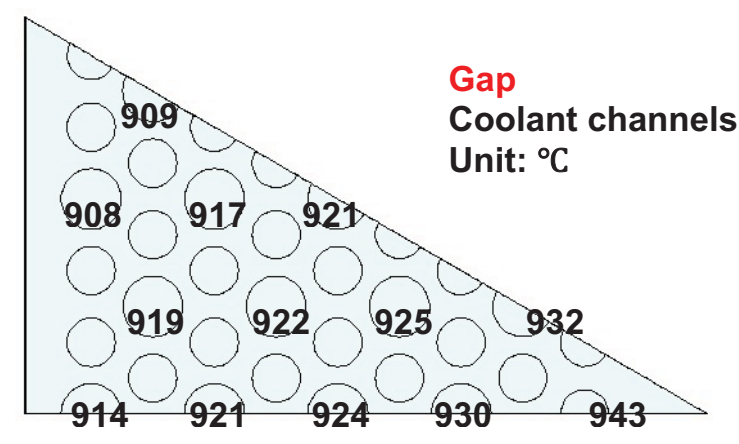

(b) $0 \mathrm{~mm}$ with $\mathrm{k} \sim \omega$ model

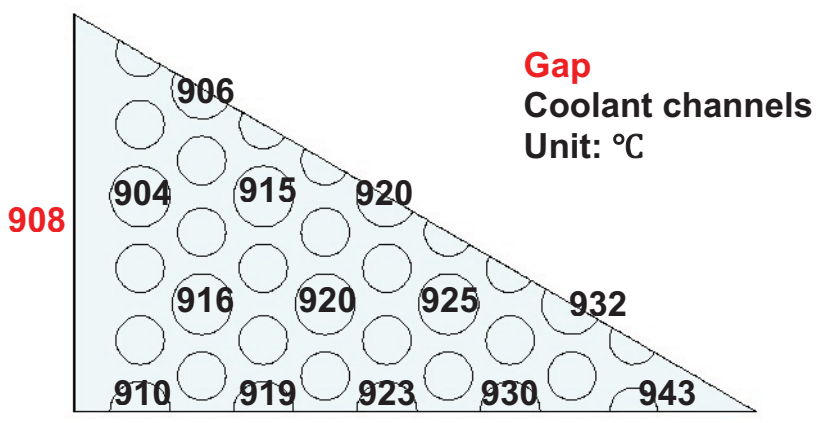

(d) $1 \mathrm{~mm}$ with $\mathrm{k} \sim \omega$ model

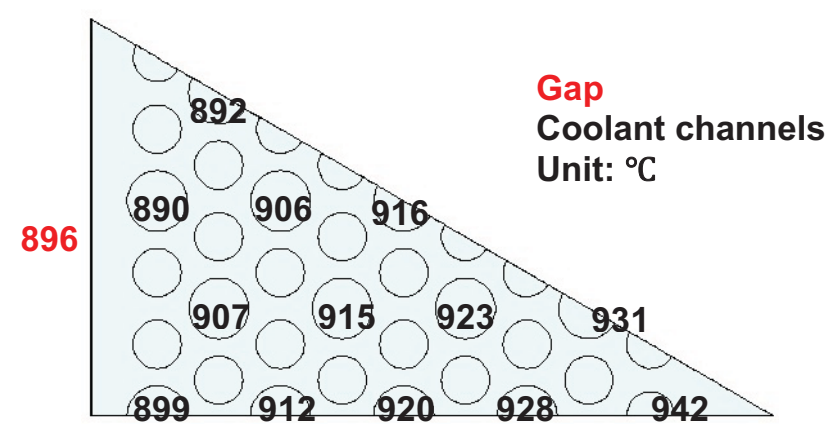

(f) $2 \mathrm{~mm}$ with $\mathrm{k} \sim \omega$ model

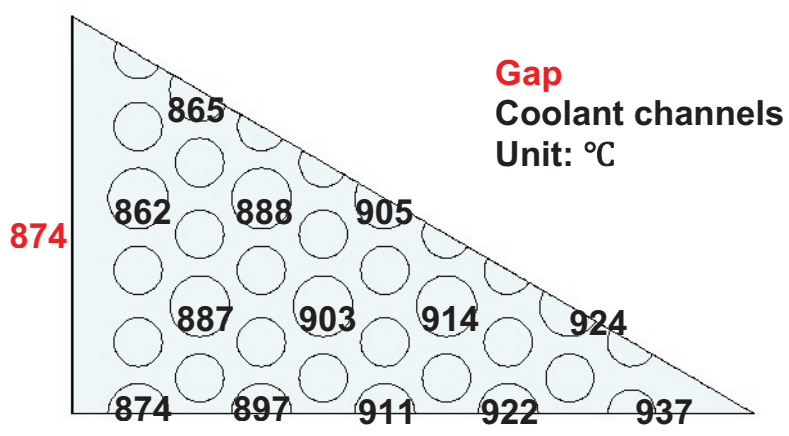

(h) $3 \mathrm{~mm}$ with $\mathrm{k} \sim \omega$ model

Figure 4-20. Bulk mean helium outlet temperatures $\left({ }^{\circ} \mathrm{C}\right)$ for channels and gaps for two turbulence models. 
Figure 4-21 shows the comparison of wall shear stress at the center of the gap for the two turbulence models for the $3 \mathrm{~mm}$ gap-width case. As can be seen, the difference in wall shear stress is small, less than $1.6 \%$, but in the cylindrical coolant channel regions, the previous validation study indicates that the standard $\mathrm{k} \sim \varepsilon$ model with enhanced wall treatment shows much better agreement with empirical correlations. These results imply that the flow increase is mainly because of the difference of friction in the coolant channel region. They also indicate the importance of validation for both the flow and heat transfer aspects of the bypass and coolant channel flow.

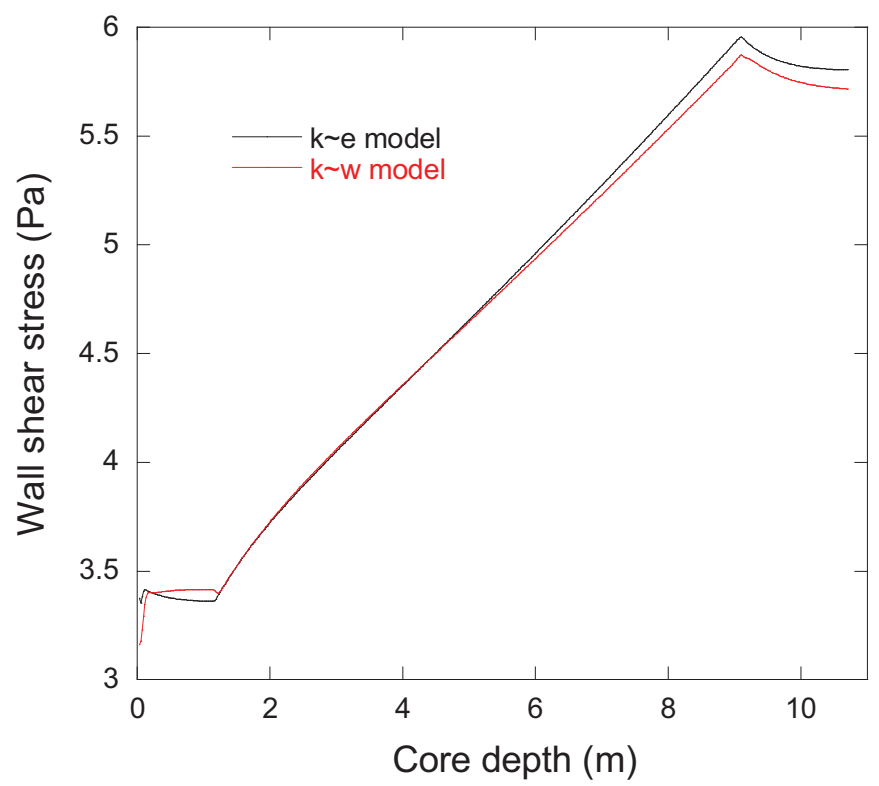

Figure 4-21. Comparison of gap wall shear stress for different turbulence model for $3 \mathrm{~mm}$ gap width.

\subsubsection{Effect of Gap Width for Fixed Total Mass Flow Rate}

This study calculates flow and heat transfer for gap widths of $0,1,2,3$, and $5 \mathrm{~mm}$ for the one-twelfth sector. The total mass flow is kept constant for these calculations, requiring that a lower differential pressure be used as gap width increases. In the actual reactor vessel, the presence of the bypass flow area will decrease the resistance to flow through the core for the helium coolant. This will increase the total mass flow of helium through the core. For a typical circulator, an increase in the mass flow rate results in a decrease in pressure head provided by the circulator. Inasmuch as the actual performance of the circulator is unknown at this time, the mass flow is kept constant, causing the pressure differential to decrease. Keeping the mass flow rate constant, while increasing gap width, is a more severe situation than actual expected conditions. The heat generation rate of $27.88 \mathrm{MW} / \mathrm{m}^{3}$ in the fuel pins is held uniform throughout the core, and the standard $\mathrm{k} \sim \varepsilon$ turbulence model with enhanced wall treatment is employed.

Figure 4-22 shows temperature contours for the middle plane of the fuel block (5.154 $\mathrm{m}$ core depth). Clearly, the cooling effect provided by the bypass flow increases with gap width, even though the total mass flow decreases. Figure 4-23 shows the temperature distribution along line A-B (see Figure 3-2) for all five gap-width cases. As can be seen, temperatures within the block decrease from the center to the gap. The largest gap-width case shows the largest temperature difference from the center outward, while the 0 and $1 \mathrm{~mm}$ gap-width cases show little temperature difference. The maximum temperature difference within the block for the $5 \mathrm{~mm}$ gap-width case is approximately $156^{\circ} \mathrm{C}$. As the gap width increases temperatures in the center region increase. In contrast, temperature in the peripheral region decreases as the gap width increases. 


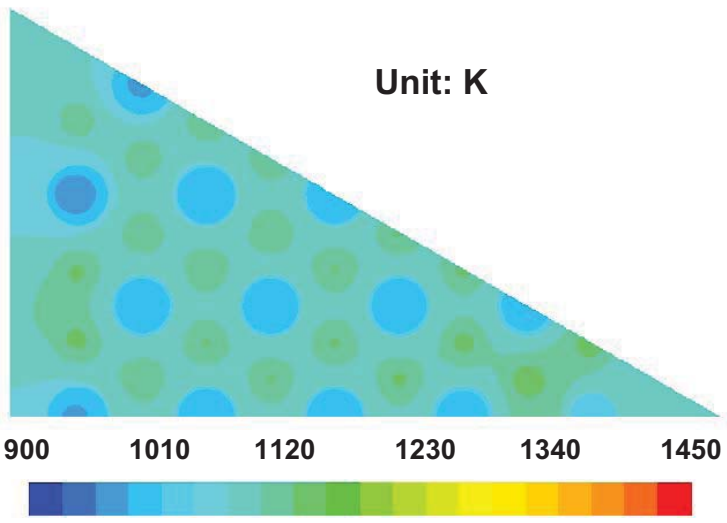

(a) $0 \mathrm{~mm}$

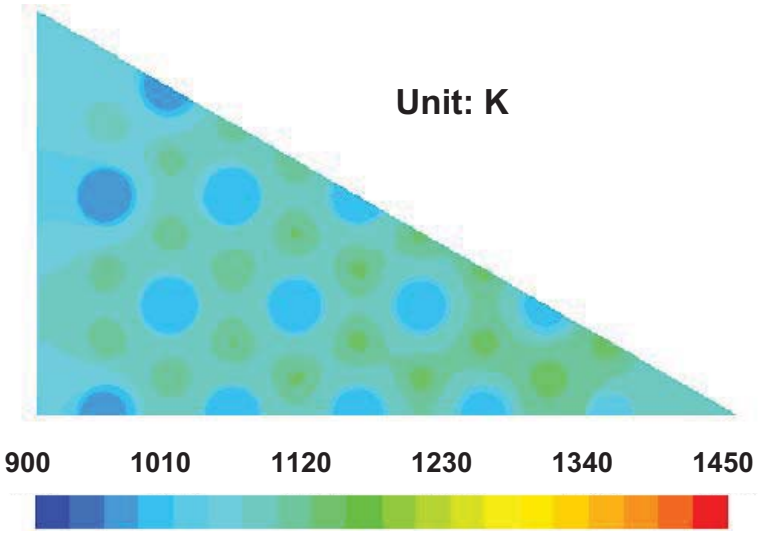

(c) $2 \mathrm{~mm}$

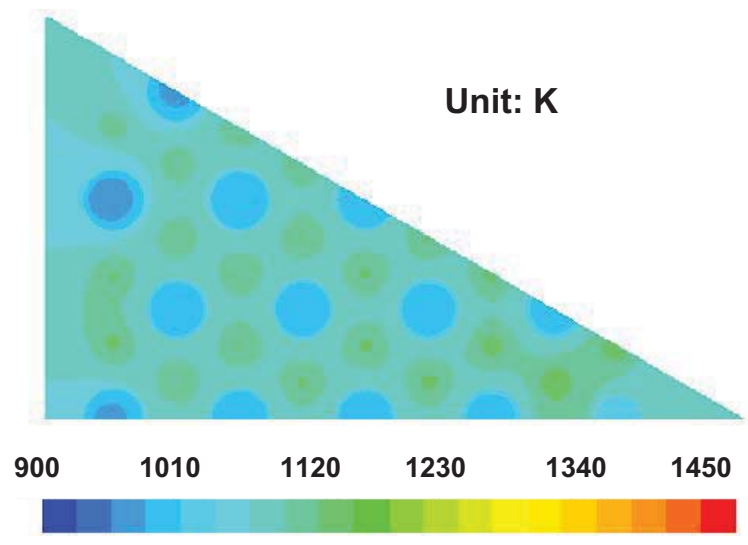

(b) $1 \mathrm{~mm}$

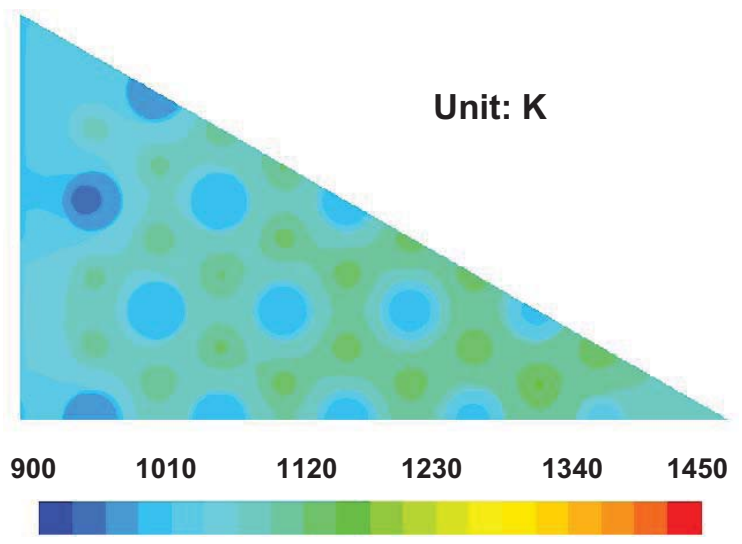

(d) $3 \mathrm{~mm}$

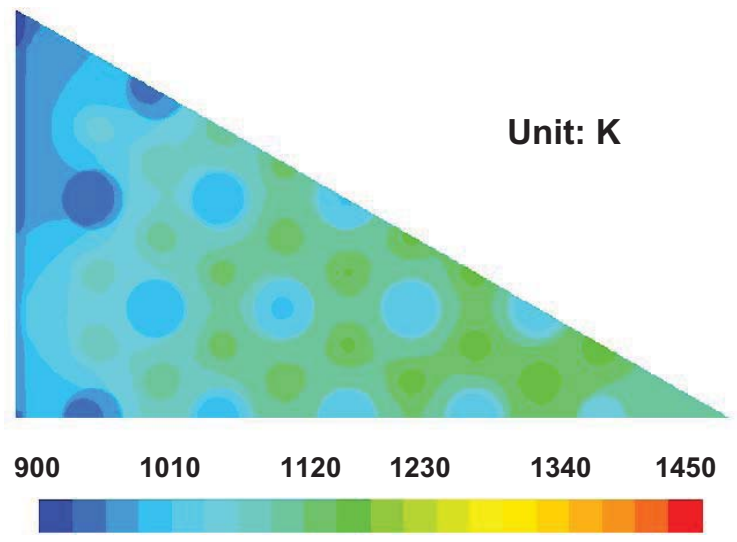

(e) $5 \mathrm{~mm}$

Figure 4-22. Temperature contours at the middle plane of the fuel block for different gap widths. 


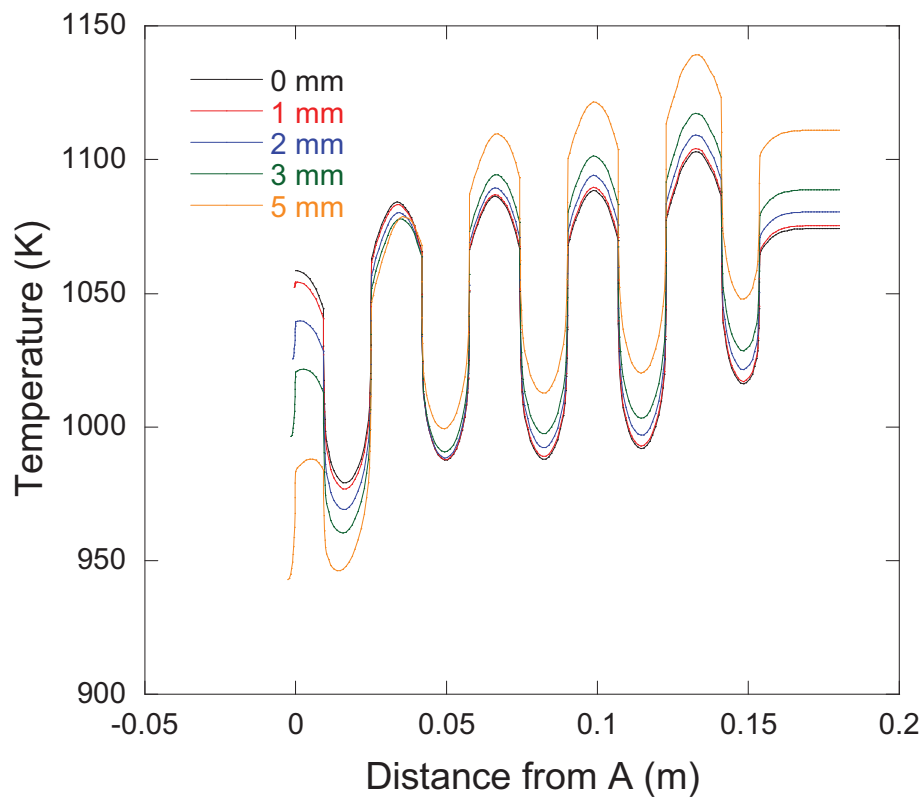

Figure 4-23. Temperature along line A-B (see Figure 3-2) of the middle plane of the fuel block for different gap widths.

Figure 4-24 shows the temperature contours of the plane involving the fuel hot spot, which is about $0.06 \mathrm{~m}$ above the bottom of the fueled section for all cases. The temperature in the gap region decreases significantly as gap width increases while the temperature in the center region significantly increases. In contrast, for the case where the differential pressure drop is kept constant as shown in Figure 4-5, the gap region became cooler while the center region remained at about the same temperature as the gap width increased. The present case, where the total mass flow is not allowed to increase, can be described as the case where mass flow is 'robbed' from the coolant channels to provide helium for the bypass flow. Figure 4-25 shows the temperature distribution along line A-B (see Figure 3-2). As can be seen, the hottest region is at the fuel channel closest to the center of hexagonal block, while the temperature within the block decreases from the center to the gap region and the maximum temperature difference within a graphite block is approximately $201{ }^{\circ} \mathrm{C}$ (for the $5 \mathrm{~mm}$ gap-width case), similar to the middle plane temperature gradients. Fuel temperatures close to the gap region decreases as the gap width increases, but fuel temperatures close to the center increase as the gap width increases.

Figure 4-26 shows the bulk mean helium gas temperature at the coolant channels and gap outlets. The hottest temperature appears at the small $12.70 \mathrm{~mm}$ diameter coolant channel outlet located at the center region of the block. The outlet temperatures in the outer coolant channels decrease as the gap width increases, while the temperatures in the central coolant channel increase as the gap width increases. The temperature gradient within the graphite block increases as the gap width increases.

Table 4-5 shows the calculation inputs and results for total mass flow, gap flow fraction, core differential pressure, max fuel temperature, and gap and max channel outlet temperatures for constant total mass flow for different gap widths. As expected, the flow fraction increases as the gap width increases. The pressure difference required to obtain the same total mass flow rate decreases as the gap width increases and the difference between 0 and $5 \mathrm{~mm}$ cases are about $0.82 \mathrm{psi}$, which is $16 \%$ of the total pressure difference. This result implies that the pressure drop across the reactor core is significantly affected by the gap geometry. Calculation results show that the maximum fuel temperature increases as the gap width increases because of the decrease in channel coolant flow rate, which cools the center region of hexagonal block more effectively. 


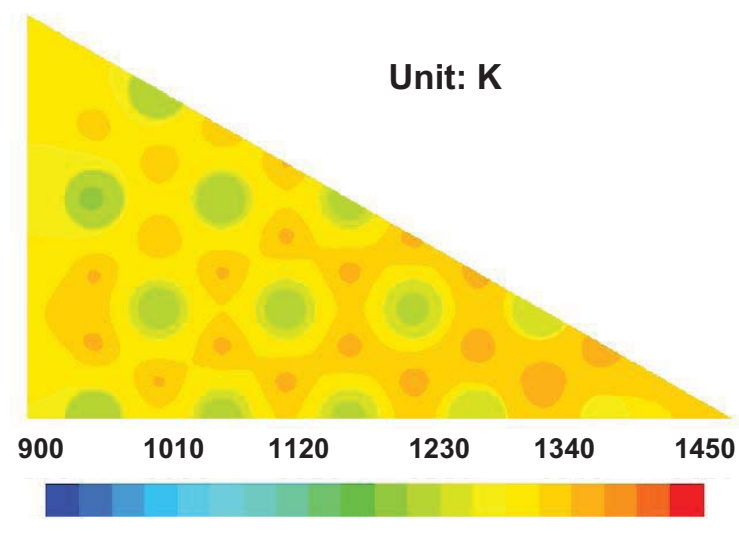

(a) $0 \mathrm{~mm}$

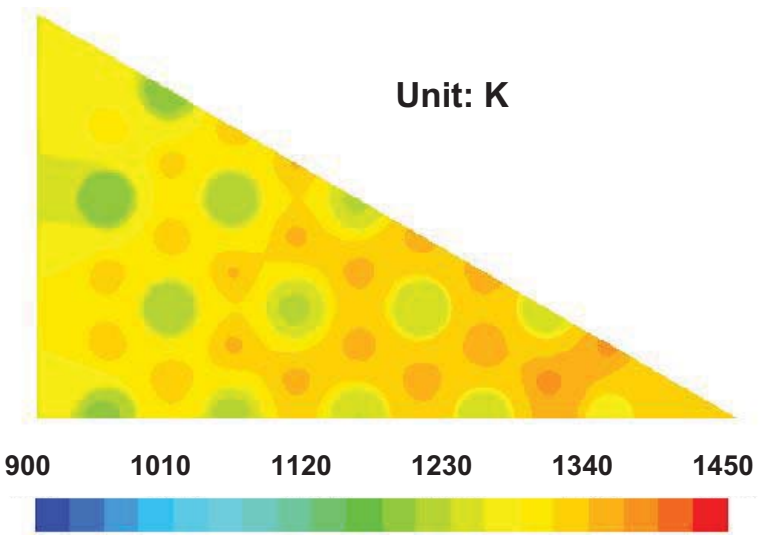

(c) $2 \mathrm{~mm}$

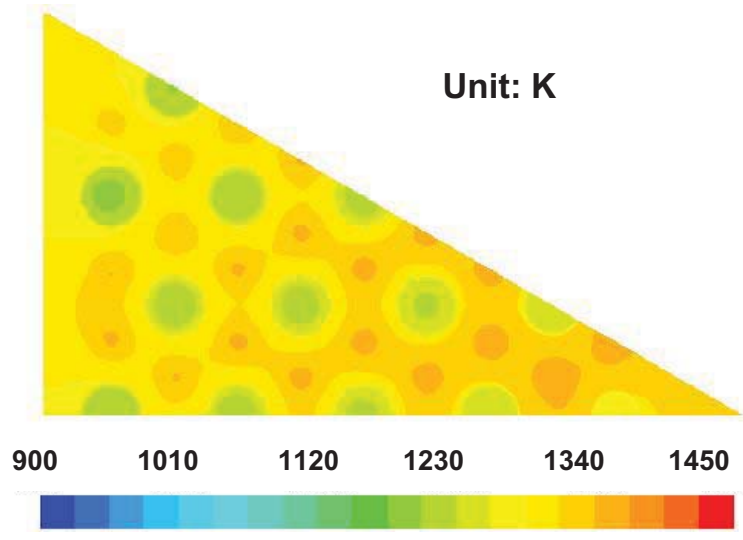

(b) $1 \mathrm{~mm}$

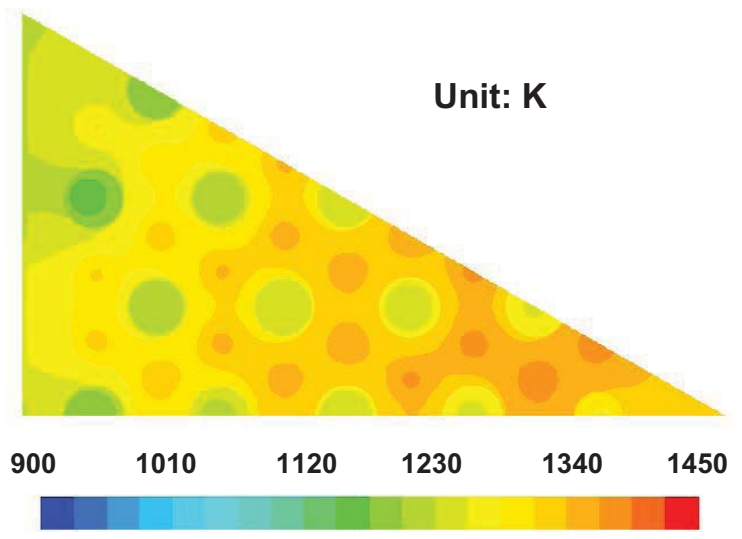

(d) $3 \mathrm{~mm}$

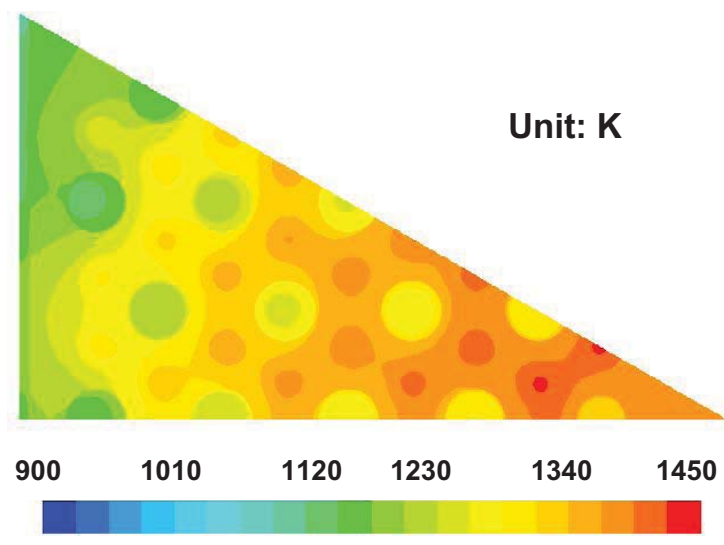

(e) $5 \mathrm{~mm}$

Figure 4-24. Temperature contours at the fuel hot spot plane for different gap widths. 


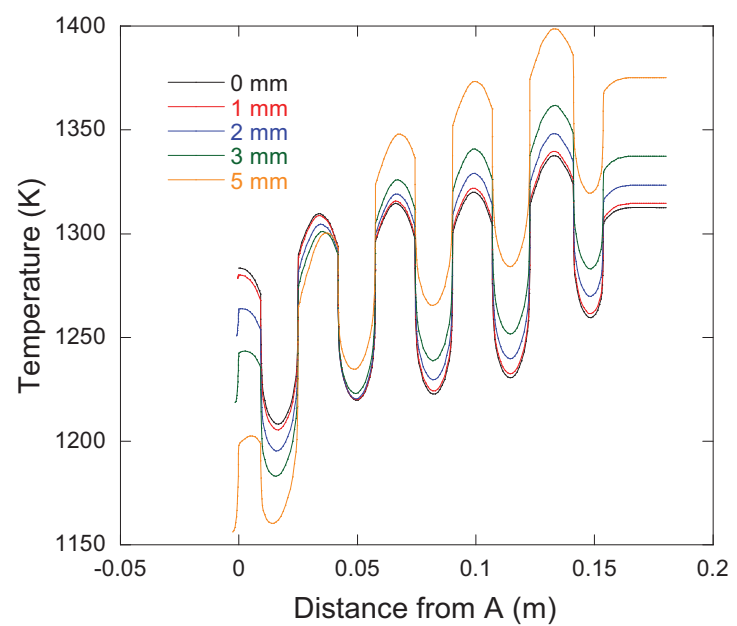

Figure 4-25. Temperature along line A-B (see Figure 3-2) of fuel hot spot plane for different gap widths. 


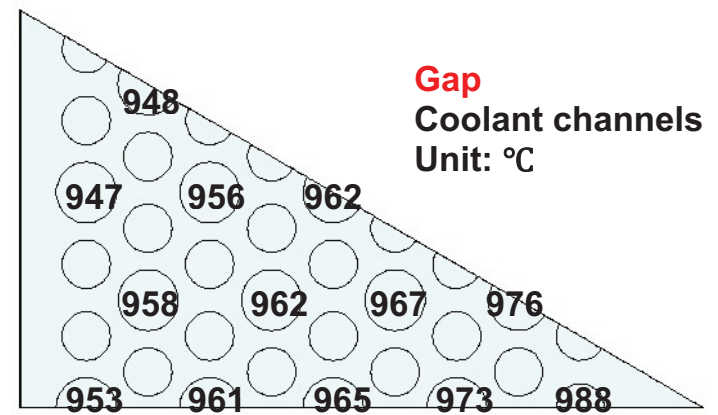

(a) $0 \mathrm{~mm}$

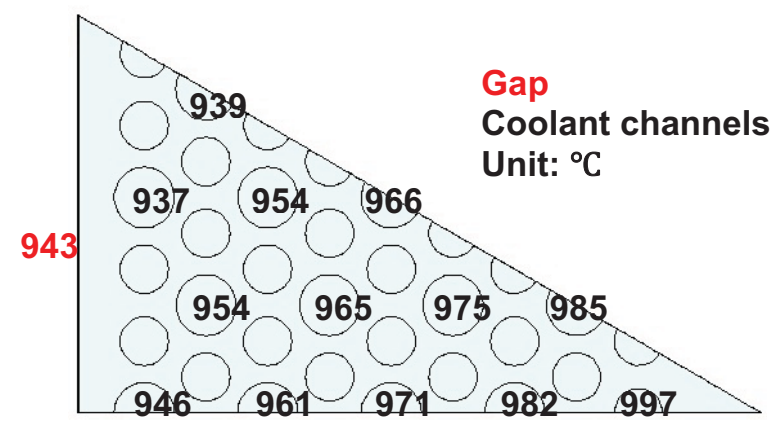

(c) $2 \mathrm{~mm}$

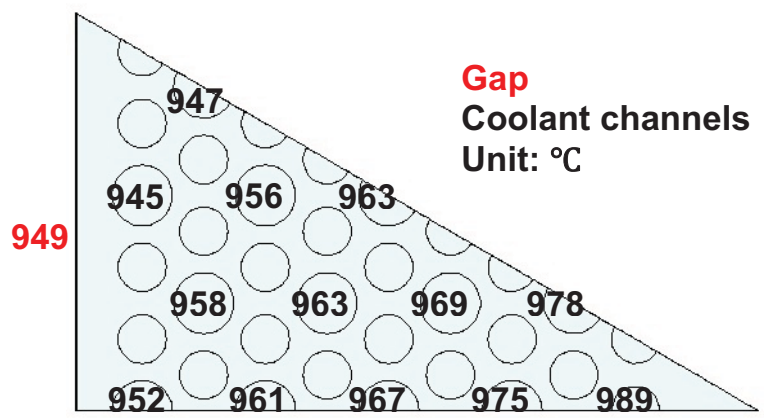

(b) $1 \mathrm{~mm}$

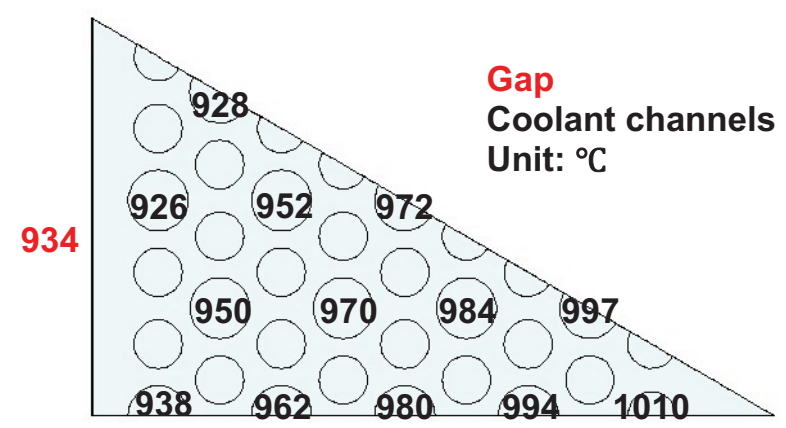

(d) $3 \mathrm{~mm}$

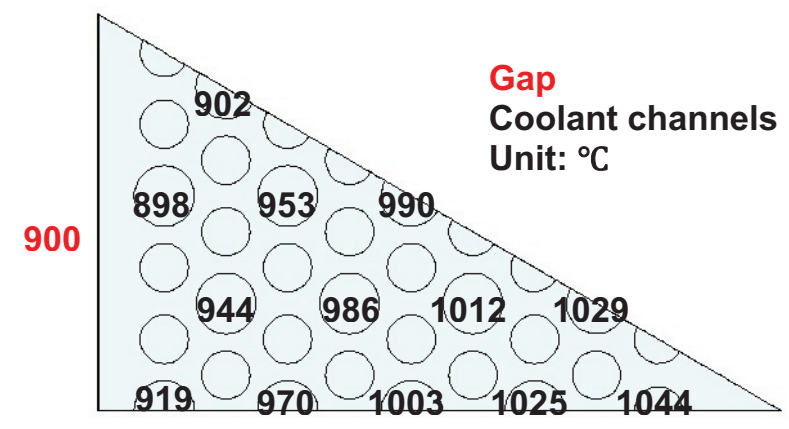

(e) $5 \mathrm{~mm}$

Figure 4-26. Bulk mean helium gas outlet temperatures $\left({ }^{\circ} \mathrm{C}\right)$ for channels and gaps for different gap widths.

Table 4-5. Calculation inputs and results for total mass flow, gap flow fraction, core differential pressure, max fuel temperature, and gap and max channel outlet temperatures for constant total mass flow for different gap widths.

\begin{tabular}{lccccc}
\hline \multicolumn{1}{c}{ Gap width $(\mathrm{mm})$} & 0.0 & 1.0 & 2.0 & 3.0 & 5.0 \\
\hline Pressure difference $(\mathrm{psi})$ & 5.000 & 4.975 & 4.847 & 4.646 & 4.185 \\
Total mass flow rate $(\mathrm{kg} / \mathrm{s})$ & 0.200 & 0.200 & 0.200 & 0.200 & 0.200 \\
Gap flow fraction $(\%)$ & - & 0.423 & 1.94 & 4.15 & 9.79 \\
Maximum fuel temperature $\left({ }^{\circ} \mathrm{C}\right)$ & 1093 & 1095 & 1103 & 1117 & 1153 \\
Gap outlet temperature $\left({ }^{\circ} \mathrm{C}\right)$ & - & 949 & 943 & 934 & 900 \\
Max channel temperature $\left({ }^{\circ} \mathrm{C}\right)$ & 988 & 989 & 997 & 1010 & 1044 \\
\hline
\end{tabular}




\subsection{Calculation Simulating VHTR Bypass Flow Ratio}

Bypass flow in the actual VHTR can be observed in the core region as well as in the center and outer reflector regions. In order to understand the actual flow and temperature distribution, these nonheated regions should be taken into account. However, calculating the whole core region with the reasonable mesh quality is out of current computational capability. In the present study, the following procedure is employed to achieve and simulate a bypass flow ratio of $20 \%$ in the GTMHR design (General Atomics 1996).

1. Calculate the flow rate in an unheated fixed $3.5 \mathrm{~mm}$ gap to simulate the interstitials adjacent to reflector blocks in the inner and outer reflector regions.

2. Calculate the flow and heat transfer in the full fueled core model (gap, coolant channels, and fuel pins) with the gap width as a parameter.

3. Sum the flow rates to calculate the overall bypass flow ratio.

4. Iterate calculation (2), changing the gap width, until the bypass flow achieves $20 \%$ of the total flow rate in the reactor core.

The above procedure is followed using FLUENT with the same solver specifications as for previous calculations.

To complete calculation (1), a grid of a simple channel representative of gaps in the inner and outer reflector regions is generated in order to estimate the flow rate in the reflector regions. A gap with a width of $3.5 \mathrm{~mm}$ is extruded to the whole core depth of $10.704 \mathrm{~m}$. The total number of mesh cells for the gap model is approximately 2.0 million. An isothermal calculation with helium properties at $490{ }^{\circ} \mathrm{C}$ is conducted. A differential pressure of $5.0 \mathrm{psi}$ is set from top to bottom. The standard $\mathrm{k} \sim \varepsilon$ turbulence model with enhanced wall treatment using FLUENT is employed.

For calculation (2) in the fueled section, a nonuniform heat generation profile with axial variation at the average radial factor (axial factor $=1.3$, radial factors $=1.0$ ) is employed. A differential pressure of $5.0 \mathrm{psi}$ is used. The standard $\mathrm{k} \sim \varepsilon$ model with enhanced wall treatment is employed, using FLUENT with the same solver specifications as for previous calculations. After iterating steps $2-4$, it was found that a gap of $5.46 \mathrm{~mm}$ provided an overall bypass flow of about $20 \%$. This gap width was then used for the nonuniform heat generation profile with axial variation at the peak radial factor (factors 1.3 and 1.25). The second case slightly increased the bypass flow from 20.1 to $20.6 \%$.

Figure 4-27 shows temperature contours of the middle plane of the fuel block (5.154 $\mathrm{m}$ core depth) for the two $20 \%$ bypass flow cases. Clearly, the case for the peak radial factor produces higher overall temperatures. Figure 4-28 shows the comparison of temperature distribution along line A-B (Figure 3-2) for the two $20 \%$ bypass flow cases. As can be seen, higher temperature is observed for the case with axial variation at the peak radial factor. The temperature difference between the two cases increases as the location approaches the center of graphite block with the maximum temperature difference of about 105 ${ }^{\circ} \mathrm{C}$. Temperature within the block increases as the location comes close to the center in both cases. The temperature difference between the center and peripheral regions for the case with axial variation only and for axial variation at the peak radial factors are about $164{ }^{\circ} \mathrm{C}$ and $210{ }^{\circ} \mathrm{C}$, respectively. 


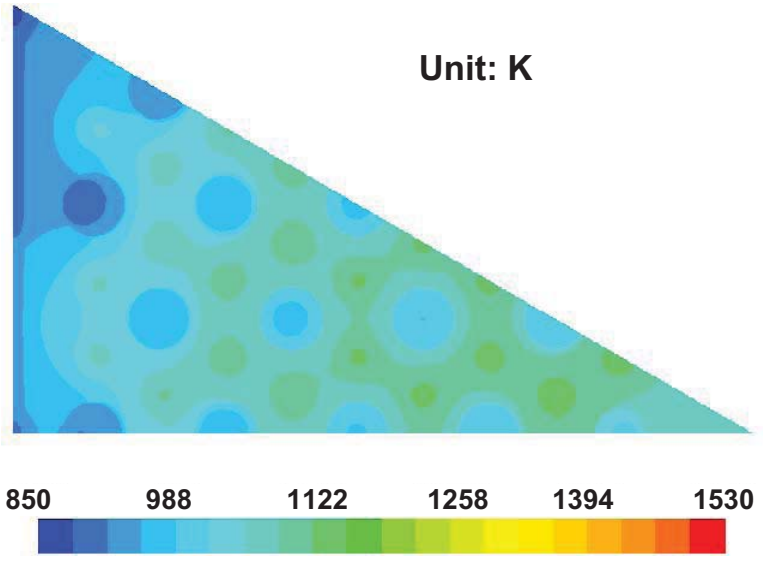

(a) With axial peaking factor

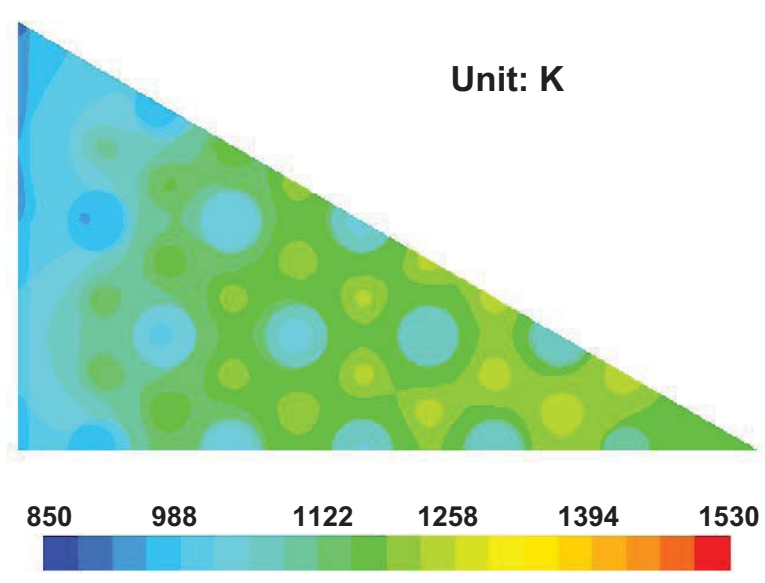

(b) With axial and radial peaking factors

Figure 4-27. Temperature contours at the middle plane of the fuel block for different heat generation rates.

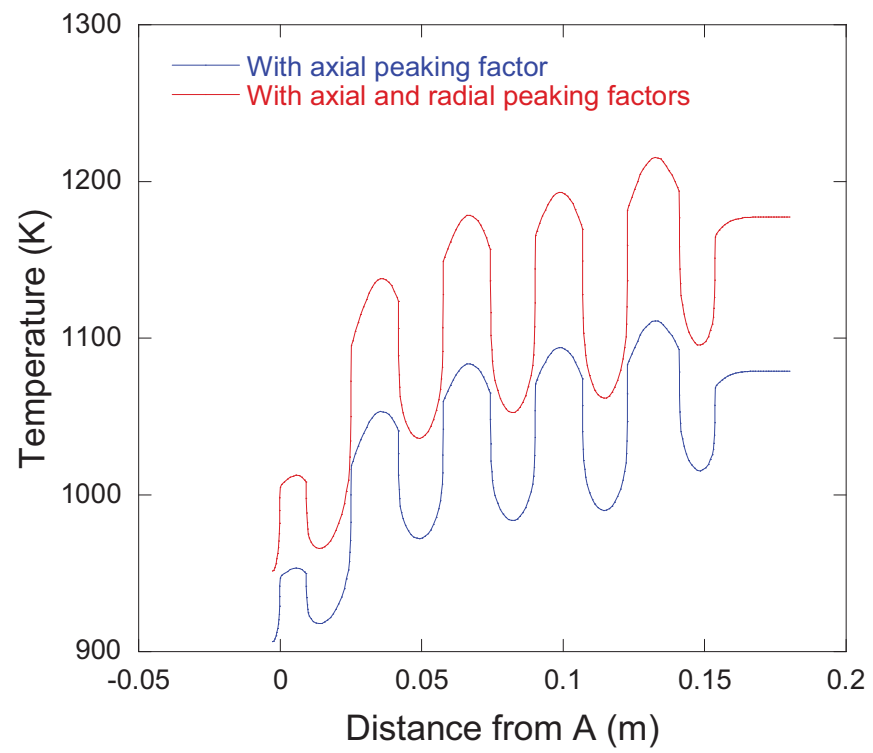

Figure 4-28. Temperature along line A-B (see Figure 3-2) of the middle plane of the fuel block for different heat generation rates. 
Figure 4-29 shows the temperature contours of the plane involving the fuel hot spot. The plane is located at about $0.06 \mathrm{~m}$ above the bottom of the fuel section. The temperatures for the axial variation at the peak radial factor are significantly higher. These cases can also be compared with earlier cases where gap widths of $3 \mathrm{~mm}$ are used, as in Figure 4-12. For both variable heat profile cases, the block regions near the gap are cooler for the present $5.46 \mathrm{~mm}$ gap-width cases than for the $3 \mathrm{~mm}$ gap-width cases because of the increase cooling from the larger bypass flow. Figure 4-30 shows the temperature distributions along line A-B (see Figure 3-2) for the two cases at the fuel hot spot. As can be seen, hot spots are located at the fuel channel closest to the center of hexagonal block in both cases. Temperature within the block decreases from the center to the gap region. The maximum temperature difference within the graphite block is higher than those of the middle plane, and the temperature difference for the axial variation at the average radial factor and the axial variation at the peak radial factor are about $193{ }^{\circ} \mathrm{C}$ and $248^{\circ} \mathrm{C}$, respectively.

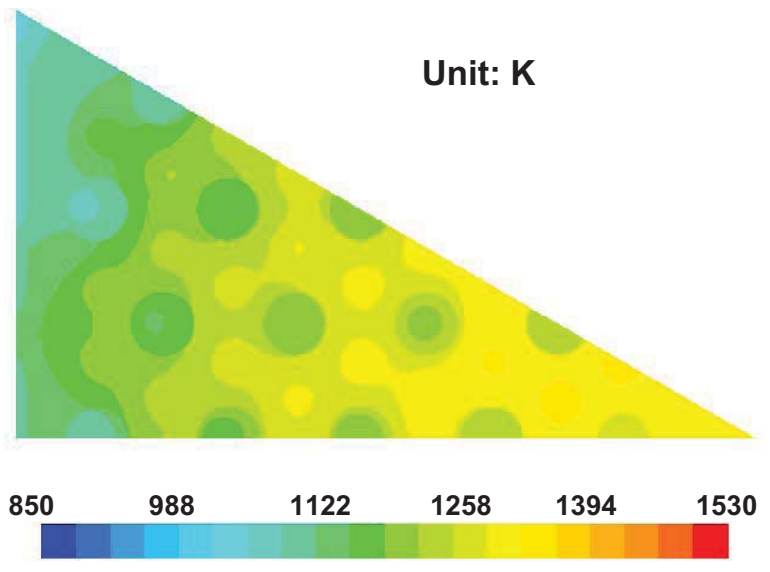

(a) With axial peaking factor

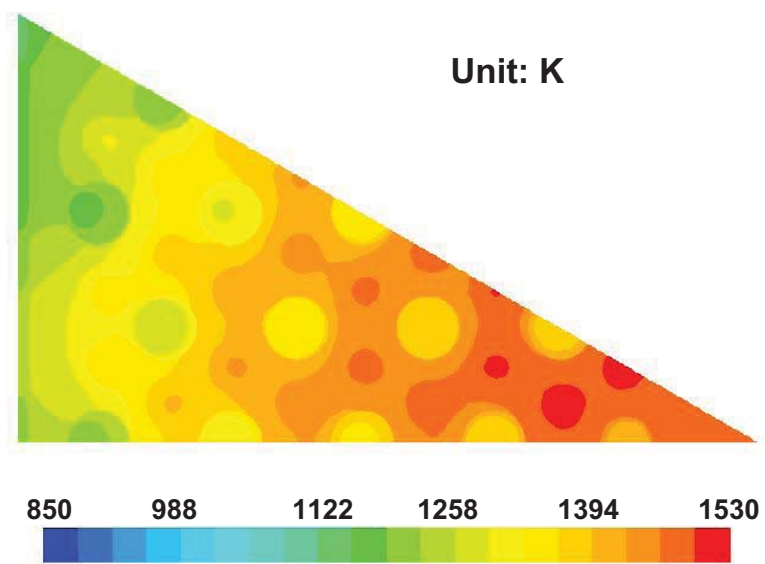

(b) With axial and radial peaking factors

Figure 4-29. Temperature contours at the fuel hot spot plane for different heat generation rates.

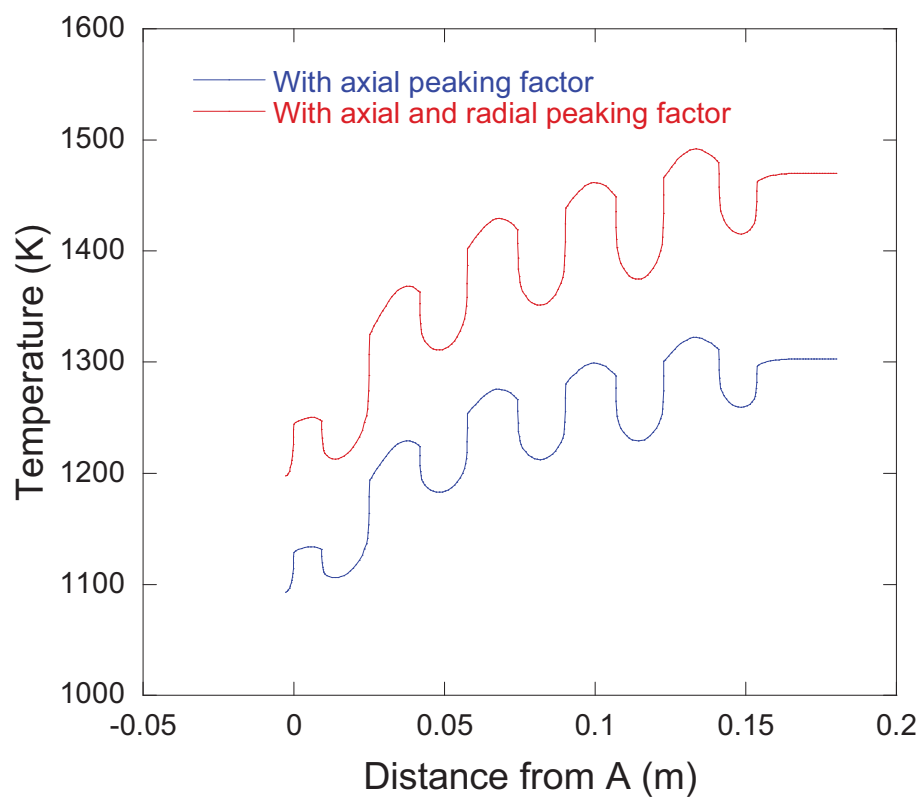

Figure 4-30. Temperature along line A-B (see Figure 3-2) of the fuel hot spot plane for different heat generation rates. 
Figure 4-31 shows the bulk mean helium gas temperatures at the coolant channels and gap outlets. As can be seen, the hottest temperature appears at the small $12.70 \mathrm{~mm}$ diameter coolant channel outlet located at the center region of block in both cases. The gap outlet temperatures are lower for these cases than for the similar cases for $3 \mathrm{~mm}$ gap width as seen in Figure 4-14(b) and (c).

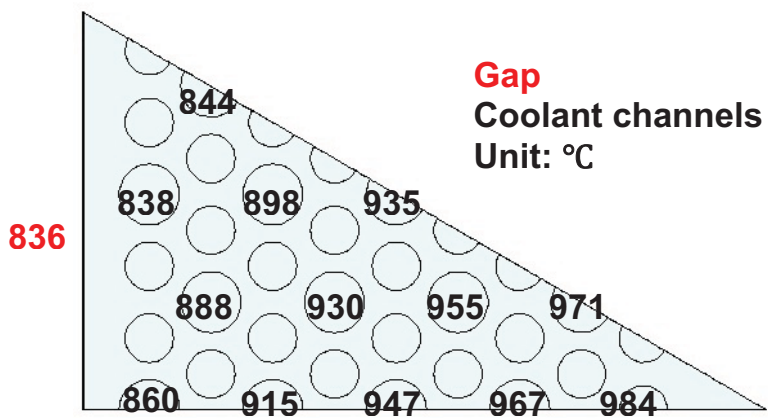

(a) With axial peaking factor

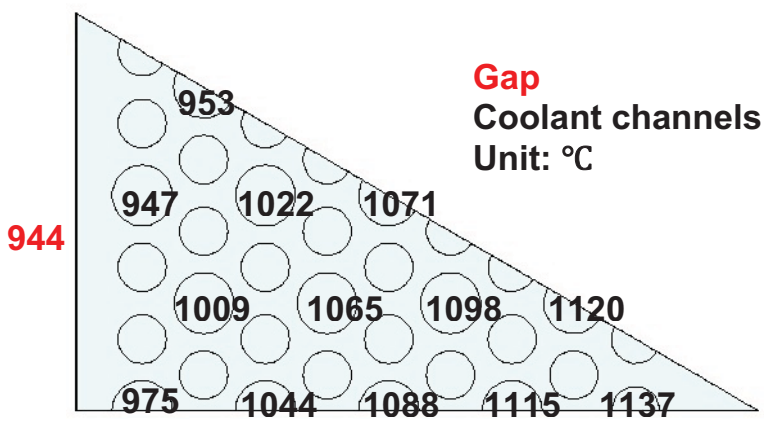

(b) With axial and radial peaking factors

Figure 4-31. Bulk mean helium gas outlet temperatures $\left({ }^{\circ} \mathrm{C}\right)$ at coolant channels and gaps for different heat generation rates.

Table 4-6 shows the calculation results for coolant channel, gap, and total flow rates; bypass flow ratio; and the maximum fuel and coolant channel temperature in the reactor for different heat generation rate profiles for $20 \%$ bypass flow.

Table 4-6. Calculation results for coolant channel, gap, and total flow rates; bypass flow ratio; and the maximum fuel and coolant channel temperature in the reactor for different heat generation rate profiles for $20 \%$ bypass flow.

\begin{tabular}{lccccccc}
\hline $\begin{array}{c}\text { Heat } \\
\text { generation } \\
\text { profile }\end{array}$ & $\begin{array}{c}\text { Coolant } \\
\text { channel } \\
\text { flow rate } \\
(\mathrm{kg} / \mathrm{s})\end{array}$ & $\begin{array}{c}\text { Gap flow } \\
\text { rate } \\
(\mathrm{kg} / \mathrm{s})\end{array}$ & $\begin{array}{c}\text { Total flow } \\
\text { rate } \\
(\mathrm{kg} / \mathrm{s})\end{array}$ & $\begin{array}{c}\text { Bypass } \\
\text { flow ratio } \\
(\%)\end{array}$ & $\begin{array}{c}\text { Maximum } \\
\text { fuel temp. } \\
\left({ }^{\circ} \mathrm{C}\right)\end{array}$ & $\begin{array}{c}\text { Gap outlet } \\
\text { temp. } \\
\left({ }^{\circ} \mathrm{C}\right)\end{array}$ & $\begin{array}{c}\text { Maximum } \\
\text { coolant } \\
\text { temp. } \\
\left({ }^{\circ} \mathrm{C}\right)\end{array}$ \\
\hline $\begin{array}{l}\text { Axial with } \\
\text { average radial }\end{array}$ & 238 & 60.1 & 298 & 20.1 & 1,073 & 836 & 984 \\
$\begin{array}{l}\text { Axial with } \\
\text { peak radial }\end{array}$ & 228 & 59.0 & 287 & 20.6 & 1,247 & 944 & 1,137 \\
\hline
\end{tabular}

In comparing the results from Table 4-6 to similar results in Table 4-3, where the only difference is the gap width of $3 \mathrm{~mm}$, the maximum coolant and fuel temperatures are within $4^{\circ} \mathrm{C}$. This result compares well with the results reported in Table 4-2 for the uniform heat generation for varying gap width, but the same differential pressure. That is, there is little change between cases for the maximum fuel and coolant outlet temperatures as a function of gap width if the differential pressure is maintained to be the same. Again, what is needed is the actual performance curve of the helium circulator to see what the decrease in differential pressure would be for an increase in mass flow from increased gap width. 


\subsection{Calculation Simulating Irradiation Induced Dimensional Change}

This study investigates the effects of irradiation-induced dimensional change in the graphite block region to flow and temperature distributions in the reactor core. The one-twelfth sector column reference grid, which includes upper and lower reflector sections and a nominal $1 \mathrm{~mm}$ gap width, is shrunk by $1.23 \%$ in the radial direction and by $2.35 \%$ in axial direction uniformly. These geometric changes are maximum dimensional changes experienced by H451 graphite from irradiation (General Atomics 1988). The shrinkage in the radial direction increases the gap width and shrinks the diameters of the coolant channels. Uniform dimensional change in the axial direction shrinks the length of the hexagonal block. As a result, the gap width increases from the assumed nominal $1 \mathrm{~mm}$ to $5.5 \mathrm{~mm}$, and the total length of the one-twelfth sector shrinks from $10.704 \mathrm{~m}$ to $10.45 \mathrm{~m}$, respectively. Calculations are made for the above case and compared to a reference case where no shrinkage occurs; the reference case is also assumed to have a $5.5 \mathrm{~mm}$ gap width. The differential pressure is predetermined parametrically to obtain the same total flow rate as the $0 \mathrm{~mm}$ gap-width case in Section 4.1, which is $0.200 \mathrm{~kg} / \mathrm{sec}$. Nonuniform heat generation with axial variation at the peak radial factors ( $\mathrm{Ap}=1.3$ and $\mathrm{Ar}=1.25$, respectively $)$ is applied to both the shrinkage and the reference nonshrinkage cases in order to accentuate the impact of dimensional change on the temperature distribution in the fuel column. The standard $\mathrm{k} \sim \varepsilon$ turbulence model, with enhanced wall treatment, is employed.

Figure 4-32 shows temperature contours of the middle plane of the fuel block for the no-shrinkage and shrinkage cases (5.145 and $5.032 \mathrm{~m}$ core depth for the no-shrinkage and shrinkage cases, respectively). The shrinkage case is actually cooler than the no-shrinkage reference case. Figure 4-33 shows the temperature distribution along line A-B (see Figure 3-2) for all four gap-width cases. As can be seen, the temperature within the block decreases from the center to the gap and the trend is the same for both cases. The temperature for the no-shrinkage case is much higher than for the shrinkage case in the graphite block region. In contrast, temperatures in the coolant regions are almost the same for both cases. The maximum temperature difference between the two cases is about $92{ }^{\circ} \mathrm{C}$.

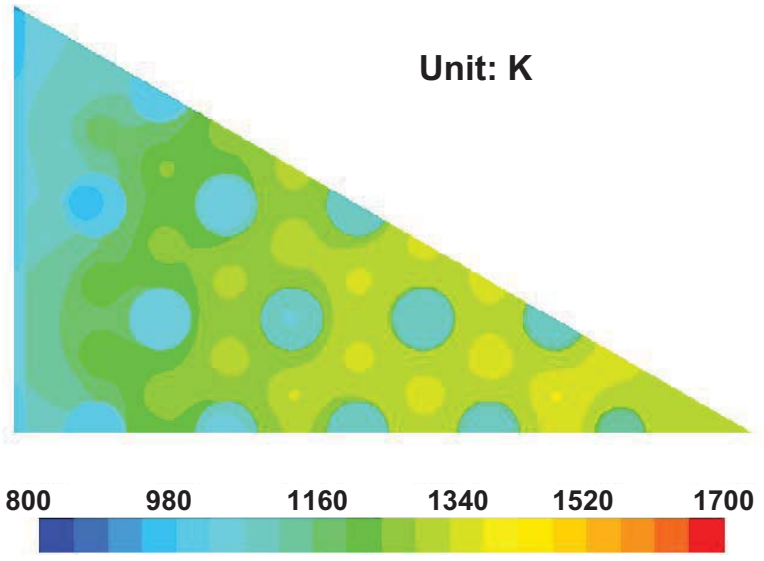

(a) Without shrinkage (gap width $5.5 \mathrm{~mm}$ )

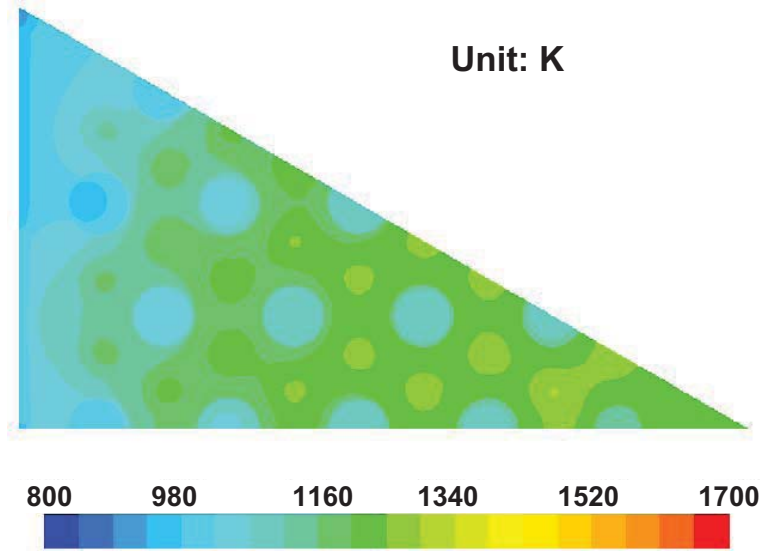

(b) With shrinkage (gap width $5.5 \mathrm{~mm}$ )

Figure 4-32. Temperature contours at the middle plane of the fuel block for different geometries. 


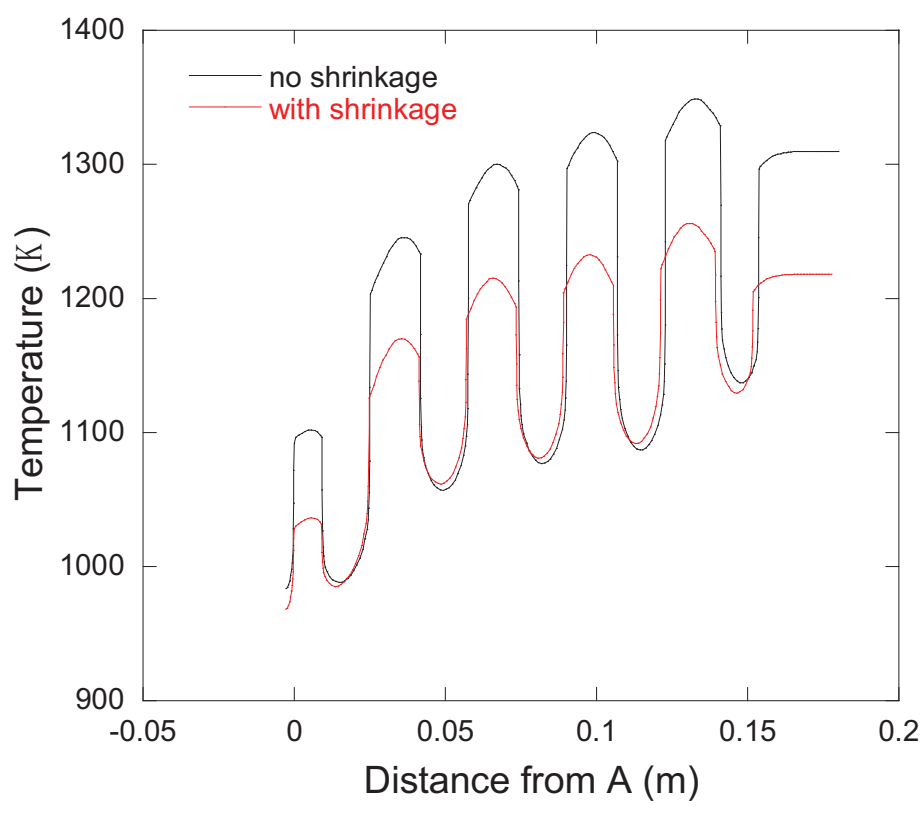

Figure 4-33. Temperature along line A-B (see Figure 3-2) for the fuel hot spot plane for different geometries.

Figure 4-34 shows the temperature contours of the plane involving the fuel hot spot. The plane is located about $0.06 \mathrm{~m}$ above the bottom of the fuel section. Again, the temperatures for the shrinkage case are cooler than for the no-shrinkage case. Figure 4-35 shows the comparison of temperature distribution along line A-B (see Figure 3-2). The hottest region is at the fuel channel closest to the center of the hexagonal block for both cases. Higher temperatures are observed in the block region for the no-shrinkage case, although temperatures in the coolant regions show only slight difference between the two cases. The maximum temperature difference between the cases along A-B is about $72{ }^{\circ} \mathrm{C}$.

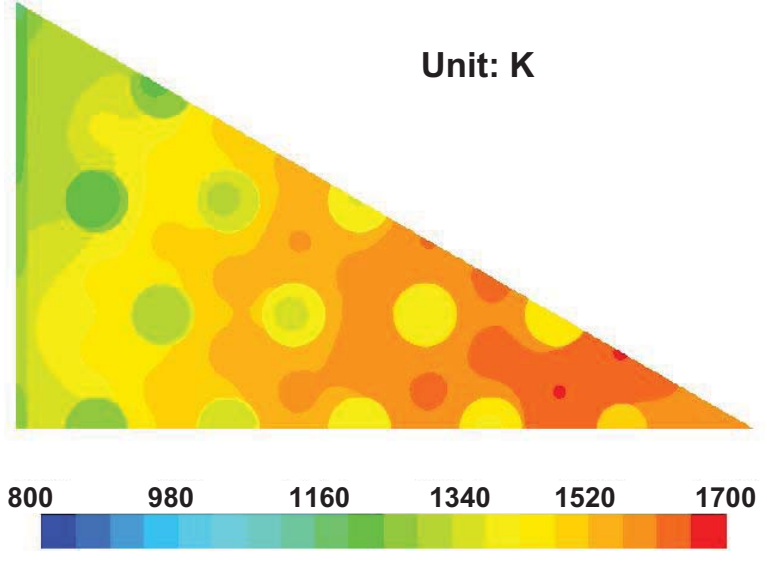

(a) Without shrinkage (gap width $5.5 \mathrm{~mm}$ )

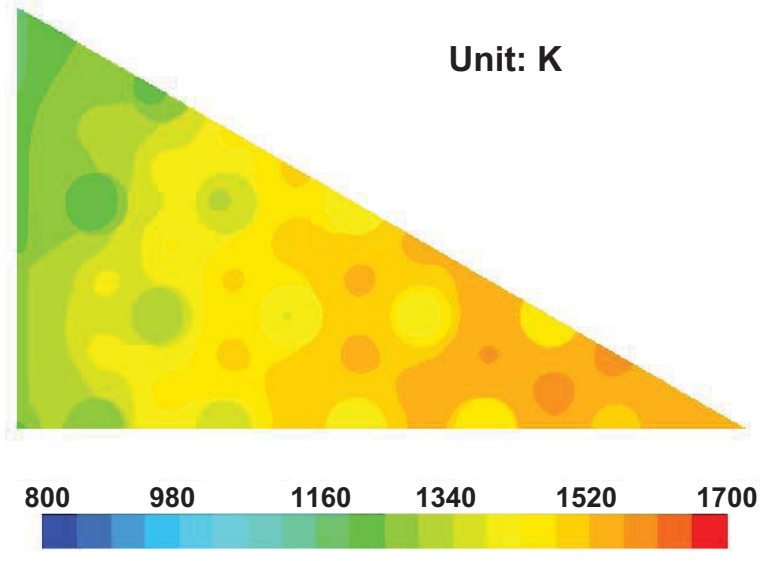

(b) With shrinkage (gap width $5.5 \mathrm{~mm}$ )

Figure 4-34. Temperature contours at the fuel hot spot plane of the fuel block for different geometries. 


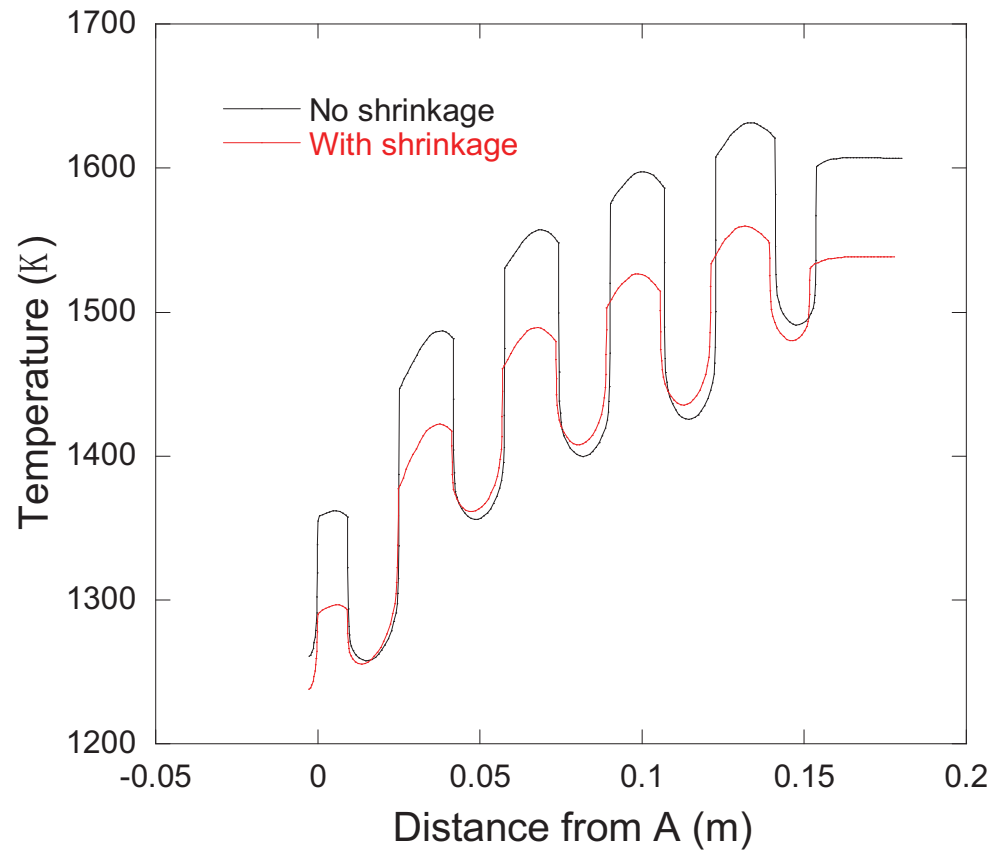

Figure 4-35. Temperature along line A-B of the fuel hot spot plane for different geometries.

Figure 4-36 shows the bulk mean helium gas temperatures at the coolant channels and gap outlets. The hottest outlet temperature appears for the coolant channel located near the center of the block and the temperature decreases as the location approaches the gap in both cases. As stated above, the coolant outlet temperature differences between the no-shrinkage and shrinkage cases are small. In contrast, a slightly lower gap outlet temperature is observed for the shrinkage case because the gap flow is higher.

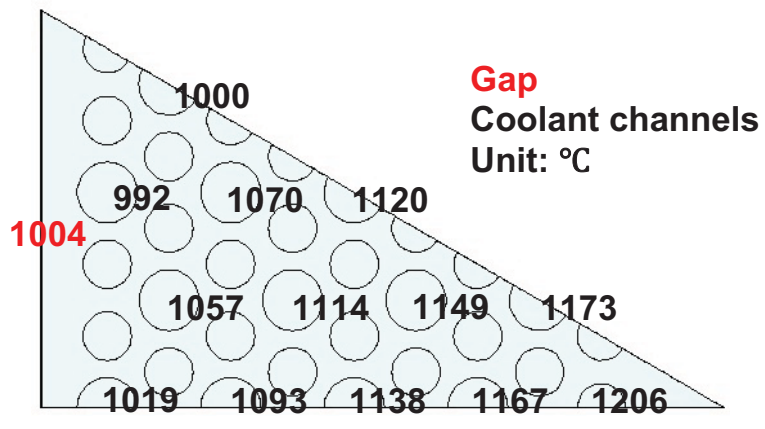

(a) Without shrinkage

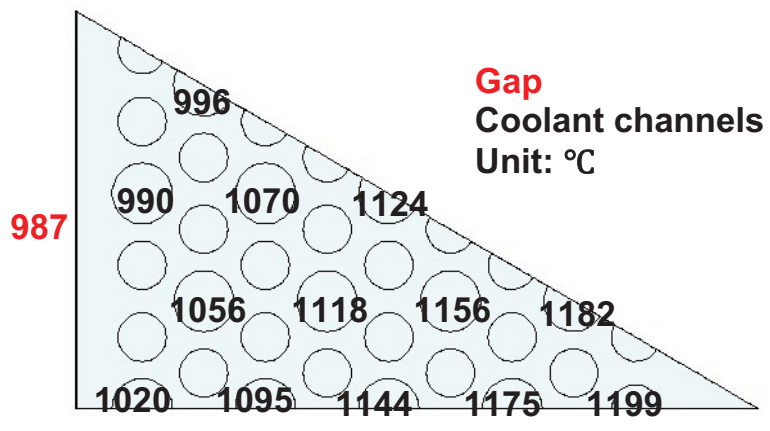

(b) With shrinkage

Figure 4-36. Bulk mean helium gas outlet temperatures $\left({ }^{\circ} \mathrm{C}\right)$ at coolant channels and gaps for different geometries in block region.

Table 4-7 shows the calculation inputs and results for differential pressures, total mass flows, gap flow fractions, maximum fuel temperatures, gap outlet temperatures, and max channel outlet temperatures. As expected, the gap flow fraction and core differential pressure increases for the shrinkage case because of the decrease of coolant channel flow area. Considerably higher maximum fuel temperature is observed in the no-shrinkage case with a difference of about $73{ }^{\circ} \mathrm{C}$. This result is a complicated function of the thermal hydraulics because the Reynolds and Prandtl numbers, which establish the heat transfer coefficient, are functions of the channel diameter, bulk velocity, and fluid properties, all of which vary between the two cases. 
Table 4-7. Calculation inputs and results of total mass flows, gap flow fractions, and maximum fuel temperatures for different geometries.

\begin{tabular}{lcc}
\hline \multicolumn{1}{c}{ Case } & Without shrinkage & With shrinkage \\
\hline Pressure difference $(\mathrm{psi})$ & 4.41 & 4.54 \\
Total mass flow rate $(\mathrm{kg} / \mathrm{s})$ & 0.200 & 0.200 \\
Gap flow fraction $(\%)$ & 11.3 & 11.7 \\
Maximum fuel temperature $\left({ }^{\circ} \mathrm{C}\right)$ & 1388 & 1315 \\
Gap outlet temperature $\left({ }^{\circ} \mathrm{C}\right)$ & 1004 & 987 \\
Max coolant temperature $\left({ }^{\circ} \mathrm{C}\right)$ & 1206 & 1199 \\
\hline
\end{tabular}




\section{SUMMARY AND CONCLUSIONS}

The 3-D conjugate heat transfer and fluid flow calculations for a one-twelfth sector of a fuel column in a reference prismatic VHTR are conducted using commercial CFD codes FLUENT and STAR-CCM+ in order to investigate the influence of several factors related to bypass flow on flow and temperature distribution in the reactor core. Parametric studies varying the factors, including gap width with and without a reduction in differential pressure, the turbulence model, heat generation profiles, and geometry changes resulting from irradiation shrinkage in the prismatic block, are conducted to understand the effects of core bypass flow. Calculations are also made to determine what gap widths would be required to realize a $20 \%$ bypass flow ratio in the whole core; for gap widths of $3.5 \mathrm{~mm}$ in the reflector regions, the gap width that produces about $20 \%$ bypass flow in the heated core is about $5.5 \mathrm{~mm}$. The study revealed that flow and temperature distributions in the prismatic fuel assembly are strongly coupled and therefore detailed 3-D thermal hydraulic analyses using CFD, which can take local physics into account, is an effective method for evaluating the coolant bypass phenomena. In particular, the flow rates of coolant in the channels and in the interstitial gaps are a function of the solution and are not known a priori. Table 5-1 summarizes present comparative studies. The following conclusions are drawn from these studies:

- Bypass flow in the gap provides a significant cooling effect on the prismatic block.

- Bypass flow establishes a large radial temperature gradient in the block.

- The maximum fuel temperature and maximum coolant channel outlet temperature are significantly increased by an increase of gap width in the bypass flow if the gap flow is 'robbed' from the coolant channel flow. This conclusion indicates that the bypass flow has a significant effect on hot spots in the core and on the variation in temperature of jets flowing from the core into the lower plenum.

- The axial variation of heat generation profile, but with the same total generation, has little effect on the thermal hydraulic characteristics versus uniform generation, except that the maximum fuel temperature is lower because the heat generation rate at the hot spot is relatively lower.

- The axial location of the fuel hot spot, about $0.06 \mathrm{~m}$ above the lower end of the fueled section is not affected by the gap width, turbulence model, heat generation profile, or irradiation shrinkage.

- The standard $\mathrm{k} \sim \varepsilon$ model with enhanced wall treatment is shown to agree with accepted empirical correlations for the wall friction, whereas the standard $\mathrm{k} \sim \omega$ model shows significant disagreement; the results for the two turbulence models exhibit large differences in maximum fuel and coolant outlet temperatures. Further validation of these and other turbulence models is clearly desired.

- An increase in heat generation rate increases the temperature of the helium in the channels, gap, graphite, and fuel, but it decreases the coolant flow rates in the channels and gap and the bypass flow ratio.

- Irradiation-caused shrinkage of the prismatic block produces an increase in gap flow ratio and a decrease in maximum fuel temperature.

Future directions for study can include (1) consideration of thermal property changes for graphite because of neutron fluences from the beginning to the end of the fuel cycle; (2) transition of flow regime from laminar to turbulent flow for small gap-width cases; (3) consideration of nonuniform deformation of the graphite block, which would induce nonuniform flow in the gap region; (4) a study of wall roughness influence on flow and temperature distributions; and (5) multiphysics simulations, taking into account neutronics, thermal-mechanics, and fluid dynamics. Future experimental data obtained from the INL's Matched-Index-of-Refraction facility will also contribute to the validation of turbulence models, especially for the gap region in order to ensure the credibility of the evaluation method. 


\begin{tabular}{|c|c|c|c|c|c|c|}
\hline & & & & - & $\stackrel{\infty}{8}$ & $\stackrel{8}{\frac{8}{2}}$ \\
\hline & 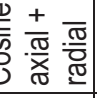 & $\vec{d}$ & & 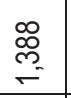 & 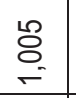 & 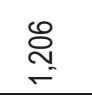 \\
\hline & 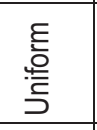 & $\begin{array}{l}\overrightarrow{0} \\
\\
\infty\end{array}$ & & 总 & 营 & 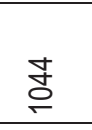 \\
\hline & $\begin{array}{l}\text { ह⿸厂彡 } \\
\text { 亭 }\end{array}$ & $\vec{\rho}$ & $\frac{n}{4}$ & 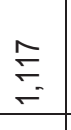 & 今 & : \\
\hline & 高 & $\overrightarrow{\mathrm{O}}$ & : & 䵫 & F。 & 命 \\
\hline & 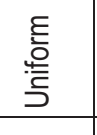 & $\underset{\dot{m}}{\overrightarrow{0}}$ & ఫ్d: & 兽 & 1 & $\stackrel{\circ}{\circ}$ \\
\hline & $\begin{array}{l}\frac{6}{5} \\
\text { 高 } \\
\end{array}$ & $\begin{array}{l}\overrightarrow{0} \\
\dot{\infty}\end{array}$ & & 飬 & $\underset{\infty}{\mathbf{D}}$ & 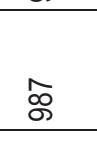 \\
\hline & $\begin{array}{l}\frac{E}{0} \\
\text { 誩 } \\
\end{array}$ & $\begin{array}{l}\overrightarrow{0} \\
\dot{\infty} \\
\end{array}$ & & 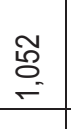 & $\begin{array}{l}\varnothing \\
\infty \\
\end{array}$ & $\tilde{\tilde{n}}$ \\
\hline & 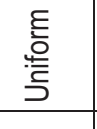 & 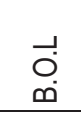 & 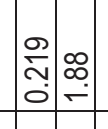 & 总 & $\stackrel{\infty}{\circ}$ & fै \\
\hline & $\begin{array}{l}\frac{E}{0} \\
\text { 咅 } \\
\end{array}$ & $\overrightarrow{\stackrel{0}{0}}$ & & $\begin{array}{l}8 \\
- \\
-\end{array}$ & 1 & $\frac{8}{0}$ \\
\hline & $\begin{array}{l}\frac{E}{0} \\
\frac{3}{5}\end{array}$ & 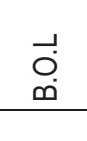 & & $\begin{array}{l}\bar{g} \\
\stackrel{-}{-}\end{array}$ & $\stackrel{0}{0}$ & 帝 \\
\hline & 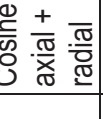 & $\overrightarrow{\dot{\infty}}$ & & 怘 & $\stackrel{\text { ळ. }}{\circ}$ & $\underset{F}{F}$ \\
\hline & 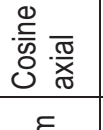 & 岕 & & 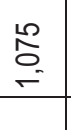 & $\stackrel{m}{\sigma}$ & $\stackrel{8}{\circledR}$ \\
\hline & $\begin{array}{l}\frac{E}{\bar{g}_{5}} \\
\end{array}$ & $\begin{array}{l}\overrightarrow{0} \\
\stackrel{\infty}{\infty}\end{array}$ & & s. & $\stackrel{\infty}{\sigma}$ & $\stackrel{\infty}{\infty}$ \\
\hline & 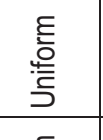 & $\vec{\rho}$ & & 兽 & $\ddot{\infty}$ & $\stackrel{\infty}{\infty}$ \\
\hline & $\begin{array}{l}\frac{E}{5} \\
\text { 亭 } \\
\end{array}$ & $\begin{array}{l}\overrightarrow{0} \\
\stackrel{\infty}{\infty}\end{array}$ & 8 & : & 思 & $\stackrel{\infty}{\infty}$ \\
\hline & $\begin{array}{l}\text { E⿱亠⿳口卄口 } \\
\text { 讋 }\end{array}$ & $\begin{array}{l}\overrightarrow{0} \\
\text { ம. } \\
\end{array}$ & $\begin{array}{lll}0 & 1 \\
0 & 1\end{array}$ & $\begin{array}{c}\stackrel{8}{8} \\
- \\
-\end{array}$ & 1 & $\stackrel{\infty}{\infty}$ \\
\hline 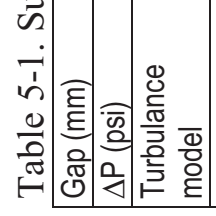 & 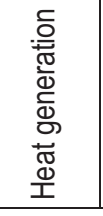 & 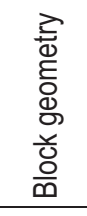 & 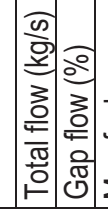 & & 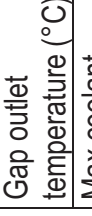 & 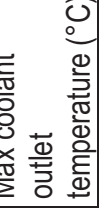 \\
\hline
\end{tabular}




\section{REFERENCES}

FLUENT, 2006, Version 6.3.26, FLUENT Inc., Lebanon, NH, USA, 2006.

Fox, W. R., and A. T. McDonald, 1985, Introduction to Fluid Mechanics, $3^{\text {rd }}$ ed., John \& Wiley \& Sons, New York, 1985.

General Atomics, 1977, Safety Analysis Report use of H451 Graphite in Fort St. Vrain Fuel Elements, GLP-5588.

General Atomics, 1988, Graphite Design Handbook, DOE-HTGR-88111, Rev. 0.

General Atomics, 1996, Gas Turbine-Modular Helium Reactor (GT-MHR) Conceptual Design Description Report, No. 910720, Rev. 1.

Johnson, R., and R. Schultz, 2004, Bounding Estimates for the 'Hot' Channel Coolant Temperature and Preliminary Calculation of Mixing in the Lower Plenum for the NGNP Point Design Using CFD, INEEL/EXT-04-02570.

MacDonald, P., J. Sterbentz, R. Sant, P. Bayless, R. Shultz, H. Gougar, R. Moore, A. Ougouag, and W. Terry, 2003, NGNP Preliminary Point Design Results of the Initial Neutronics and ThermalHydraulic Assessments, INEEL/EXT-03-00870.

Nakano, M., N. Tuji, and Y. Tazawa, 2008, “Conceptual Reactor Design Study of Very High Temperature Reactor (VHTR) with Prismatic-Type Core," Journal of Power and Energy Systems, Vol. 2, No. 2, pp.768-774.

NIST, 2009, "NIST Thermophysical Properties of Fluid Systems," http:// webbook.nist.gov 2009.

Patankar, S., and D. Spalding, 1972, "A Calculation Procedure for Heat Mass and Momentum Transfer in Three-Dimensional Parabolic Flows," Int. J. Heat Mass Transfer, Vol. 15, pp.1787-1806.

Schlichting, H. and K. Gersten, Boundary Layer Theory, 8th revised and enlarged edition, SpringerVerlag, Berlin, 2000, p.552.

STAR-CCM+, 2008, Version 4.02.007. CD-adapco, New York, NY, USA.

Tak, N., M. Kim, and W. Lee, 2008, "Numerical Investigation of a Heat Transfer within the Prismatic Fuel Assembly of a Very High Temperature Reactor," Annals of Nuclear Energy, Vol. 35, pp. 1892-1899.

Takada, E., S. Nakagawa, N. Fujimoto and D. Tochio, 2004, "Core Thermal-Hydraulic Design," Nuclear Engineering and Design, Vol. 233, pp. 37-43.

U.S. Congress, 2005, Energy Policy Act of 2005.

Zigrang, D. J., and N. D. Sylvester, 1985, "A Review of Explicit Friction Factor Equations," Transactions of ASME, Journal of Energy Resources Technology, Vol. 107, pp. 280-283. 